\title{
Therapeutic Potential of Copper Chelation with Triethylenetetramine in Managing Diabetes Mellitus and Alzheimer's Disease
}

\author{
Garth J.S. Cooper ${ }^{1,2,3,4}$
}

1 Centre for Advanced Discovery and Experimental Therapeutics, NIHR Manchester Biomedical Research Centre, Central Manchester University Hospitals NHS Foundation Trust, Manchester, UK

2 School of Medicine, University of Manchester, Manchester, UK

3 School of Biological Sciences and Maurice Wilkins Centre for Molecular Biodiscovery, Faculty of Science, University of Auckland, Auckland, New Zealand

4 Department of Pharmacology, Medical Sciences Division, University of Oxford, Oxford, UK

\section{Contents}

Abstract......................................................... 1281

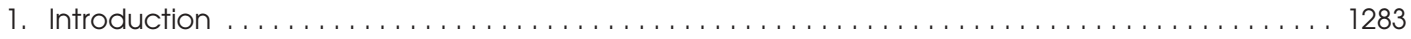

2. What Roles Might Copper Play in the Molecular Mechanisms of Diabetic Complications? . . . . . 1284

3. Copper Regulation: A Brief Overview . ..................................... 1285

4. Copper Deficiency: Neurodegeneration, Cardiovascular and Haematological Disorders, Impaired Antioxidant Defences and Defective Copper-Mediated Processes . . . . . . . . . . . 1286

5. Copper Overload States: Hepatic, Nervous System and Haematological Diseases with Increased Oxidative Stress . . . . . . . . . . . . . . . . . . . . . . . . . . . . . . . . . . . . . . . . . 1288

6. Trientine in Wilson's Disease: A Brief Summary . . . . . . . . . . . . . . . . . . . . . . . . . . . . . . . . . . 1289

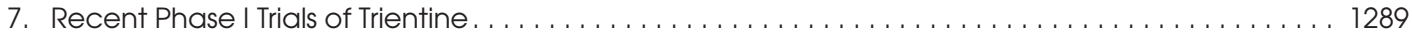

8. Trientine Treatment of Diabetic Cardiovascular Diseases. . . . . . . . . . . . . . . . . . . . . . . . . . 1291

9. Effects of Copper Chelation in an Animal Model of Diabetic Nephropathy . . . . . . . . . . . . . . . 1296

10. Evidence that Trientine Can Improve Pathogenetic Mechanisms in Diabetic Neuropathy . . . . . . 1302

11. Diabetes Causes a Copper Overload State that is Reversible by Highly Selective Chelation. . . . . . 1302

12. A Randomized, Placebo-Controlled Phase II Trial to Measure the Effects of Trientine on Transition Metal Regulation in Patients with Type 2 Diabetes (T2DM) and Matched Nondiabetic Volunteers. . 1303

13. Evidence That an Acquired Copper-Overload State is a Key Metabolic Defect that Causes Enhanced Oxidative Stress and Tissue Damage in Diabetes . . . . . . . . . . . . . . . . . . . . . . . . 1306

14. What are the Necessary and Sufficient Properties of a Highly Selective Copper Chelator? . . . . . . 1307

15. Close Linkages between Diabetes and Common Neurodegenerative Disorders Point to a Role of Divalent Copper (Cu") Toxicity in the Pathogenesis of Dementia . . . . . . . . . . . . . 1308

16. Recommendation for an Experimental Therapeutic Programme in AD and Vascular Dementia . . . 1310

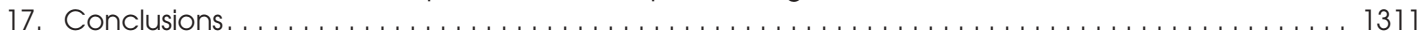
my group's research programme, which has identified for the first time a previously unknown copper-overload state that is central to the pathogenesis 
of diabetic organ damage. This state causes tissue damage in the blood vessels, heart, kidneys, retina and nerves through copper-mediated oxidative stress. This author now considers this copper-overload state to provide an important new target for therapeutic intervention, the objective of which is to prevent or reverse the diabetic complications.

Triethylenetetramine (TETA) has recently been identified as the first in a new class of anti-diabetic molecules through the original work reviewed here, thus providing a new use for this molecule, which was previously approved by the US FDA in 1985 as a second-line treatment for Wilson's disease. TETA acts as a highly selective divalent copper $\left(\mathrm{Cu}^{\mathrm{II}}\right)$ chelator that prevents or reverses diabetic copper overload, thereby suppressing oxidative stress. TETA treatment of diabetic animals and patients has identified and quantified the interlinked defects in copper metabolism that characterize this systemic copper overload state. Copper overload in diabetes mellitus differs from that in Wilson's disease through differences in their respective causative molecular mechanisms, and resulting differences in tissue localization and behaviour of the excess copper.

Elevated pathogenetic tissue binding of copper occurs in diabetes. It may well be mediated by advanced-glycation endproduct (AGE) modification of susceptible amino-acid residues in long-lived fibrous proteins, for example, connective tissue collagens in locations such as blood vessel walls. These AGE modifications can act as localized, fixed endogenous chelators that increase the chelatable-copper content of organs such as the heart and kidneys by binding excessive amounts of catalytically active $\mathrm{Cu}^{\mathrm{II}}$ in specific vascular beds, thereby focusing the related copper-mediated oxidative stress in susceptible tissues.

In this review, summarized evidence from our clinical studies in healthy volunteers and diabetic patients with left-ventricular hypertrophy, and from nonclinical models of diabetic cardiac, arterial, renal and neural disease is used to construct descriptions of the mechanisms by which TETA treatment prevents injury and regenerates damaged organs. Our recent phase II proof-of-principle studies in patients with type 2 diabetes and in nonclinical models of diabetes have helped to define the pathogenetic defects in copper regulation, and have shown that they are reversible by TETA. The drug tightly binds and extracts excess systemic $\mathrm{Cu}^{\mathrm{II}}$ into the urine whilst neutralizing its catalytic activity, but does not cause systemic copper deficiency, even after prolonged use. Its physicochemical properties, which are pivotal for its safety and efficacy, clearly differentiate it from all other clinically available transition metal chelators, including D-penicillamine, ammonium tetrathiomolybdate and clioquinol.

The studies reviewed here show that TETA treatment is generally effective in preventing or reversing diabetic organ damage, and support its ongoing development as a new medicine for diabetes. Trientine (TETA dihydrochloride) has been used since the mid-1980s as a second-line treatment for Wilson's disease, and our recent clinical studies have reinforced the impression that it is likely to be safe for long-term use in patients with diabetes and related metabolic disorders. There is substantive evidence to support the view that diabetes shares many pathogenetic mechanisms with Alzheimer's disease and vascular dementia. Indeed, the close epidemiological and molecular linkages between them point to Alzheimer's disease/vascular dementia as a further therapeutic target where experimental pharmacotherapy with TETA could well find further clinical application. 


\section{Introduction}

Oxidative stress is implicated as a disease mechanism in numerous metabolic and neurodegenerative diseases, including diabetes mellitus, heart failure, end-stage renal disease, Alzheimer's disease (AD), vascular dementia, Parkinson's disease, Huntington's disease and amyotrophic lateral sclerosis, amongst many others. ${ }^{[1-11]}$ However, numerous questions concerning the precise causes/mechanisms and possible roles of oxidative stress in various diseases remain unanswered, and its overall impact compared with other pathogenetic processes, such as metabolic and ionic stress and the cytotoxic impacts of protein aggregation have remained uncertain. ${ }^{[12-15]}$ Furthermore, which of the myriad different possible mechanisms might account for the precise molecular basis of oxidative stress in any of these disease contexts, ${ }^{[8]}$ what the actual extent of its relative contribution might be to their overall pathogenesis, and how it might account for so many disparate syndromes localized to so many different tissues and organ systems, have all remained largely unresolved.

An understanding of the relative importance of the different specific mechanisms that might cause oxidative stress in any of these diseases is yet to emerge and is a major challenge for current molecular pathology. Nevertheless, to develop new and more effective therapies for the prevention and treatment of those diseases where oxidative stress has been identified as a pathogenetic mechanism remains a major imperative for modern medicine. Unfortunately, strategies targeted at oxidative stress have not had notable success to date. Indeed, a great deal of effort and resources have been invested in recent decades in pursuing anti-oxidant strategies for the therapy of various diseases, but results so far have been largely unrewarding. ${ }^{[3,16-18]}$ These observations indicate that the exact nature of oxidative stress, and the factors that promote it in different disease contexts, are incompletely understood.

Some progress has been made. Research on signalling pathways has led to improved understanding; for example, with the identification of oxidative stress-responsive pathways such as that mediated by transforming growth factor (TGF)- $\beta$, which can regulate tissue remodelling and therefore control the development and regression of pathological lesions in diabetes-damaged organs such as the kidney. ${ }^{[19-21]}$ Another important advance has come with improved understanding of the mechanisms by which oxidative stress damages long-lived proteins, causing the accumulation of advanced glycation endproducts (AGEs) ${ }^{[22-27]}$ in damaged arterial walls, particularly in diabetes, $\mathrm{AD}^{[28,29]}$ and atherosclerosis. ${ }^{[30]}$ Some AGEs are thought to generate pathogenetic transition-metal binding in sites such as the extracellular matrix $(\mathrm{ECM})$ of blood vessel walls, ${ }^{[31-34]}$ or the lens, ${ }^{[35]}$ although only incomplete data concerning the characteristics of copper binding to AGEs are available as yet. ${ }^{[36]}$ Mitochondria have also been shown to play major roles in generating reactive oxygen species (ROS) and activating apoptotic pathways that mediate tissue damage. ${ }^{[37-39]}$

The purpose of this review is two-fold. First, to provide a succinct overview of the background to enable the reader to evaluate the evidence that dysglycaemia/diabetes causes pathogenetic copper overload coupled with enhanced copper-mediated oxidative stress, which in turn leads to or causes the forms of tissue damage known as the diabetic 'complications'. Similar tissue damage also occurs in pre-diabetic states and the common dementias, where many of the same mechanisms are also operative. ${ }^{[40]}$ Because of its oxidation-reduction properties, divalent copper $\left(\mathrm{Cu}^{\mathrm{II}}\right)$ readily participates in reactions that elicit ROS production. ${ }^{[8,41]}$ Possible roles for copper-catalyzed chemical reactions in diabetic complications have been discussed previously, ${ }^{[2,3]}$ and the relative importance of copper in diabetes in vivo was shown when we demonstrated the reversal of heart disease by systemic $\mathrm{Cu}^{\mathrm{II}}$ chelation in diabetic rats and patients. ${ }^{[42,43]}$

The second objective is to review and critique the evidence that triethylenetetramine (TETA) is the first in a new class of anti-diabetic molecules, namely 'highly-selective copper chelators' that function by suppressing copper overload/coppermediated oxidative stress, thereby preventing or reversing the cardiovascular and renal complications of the disease.

Studies in rodents used as a model of diabetes and in diabetic patients have characterized some 
of the metabolic defects by which diabetes impairs copper regulation and shown that they can be prevented or ameliorated by treatment with trientine (TETA dihydrochloride), which closely resembles the natural polyamines spermine and spermidine. Molecular 'mimicry' between TETA and these two endogenous molecules probably underpins important aspects of its in vivo pharmacology, particularly its absorption and distribution. The sufficiency of the $\mathrm{Cu}^{\mathrm{II}}$-binding activity of TETA and its demonstrated ability to select in vivo for copper over other transition metals, in particular zinc and iron, as well as for $\mathrm{Cu}^{\mathrm{II}}$ over univalent copper $\left(\mathrm{Cu}^{\mathrm{I}}\right),{ }^{[44]}$ are considered pivotal for its efficacy and safety in the treatment of diabetic organ damage. Significantly, long-term trientine treatment can restore the structure and function of organs damaged by diabetes without lowering blood glucose. ${ }^{[43,45]}$

The close linkages that are now known to exist between diabetic vasculopathy and the pathogenesis of AD and vascular dementia ${ }^{[12,46-50]}$ indicate that highly selective copper chelation also merits exploration as a potential therapy for these neurodegenerative disorders, which may well represent, at least in part, manifestations of the effects of diabetes-like vascular disease that targets catalytically active $\mathrm{Cu}^{\mathrm{II}}$ and the resultant $\mathrm{Cu}^{\mathrm{II}}$ catalyzed oxidative stress to particular vascular beds in the brain ('diabetes in the brain').

\section{What Roles Might Copper Play in the Molecular Mechanisms of Diabetic Complications?}

Diabetes is a multi-faceted metabolic disorder whose current definition is based on the demonstration of pathologically elevated blood glucose levels. It causes most of its morbidity and mortality through its propensity to cause damage in organs, including the heart, arteries, kidneys, retina and nerves. ${ }^{[51-54]}$

In many respects, diabetes can be considered as a microvascular disease, which is a leading cause of blindness, renal failure and nerve damage, and diabetes-accelerated atherosclerosis leads to increased risk of myocardial infarction, stroke and limb amputation. ${ }^{[37,38]}$ However, blood vessel dis- ease detectable before glucose levels become elevated is an early pathological finding before and at its onset, and hyperglycaemia may be neither the only nor indeed the earliest metabolic perturbation to occur in either of the major forms of diabetes. ${ }^{[55]}$ The question of whether elevated glucose is the cause of blood vessel disease in diabetes remains unresolved. Intensive blood glucose control may or may not prevent or reverse diabetic tissue damage, ${ }^{[56-59]}$ which is probably more responsive to anti-hypertensive therapy, ${ }^{[60,61]}$ and diabetic vascular disease remains largely refractory to all available treatments. ${ }^{[62]}$

The precise nature of oxidative stress in diabetes, and of the exact mechanism by which it might cause tissue damage, are questions that are yet to be answered. ${ }^{[3]}$ One prominent suggestion has focussed on four main molecular mechanisms that may reflect a single hyperglycaemia-induced process of superoxide overproduction by the mitochondrial electron-transport chain leading to progressive compromise of anti-oxidant defences. ${ }^{[38,39,63]}$ Another less widely known suggestion implicates excessive transition metal-catalyzed oxidative stress. ${ }^{[1,3]}$

Free iron and copper ions are highly redoxactive, ${ }^{[44]}$ and could contribute to tissue damage by generating ROS, in part through hydroxyl radical formation, ${ }^{[8]}$ but the in vivo bioavailability of catalytically active iron and copper is usually very restricted. ${ }^{[44]}$ There is evidence, reviewed below, that diabetes itself may increase the bioavailability of catalytically active $\mathrm{Cu}^{\mathrm{II}}$, causing oxidative stress and tissue damage that is suppressible by highly selective copper chelation. ${ }^{[42,43,45,64]}$

There is also evidence from a study of collagen structure in the lenses of streptozotocin (STZ)diabetic rats that may shed further light on this question. ${ }^{[35]}$ There, effects of in vivo trientine treatment on the levels of the carbonyl compounds methylglyoxal (MG) and 3-deoxyglucosone (3-DG), the advanced glycation endproduct 8-hydroxy-2'deoxyguanosine (8-OHdG), and polyol pathway metabolites along with semicarbazide-sensitive amine oxidase (SSAO) enzyme activity were measured. MG and 3-DG levels were significantly higher in diabetic rats than in nondiabetic controls, and trientine significantly reversed increases in 
these compounds. Lens argpyrimidine was also increased in diabetic rats compared with controls and was significantly reduced by trientine. Lens SSAO activity and 8-OHdG were also significantly elevated in diabetic rats, and trientine suppressed both of them, whereas it had no effect on the polyol pathway metabolites. The results are consistent with the proposition that transition metals play a significant role in the formation of $\mathrm{MG}$ and 3-DG via oxidative stress and SSAO activity. ${ }^{[35]}$ By arguments developed below, these are likely to be $\mathrm{Cu}^{\mathrm{II}}$-mediated effects. They are consistent with trientine-mediated suppression of hydroxyl radical production and resulting suppression of collagen damage.

The biology of transition metals other than copper, including zinc, manganese, molybdenum, chromium, vanadium and iron, has been evaluated in the context of diabetic tissue damage. In haemochromatosis, excess myocardial iron can cause heart disease, and iron-mediated islet damage can cause diabetes. ${ }^{[65]}$ Myocardial iron excess also causes heart disease in haemosiderosis, in association with excessive dietary iron intake, or ineffective erythropoiesis, as in thalassemia or sideroblastic anaemia. ${ }^{[66,67]}$ Altered cardiac iron metabolism is also implicated in the mechanism of heart disease in additional circumstances. ${ }^{[8]}$ However, abnormalities in the regulation of transition metals other than copper have not been convincingly linked to pathogenesis in the two major classes of diabetes, type 1 diabetes mellitus (T1DM) and type 2 diabetes mellitus (T2DM), and the role of altered copper metabolism and its relevance to diabetic complications has not been explored in depth until recently. ${ }^{[42,43,45,64,68]}$

Studies with transition metal chelators have provided additional evidence for a link between altered transition metal regulation and the pathogenesis of diabetes in animal models. ${ }^{[69-72]}$ For example, administration of an iron chelator and a copper chelator in a 2-week experiment in diabetic rats was reported to ameliorate decreases in sciatic motor nerve conduction velocity, restore nutritive endoneurial blood flow, decrease systemic arterial pressure, and cause supranormal sciatic nutritive vascular conductance. ${ }^{[70]}$

Whereas iron overload, for example in haemochromatosis, can be managed in its early as- pects by phlebotomy, this approach is not effective once significant iron stores have accumulated in organs, for example in the heart after multiple transfusions in thalassaemia, at which point the only effective treatment that prolongs life is iron chelation therapy. ${ }^{[73]}$ Nor has phlebotomy ever been successful in copper overload states such as Wilson's disease, where the accepted therapy is copper chelation. ${ }^{[74]}$

Defective copper metabolism impairs cardiovascular function in at least two known settings: chronic copper deficiency, ${ }^{[75-77]}$ and defective intracellular copper transport to mitochondrial cytochrome $c$ oxidase caused by missense mutations in the second cytochrome $c$ oxidase assembly gene, $S C O 2 .{ }^{[78-80]}$ Thus, copper deficiency has been implicated as a defect of copper homeostasis that can lead to cardiac disease. ${ }^{[81]}$ By contrast, heart disease is not a prominent feature in chronic intracellular copper overload as, for example, occurs in Wilson's disease. ${ }^{[82]}$

To better understand the roles of transition metals in the pathogenesis of diabetic complications, our group has now systematically probed the relationships between transition metal regulation and diabetes in depth, in an integrated programme of nonclinical and clinical studies. The outcomes of these studies are one focus of this review.

\section{Copper Regulation: A Brief Overview}

\section{1 Regulation of Cell Copper Uptake, Distribution and Export}

The main biochemical role for copper is catalytic, and many copper enzymes act as oxidases that catalyze the reduction of dioxygen. ${ }^{[4,83]}$ There is a high degree of conservation of copper-regulating mechanisms between all eukaryotes. ${ }^{[84,85]}$

Copper is an essential but highly toxic nutrient, so its metabolism must be closely regulated in physiology. ${ }^{[86,87]}$ Cellular copper homeostasis is coordinated by processes that ensure its delivery to specific subcellular compartments and copperrequiring proteins without releasing free copper ions that could otherwise damage cellular structures. ${ }^{[88]}$ These processes are mediated by proteins 
including integral transmembrane transporters such as high-affinity copper transporter 1 (Ctr1), metalloregulatory sensors and diffusible cytoplasmic metallochaperone proteins that protect and carry metal ions to copper metalation targets such as cytochrome $c$ oxidase and copper/zinc superoxide dismutase 1 (SOD1). ${ }^{[4,89]}$ Alongside these are parallel cellular mechanisms that can defend against any untoward release of 'free' copper ions, including sequestration by metallothioneins ${ }^{[90]}$ and export via the copper-transporting adenosine triphosphatases (ATPases), ATP7A and ATP7B. ${ }^{[91,92]}$

Genetic studies in prokaryotic organisms and yeast have identified certain membrane-associated proteins as copper transporters that mediate the uptake or export of copper from cells. Within cells, small cytosolic proteins called copper chaperones have been identified, which accept $\mathrm{Cu}(\mathrm{I})$ ions from copper transporters, bind them, and deliver them to specific compartments and thence to specific copperrequiring proteins. ${ }^{[84]}$

\subsection{Regulation of Whole-Body Copper Homeostasis in Humans}

Regulation of copper balance in humans relies in significant part on the intestine for control of intake, with the main excretory route being via the biliary tract, as the capacity for renal copper excretion is much more limited under physiological conditions. ${ }^{\left[{ }^{[3-96]}\right.}$ Rates of copper excretion, mainly via the bile, are regulated to preserve copper balance. ${ }^{[97]}$ Copper absorbed from the diet is released from the gut and transported to the liver via the plasma, bound mainly to albumin and the macroglobulin transcuprein. ${ }^{[98,99]}$ Copper is released from the liver into the circulation, where $\sim 95 \%$ is bound to caeruloplasmin, a multi-copper ferroxidase. ${ }^{[86,100-102]}$ However, caeruloplasmin is not required for physiological distribution of copper to the organs, but functions instead as a copperdependent ferroxidase, the activity of which is essential in iron homeostasis and the absence of which (as, for example, in aceruloplasminaemia) causes prominent iron-mediated organ damage in the basal ganglia, with accompanying diabetes, retinal degeneration, anaemia and hepatic iron deposition. ${ }^{[44,103-106]}$ Functional defects in caeruloplasmin's ferroxidase activity can also elevate oxidative stress through defective physiological regulation of iron oxidation.

\section{Copper Deficiency: Neurodegeneration, Cardiovascular and Haematological Disorders, Impaired Antioxidant Defences and Defective Copper-Mediated Processes}

Copper is an essential trace nutrient and deficiency causes a series of well documented adverse effects. ${ }^{[96]}$ I now briefly review the evidence linking copper deficiency to organ damage, particularly in the nervous, cardiovascular and haematological systems. This section is included because copper deficiency could be a significant potential risk for the long-term treatment of diabetic patients using a copper chelator such as TETA. An understanding of the potential presentations and detection of the little known copper deficiency syndrome is required if the reader is to follow the data emerging from the clinical trials of TETA treatment in diabetes, where variables used to monitor for signs of copper deficiency have been included and interpreted accordingly. The detection/quantification of any treatment-emergent copper deficiency was a central component of the clinical trials described in sections 7, 8, 12 and 13, and their design and outcomes should be interpreted in this light.

\section{1 Copper Deficiency in Animals}

Copper is an essential trace nutrient for animals and humans. ${ }^{[86,100,107-109]}$ Copper deficiency in animals can cause CNS degeneration, ${ }^{[110,111]}$ cardiovascular disease ${ }^{[75,112]}$ and haematological disorders, including sideroblastic anaemia and neutropenia. ${ }^{[113]}$ These effects can largely be explained on the basis of acquired functional defects in specific copper proteins/pathways, including those regulating connective tissue structure as well as more generalized defects in copper-dependent anti-oxidant defence mechanisms. ${ }^{[114-117]}$ Copper deficiency is also teratogenic ${ }^{[117]}$ and exerts particularly severe effects on the development of the cardiovascular system and CNS. ${ }^{[116,118]}$ 
Spontaneous copper deficiency has been observed in farm animals, in which it can cause severe neurodegenerative disorders in the young and prominent haematological defects in adults. ${ }^{[110,111,119-122]}$ These phenomena have been replicated by the feeding of low-copper diets to farm animals under controlled conditions, ${ }^{[123]}$ and also by increased dietary intake of molybdenum, which acts to decrease systemic copper levels. ${ }^{[124,125]}$ Similar copper deficiency syndromes have also been reported in wild animals. ${ }^{[126-128]}$ Copper deficiency can also cause severe cardiovascular disease in farm animals, with deterioration in the structure and function of the aorta and heart. ${ }^{[129-132]}$

There is a substantive literature describing the effects and mechanisms of copper deficiency in laboratory rodents, in which a characteristic copper-deficiency cardiomyopathy has been thoroughly described. ${ }^{[75,76,112,133-139]}$ This cardiomyopathy can be reversed by dietary copper supplementation; ${ }^{[12]}$ its impact can also be lessened by strategies that up-regulate myocardial metallothionein, ${ }^{[90,136,140]}$ leading to the inference that the pathogenetic mechanism incorporates free radical-mediated tissue damage. Three nonspecific pathogenetic mechanisms have been linked to the cardiovascular defects induced by dietary copper deficiency: (i) peroxidation-oxygen-derived free-radical damage to lipids, proteins and possibly DNA; (ii) non-enzymatic glycation; and (iii) nitration of peptides and proteins. Furthermore, the association of these mechanisms with diabetes and aging has been interpreted to suggest that copper deficiency could possibly exacerbate deficits associated with cardiac disease in these contexts. ${ }^{[76,77,141]}$

\subsection{Copper Deficiency in Humans}

Copper deficiency in humans is rare, but has been observed under a number of scenarios. ${ }^{[142-144]}$ These include long-term parenteral nutrition with insufficient copper intake, ${ }^{[145-147]}$ infants recovering from protein-energy malnutrition ${ }^{[148]}$ and feeding of cows' milk to premature infants. ${ }^{[108,149,150]}$ Documented signs of copper deficiency in humans include low plasma copper (hypocupraemia) with low serum caeruloplasmin values, ${ }^{[145,147]}$ oedema, ${ }^{[147]}$ anaemia and neutropenia, all of which respond to increased copper intake. ${ }^{[147,151]}$

Genetic defects in copper metabolism that cause cellular copper deficiency through defective copper transport have also been identified: these include Menkes' disease, ${ }^{[143,144,152]}$ in which severe neurodegeneration is caused by mutations in the $A T P 7 A$ gene that encodes the copper transport protein ATP7A (for review, see Lutsenko et al. ${ }^{[91]}$ ), and defects in the SCO2 gene that encodes a copper chaperone that transports copper to/metalates cytochrome $c$ oxidase and deficiency of which causes defective intracellular transport of copper to that enzyme, leading to its impaired function and a lethal cardiomyopathy. ${ }^{[78-80]}$

\subsection{Could Diabetic Patients Have Significant Copper Deficiency?}

Neither diabetic animals nor patients demonstrate biochemical signs of overt systemic copper deficiency, ${ }^{[42,45]}$ such as hypocupraemia and low plasma caeruloplasmin values, anaemia or neutropenia, ${ }^{[96,153]}$ nor did year-long treatment with an effective dosage $(1200 \mathrm{mg} /$ day $)$ of the highly selective copper chelator trientine cause signs of copper deficiency (section 8.1). ${ }^{[43]}$ It is not entirely clear whether these usual indices of copper status are useful when copper intake is marginal, however, since parameters such as serum copper and caeruloplasmin levels may become elevated, for example, through the effects of inflammation in conditions such as coronary artery disease, heart failure and diabetes. ${ }^{[153]}$ Our comparative balance study reviewed in sections 12 and 13 did not provide evidence for the occurrence of even mild systemic copper deficiency in patients with T2DM, ${ }^{[45]}$ and basal urinary copper excretion is generally elevated in diabetic patients compared with matched controls. ${ }^{[45]}$ This latter observation is likely to be significant, since urinary copper is a key point of copper regulation and becomes lowered in marginal copper deficiency states ${ }^{[97]}$ In summary, there is little evidence to date for symptomatic systemic copper deficiency in T1DM or T2DM.

However, short-term balance studies have acknowledged limitations, ${ }^{[97,153-156]}$ so additional 
appropriately designed, longer term studies are required to further characterize copper regulation in diabetic patients before the presence of masked or occult copper deficiency can be certainly excluded.

\section{Copper Overload States: Hepatic, Nervous System and Haematological Diseases with Increased Oxidative Stress}

Although copper is an essential trace nutrient normally subject to effective homeostatic regulation, excess dietary intake can be toxic in certain circumstances. ${ }^{[157-159]}$ Many of the toxic effects of excess copper, such as increased peroxidation of cell membrane lipids and damage to extracellular connective-tissue proteins and DNA, are thought to be related to its role in the generation of ROS. ${ }^{[157,160]}$ Biochemical variables such as serum copper and caeruloplasmin levels, useful for monitoring copper deficiency states, are ineffective for the detection and monitoring of copper-overload states. ${ }^{[42,96,161]}$ Monitoring of urinary copper output following trientine treatment may provide a more effective means of detection and monitoring of copper excess in animal models and diabetic patients (section 12). ${ }^{[42,43,45]}$

\subsection{Chronic Copper Toxicity in Mammals}

The generally low incidence of chronic copper toxicosis in mammals, despite considerable variation in copper intakes, probably reflects the efficiency of the homeostatic control mechanisms that operate at the levels of both intestinal absorption and biliary excretion to keep tissue copper concentrations within a tolerable range. ${ }^{[94,157,162]}$ Different mammals display quite different tolerances to toxic levels of copper exposure, due probably to variation in species-specific factors as well as genetics, age and diet. ${ }^{[157]}$ For example, pigs are relatively resistant to high copper intakes, whereas sheep are much more susceptible, possibly because they are less able to excrete excess copper into the bile. Neonatal and milk-fed animals are more susceptible to copper poisoning than their adult counterparts, probably because of the high efficiency of copper absorption and the immaturity of biliary excretory mechanisms, ${ }^{[157]}$ an observation that may help to explain why chronic copper toxicosis in humans manifests mainly in childhood. ${ }^{[163-165]}$ Dietary antagonists of copper metabolism, such as sulfur and other trace metals, and of hepatotoxins or protective factors are also important. For example, dietary zinc supplements, which can restrict the uptake and accumulation and modify the distribution of copper in the liver, can be used to prevent copper toxicosis, both in sheep and in patients with Wilson's disease. ${ }^{[166,167]}$

The symptoms of chronic copper toxicosis vary between species. ${ }^{[157]}$ In pigs, which are relatively tolerant of copper, excessive intakes eventually cause weakness, respiratory distress, anaemia and jaundice, with pulmonary oedema and ulceration of the oesophageal region of the stomach. ${ }^{[168]}$ Rats are also relatively tolerant of copper but, at high intakes, growth is impaired and extensive hepatic necrosis develops. There is also widespread necrosis of proximal convoluted tubule epithelial cells of the kidney. However, rats can adapt to prolonged high copper exposure, and hepatic copper concentrations eventually decrease in association with liver regeneration..$^{[169-171]}$

In contrast, chronic copper toxicosis in sheep develops in two stages, even at relatively low dietary intakes. The first phase comprises mainly the progressive accumulation of copper in the liver without much systemic manifestation. The second phase comprises the acute onset of haemolysis with jaundice, anorexia, excessive thirst and haemoglobinuria, after which most animals die within a few days. ${ }^{[172,173]}$ The onset of these symptoms is associated with liberation of stored copper from the liver and a massive increase in blood copper levels, associated with hepatic necrosis. There is also considerable kidney damage, and renal copper concentrations increase dramatically at this time, possibly as a result of enhanced tubular copper resorption. ${ }^{[172,173]}$

Hepatic tissue copper accumulation is a key feature of copper toxicity in mammals. However, even very high liver copper concentrations by themselves may be insufficient to cause hepatocellular damage, depending on the circumstances. 


\subsection{Molecular Pathways that Combat Tissue Damage by Copper Excess}

To avoid copper-induced toxicity, most organisms use a redundant combination of copperregulated import inhibition, sequestration and enhanced export mechanisms. ${ }^{[93]}$ Combinations of these mechanisms are used to provide a detoxification pathway controlled through copperbinding proteins at the transcriptional, translational or enzymatic-function levels. ${ }^{[87,174]}$ In yeast, an important regulatory mechanism occurs via copper-mediated activation of the copper-binding transcription factor Acelp, ${ }^{[175-177]}$ which regulates key aspects of copper metabolism through binding to the copper regulon, up-regulating anticopper defences such as those mediated by SOD1 and metallothionein, whilst concomitantly downregulating the high-affinity cell membrane copper transporter, Ctrland its associated iron-dependent copper reductase, Fre1. ${ }^{[176,178,179]}$

In mammalian cells, copper is partially detoxified by sequestration in the metal-binding metallothioneins, or export via the copper-translocating ATPases; these pathways can be redundant in function and the molecular processes that coordinate them are incompletely understood at present. ${ }^{[93,180,181]}$

\section{Trientine in Wilson's Disease: A Brief Summary}

Wilson's disease is a rare disorder of copper metabolism that causes progressive copper overload and consequent tissue damage particularly affecting the liver, CNS and eyes, ${ }^{[92,182,183]}$ although it can also damage other organs, including the heart. ${ }^{[184]}$ It is caused by genetically transmitted defects in the $A T P 7 B$ transporter gene, ${ }^{[91,92,182]}$ and, if untreated, is almost always fatal. Tissue distribution of ATP7B thus determines the location of copper excess in Wilson's disease, which in turn localizes the tendency to tissue damage. The mainstay of treatment in Wilson's disease is copper chelation with penicillamine, ${ }^{[185]}$ to which ammonium tetrathiomolybdate, a second copper chelator and/or zinc therapy may be added in certain cases. ${ }^{[186]}$
Trientine is a potent copper chelator that was first registered by the US FDA in 1985 for the second-line treatment of Wilson's disease. In brief, it is effective both in reducing excess body copper storage and in ameliorating symptoms in patients with Wilson's disease. The drug has generally demonstrated acceptable safety and efficacy profiles, ${ }^{[74,185,187-190]}$ although it has occasionally been linked to haematological abnormalities such as sideroblastic anaemia ${ }^{[191]}$ and thrombocytopenia, ${ }^{[188]}$ and has also been reported to cause low serum iron without anaemia. ${ }^{[89]}$

Based on its pharmacological and physicochemical properties, I chose to employ trientine over other known chelators such as penicillamine or tetrathiomolybdate, to probe systemic copper regulation in diabetes. I took this decision in part because of perceived downsides to the others, including the high rates of adverse reactions and other attendant risks of penicillamine, ${ }^{[192,193]}$ and the known propensity of molybdenum overload to induce/exacerbate diabetes, ${ }^{[127]}$ to cause neurodegeneration under some circumstances, and therefore, potentially to aggravate diabetic neuropathy ${ }^{[124]}$ and to cause molybdenosis. ${ }^{[96,194,195]}$

\section{Recent Phase I Trials of Trientine}

\subsection{New Uses for Trientine}

Since trientine is an orphan drug used for treatment of an orphan disease, ${ }^{[196]}$ the original regulatory approach relied upon in its licensing for use in Wilson's disease was very much abbreviated. Consequently, available data concerning many aspects of its safety profile and metabolism have been insufficient to support its licensing for use in widespread indications such as diabetes, heart disease or dementia, even if efficacy studies were ultimately to demonstrate its probable utility. Furthermore, available regulatory documentation and pharmaceutical preparations of trientine were judged to be of insufficient quality to support its widespread use in such prevalent indications.

Our group sought to rectify these deficiencies by generating safety data from suitable phase I trials (see sections 7.2 and 7.3) and requisite supporting 
nonclinical studies, ${ }^{[197]}$ and by developing a new improved route for trientine synthesis and its formulation, ${ }^{[198]}$ while working under an investigational new drug application from the FDA.

\subsection{A Phase I Population Pharmacokinetic- Pharmacodynamic Dose-Escalating Study of Trientine in Healthy Volunteers}

In this trial, ${ }^{[197]}$ we measured the population pharmacokinetics (PK) and pharmacodynamics (PD) of trientine administered orally as 100, 300, 600 or $1800 \mathrm{mg}$ twice-daily doses in healthy adult male and female volunteers in a randomized, double-blind, placebo-controlled, group-sequential, dose-escalating study. Forty participants, ten per dose level (eight receiving trientine, two receiving placebo), received twice-daily doses for 14 consecutive days. A 2-compartment model for the PK and a linear direct effect model for drug-induced copper excretion (PD) were employed. Covariates tested were glomerular filtration rate (GFR), bodyweight and gender.

We found that multiple daily doses of trientine were safe and generally well tolerated in this study population. The linear 2-compartment model with first-order absorption characterized the serum concentration data well. Although its role was modest, GFR had a statistically significant influence on systemic clearance $(\mathrm{CL} / \mathrm{F})$. The augmentation of copper excretion was well described by a direct linear model in which the slope was related to GFR and gender. ${ }^{[197]}$ Thus, trientine displays consistent single-/multiple-dose PK, and dose-proportional and serum concentration-proportional effects on enhancing copper excretion.

As the ages of the participants in the study population ranged from 18 to 57 years, and older participants would be more susceptible to reduced renal function, ${ }^{[199]}$ the PK/PD model and parameters obtained in the present study should be useful to define a possible clinical dosage regimen for further clinical studies and to compare the potency of drug action with that of similar drugs or alternative dosage forms in vivo.

Trientine exhibits linear PK, is rapidly absorbed and showed a minor degree of accumula-

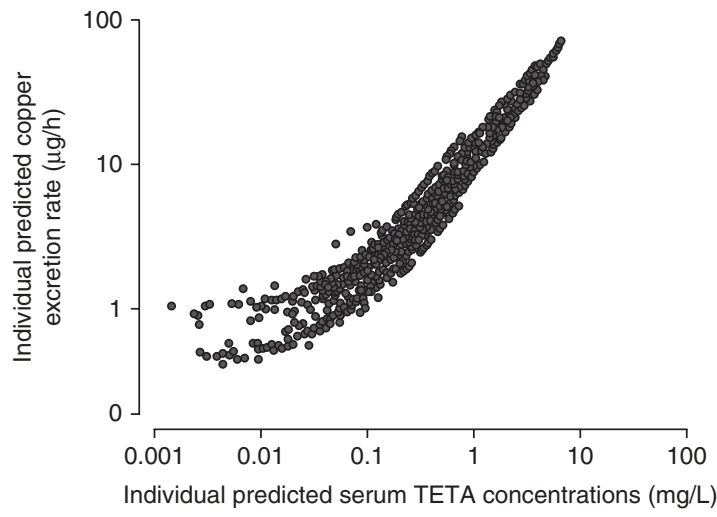

Fig. 1. Calculated summary pharmacodynamic-pharmacokinetic model derived from a dose-rising phase I clinical trial in groups of nondiabetic volunteers, illustrating the relationship between plasma triethylenetetramine (TETA) concentrations and urinary copper excretion (reproduced from Cho et al., ${ }^{[197]}$ with permission).

tion following steady-state dosing. The PK/PD and safety profiles support the administration of trientine in a twice-daily regimen at $1200 \mathrm{mg}$ /day, which is the same dosage that we found to be effective in the treatment of left-ventricular hypertrophy $(\mathrm{LVH})$ in diabetic patients, ${ }^{[43]}$ and is also equivalent to those that suppress heart disease, ${ }^{[20,42,200]}$ arteriopathy ${ }^{[20]}$ and nephropathy ${ }^{[68,201]}$ in diabetic rats. The larger dose of $3600 \mathrm{mg}$ /day produced appreciably more adverse effects, albeit all relatively mild. ${ }^{[197]}$ Doses of trientine given as $600 \mathrm{mg}$ twice daily would be expected to produce a significant cupriuretic effect. ${ }^{[197]}$ Shown in figure 1 is a summary of the calculated PK/PD relationship between achieved serum TETA concentrations following oral administration of trientine and urinary copper excretion modelled from the whole study population, illustrating the concentration responsiveness of the cupriuretic effect. ${ }^{[197]}$ We also found that GFR is the best population predictor for the PK/PD of trientine. The population parameters thus estimated from our population PK/PD model could provide useful indicators for the determination of dosage regimens in patients, with the caveat that specific PK/PD studies should be performed to determine whether disease-related changes in disposition or sensitivity to the drug in diabetic patients might alter the dosage recommendations. 


\subsection{A Phase I Study of Triethylenetetramine (TETA) Metabolism in Volunteers with Fast and Slow Acetylator Phenotypes}

This additional phase 1 study aimed to determine whether different $\mathrm{N}$-acetyltransferase 2 (NAT2) phenotypes might cause measureable differences in the PK or PD of trientine. ${ }^{[202]}$ Upon ingestion, trientine dissociates to release free TETA, which quickly becomes measurable in the plasma (figure 2). In addition, two acetylated metabolites, $\mathrm{N}_{1}$-acetyltriethylenetetramine (MAT) and $\mathrm{N}_{1}, \mathrm{~N}_{10}$-diacetyltriethylenetetramine (DAT), are formed in humans following oral trientine ingestion $^{[190,203-205]}$ (figure 2). TETA is therefore metabolized by acetylation, although the exact mechanism remains to be established.

It was thus necessary to determine whether the NAT2 phenotype has any effect on the pharmacological properties and safety profile of trientine. We recruited 12 fast and 12 slow NAT2phenotype healthy volunteers. ${ }^{[202]}$ After oral drug administration, plasma and urine samples were collected, and plasma concentrations of TETA and its two metabolites measured along with urinary copper concentrations and safety tests. There was no evidence for clear-cut differences in PK profiles between experimental groups with fast and slow

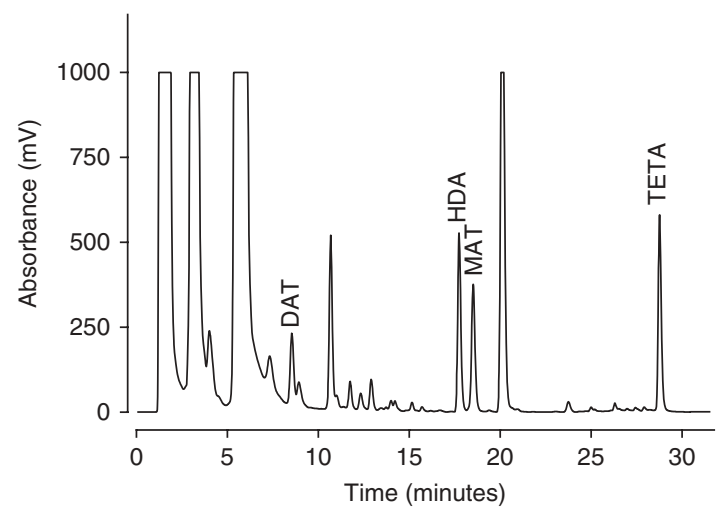

Fig. 2. High-performance liquid chromatogram showing separation/detection of fully-labeled triethylenetetramine (TETA), $N_{1}$ acetyltriethylenetetramine (MAT) and $\mathrm{N}_{1}, \mathrm{~N}_{10}$-diacetyltriethylenetetramine (DAT) in a blank human serum sample to which $3 \mathrm{mg} / \mathrm{L}$ of standards for each analyte ${ }^{[198]}$ had been added and detected by a new 9-flouorenylmethylchloroformate (FMOC)-labelling process (reproduced from Othman et al., ${ }^{[203]}$ with permission from Elsevier). HDA = hexamethylenediamine dihydrochloride (added as internal standard); $\mathbf{m V}=$ millivolts.

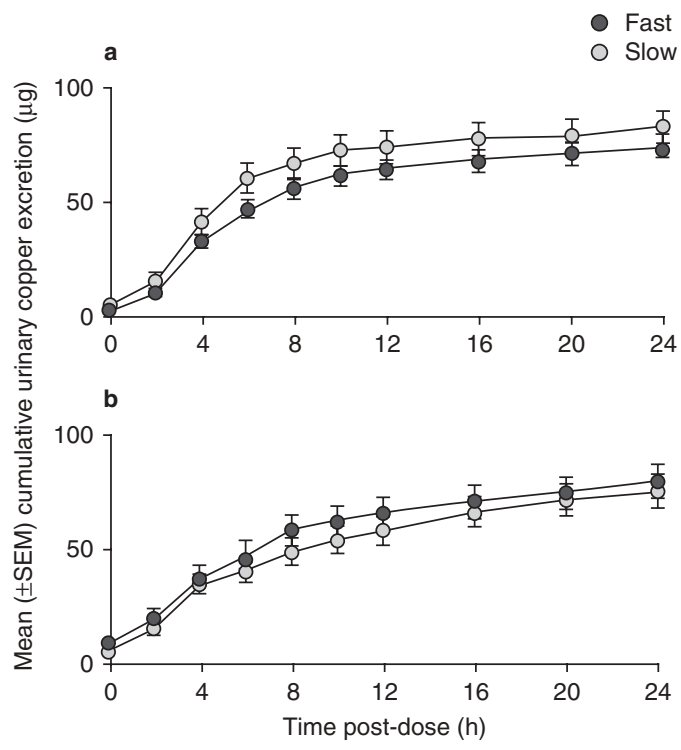

Fig. 3. Triethylenetetramine (TETA) is unlikely to be metabolized via $\mathrm{N}$-acetyltransferase 2 (NAT2). Results from a phase I clinical trial illustrating cumulative cupriuresis $(\mu \mathrm{g})$ on days (a) 1 and (b) 7 in nondiabetic volunteers with fast and slow acetylator $(n=12$ per group), who took single $600 \mathrm{mg}$ doses of trientine (TETA dihydrochloride) on days 0 and 7 , and twice-daily doses on each of days 2 through 6 (reproduced from Lu et al., ${ }^{[202]}$ with permission). $\mathrm{SEM}=$ standard error of the mean .

acetylator phenotypes, nor did PD analysis show any significant differences in cupriuresis (figure 3).

Safety results were consistent with trientine being well tolerated, and there were no significant differences in safety profiles. Based on these data, NAT2 phenotype does not affect the PK, PD or safety profiles of trientine. Thus NAT2 is unlikely to catalyse TETA acetylation. Rather, TETA may well be acetylated in humans through an alternative pathway, probably that catalysed by the spermidine/ spermine $\mathrm{N}_{1}$-acetyltranferase (SSAT), which also acetylates the endogenous polyamines. ${ }^{[206,207]}$ To our knowledge, the SSAT enzyme system has not previously been associated with metabolism of any drug, so this is likely to be the first instance in which a drug is metabolized via SSAT instead of the more traditional cytochrome P450/NAT routes. ${ }^{[202]}$

\section{Trientine Treatment of Diabetic Cardiovascular Diseases}

Cardiovascular complications are the major cause of death and disability in diabetes. 
Although altered systemic regulation of transition metals in diabetes had been the subject of numerous previous investigations, at the time we began this programme it was not known whether changed transition metal metabolism might result in heart disease in common forms of diabetes or whether metal chelation might be able to reverse the condition. Diabetic vasculopathy is a widespread complication of diabetes, affecting many or most aspects of the vascular tree, including arteries of all sizes, arterioles, capillaries and veins. It leads to a generalized hardening and stiffening of the arteries, ${ }^{[208,209]}$ named arteriosclerosis, which is accompanied by dysregulation in many molecular pathways that leads to or causes pathogenetic processes, including oxidative stress, metabolic stress and mitochondrial dysfunction, amongst others. ${ }^{[210]}$

We have found that pathogenetic molecular processes associated with diabetic arteriosclerosis in animal models, such as elevated TGF $\beta$ signalling and arterial fibrosis, are largely reversed by copper chelation, which also apparently lowers arterial hardening and stiffness ${ }^{[20]}$ (figures 4, 5). Diabetic tissue damage is accompanied by concomitant deterioration in cardiac structure and function, including a comprehensive defect of mitochondrial homeostasis, ${ }^{[211]}$ and these are also reversible by chronic trientine administration. ${ }^{[20,42,200]}$

\section{1 Trientine Treatment of Heart Disease in Rats Used as a Model of Diabetes Mellitus, and in a Phase II Trial in Diabetic Patients with Left- Ventricular Hypertrophy}

In nonclinical studies, we have found that administration of trientine to rats with streptozotocininduced diabetes causes increased urinary copper excretion compared with matched controls ${ }^{[42]}$ (figures 6, 7). A Cu${ }^{\mathrm{II}}$-trientine complex was demonstrated in the urine of drug-treated rats by measurement with electron paramagnetic resonance spectroscopy (EPR) [figure 6], and comparisons with total urinary copper indicated that all the excess excreted copper was $\mathrm{Cu}^{\mathrm{II}}$ (figure 7). ${ }^{[42,212]}$

Ex vivo infusion of a trientine solution into the coronary arteries of isolated perfused rat hearts revealed a $\sim 3$-fold increase in chelatable myo- cardial copper in diabetes that was rapidly extractable by chelation (figure 8). This finding is consistent with the elevated trapping of chelatable/ catalytically active $\mathrm{Cu}^{\mathrm{II}}$ by the cardiac ECM in diabetes. ${ }^{[42]}$

In diabetic animals with established LVH and heart failure, 7 weeks' oral trientine therapy significantly alleviated heart failure, improved cardiomyocyte structure (figure 9), and reversed elevations in left ventricular (LV) and aortic collagen and $\beta_{1}$-integrin (figures $4,5,9$ ). It did this without lowering blood glucose or blood pressure. ${ }^{[42]}$

In another study, oral treatment with trientine or another chelator, citrate, prevented the development of cardiomyopathy in the Zucker diabetic rat, an animal model of T2DM. ${ }^{[213]}$ In particular, trientine treatment prevented cardiac dilatation, and also improved ejection fraction and myocardial relaxation. These data were interpreted as supporting the use of trientine or citrate for the prevention of diabetic heart disease. ${ }^{[213]}$

Oral trientine treatment also elevated copper excretion in patients with established T2DM, in whom 12 months' treatment caused elevated LV mass to decline significantly toward normal (figure 10). This study was a randomized, placebo-controlled study of the effects of treatment with trientine ( $600 \mathrm{mg}$ given orally twice daily) on LVH in T2DM patients $(n=15$ per group at baseline) in an outpatient setting wherein participants, caregivers and those assessing outcomes were blinded to group assignment. ${ }^{[43]}$ Cardiac magnetic resonance imaging was employed to measure LV variables at baseline, and at months 6 and 12, with the change from baseline in LV mass indexed to body surface area $\left(\mathrm{LVM}_{\mathrm{bsa}}\right)$ as the primary endpoint variable. Diabetic patients had LVH with preserved ejection fraction at baseline. Trientine treatment decreased $\mathrm{LVM}_{\mathrm{bsa}}$ by $5.0 \pm 7.2 \mathrm{~g} / \mathrm{m}^{2}$ (mean $\pm \mathrm{SD}$ ) at month 6 (when 14 trientine-treated and 14 placebo-treated participants were analysed; $\mathrm{p}=0.0056$ compared with placebo), and by $10.6 \pm 7.6 \mathrm{~g} / \mathrm{m}^{2}$ at month 12 (when 9 trientine-treated and 13 placebo-treated participants were analysed; $p=0.0088$ ), whereas $\mathrm{LVM}_{\mathrm{bsa}}$ was unchanged by placebo treatment (figure 10). In a multiple-regression model that 

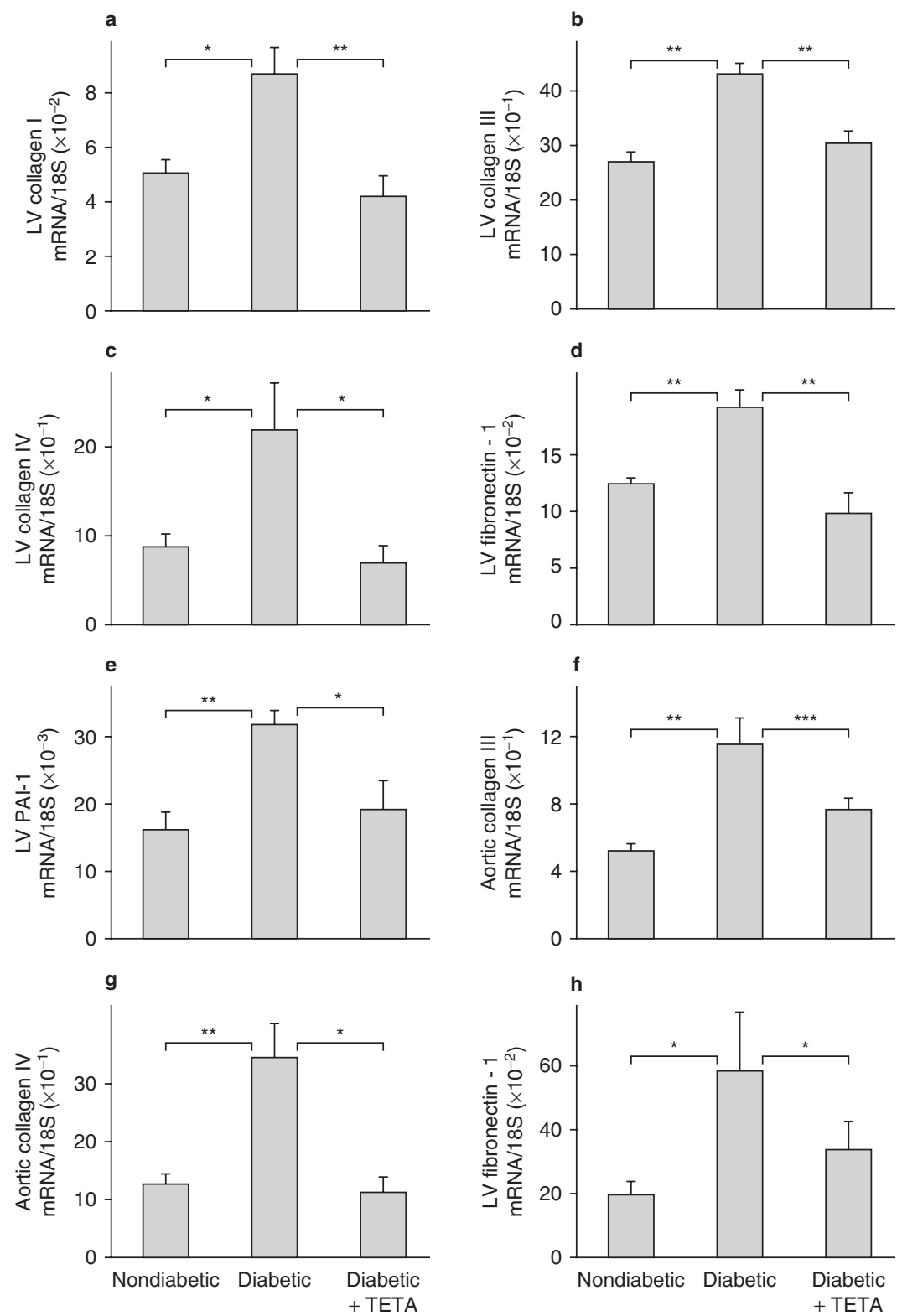

Fig. 4. Trientine treatment normalized (a) collagen I, (b) collagen III, (c) collagen IV, (d) fibronectin-1 and (e) plasminogen activator inhibitor-1 (PAl-1) messenger RNA (mRNA) levels in cardiac left ventricle (LV), and (f) collagen III, (g) collagen IV and (h) fibronectin-1 mRNA levels in the aorta of streptozotocin-diabetic rats ( $n=5$ per group) [reproduced from Gong et al., ${ }^{[20]}$ with permission]. TETA=triethylenetetramine; ${ }^{*} \mathrm{p}<0.05,{ }^{* *} \mathrm{p}<0.01,{ }^{* * *} \mathrm{p}<0.1$

explained $\sim 75 \%$ of variation $\left(\mathrm{R}^{2}=0.748 ; \mathrm{p}=0.001\right)$, cumulative urinary copper excretion over 12 months was positively associated with trientine-evoked decreases in $\mathrm{LVM}_{\mathrm{bsa}}$. Trientine treatment did not lower plasma copper or glycosylated haemoglobin $\left(\mathrm{HbA}_{1 \mathrm{c}}\right)$ values during this 12-month trial. 

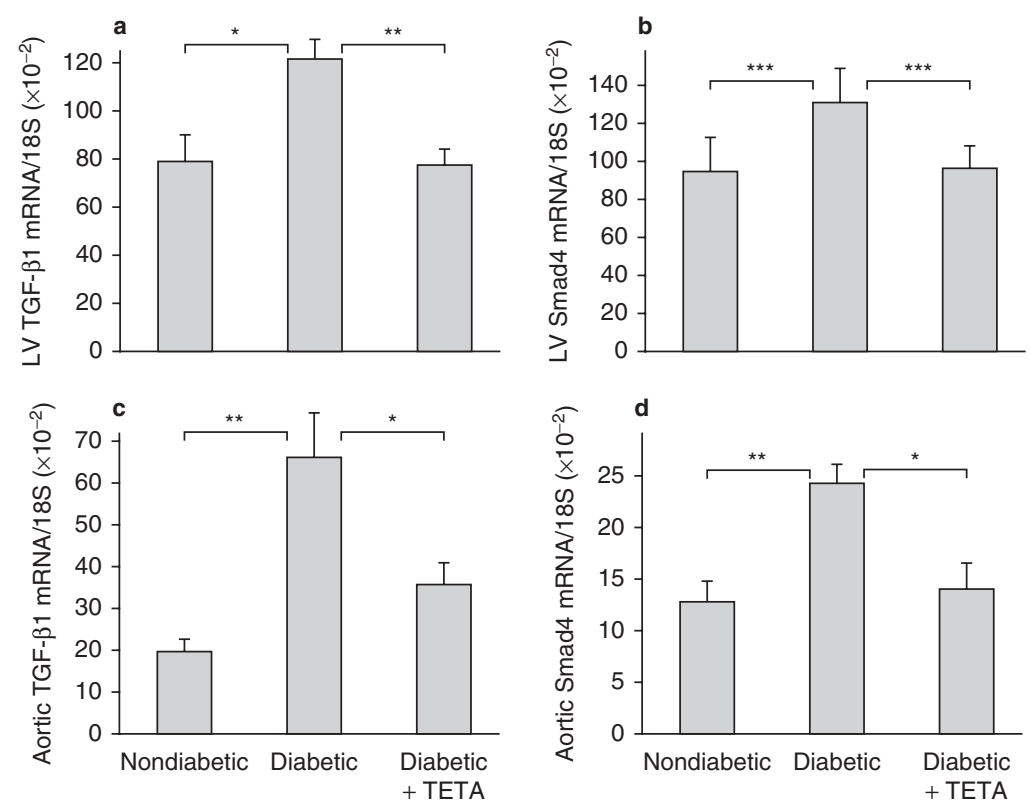

Fig. 5. Trientine treatment inhibited diabetes-induced overexpression of (a) transforming growth factor (TGF)- $\beta_{1}$, and (b) MAD homologue (Smad)4 messenger RNA (mRNA) levels in cardiac left ventricle (LV), and (c) TGF- $\beta_{1}$ and (d) Smad4 mRNA levels in the aorta of streptozotocin-diabetic rats ( $n=5$ per group) [reproduced from Gong et al., ${ }^{[20]}$ with permission]. ${ }^{*} p<0.05,{ }^{* * *} p<0.01,{ }^{* * * *} p<0.1$.

These data implicate accumulation of elevated catalytically active copper in the mechanism of cardiac damage in diabetes and support further studies of highly selective $\mathrm{Cu}^{\mathrm{II}}$ chelation in the treatment of diabetic heart disease. ${ }^{[42]}$

\subsection{Trientine Has Beneficial Effects on Vascular Endothelial Function in Experimental Diabetes}

Trientine treatment ameliorated defective vascular endothelial function in STZ-diabetic rats, as determined by actions to prevent/restore both nitric oxide (NO)- and endothelium-derived hyperpolarizing factor (EDHF)-mediated responses in the mesenteric vascular bed. ${ }^{[71]}$ These findings provide evidence for transition-metal catalysed effects in diabetes-mediated vascular disease.

Based on the arguments reviewed here, this study provides further evidence for coppermediated contributions to diabetic vasculopathy, and the beneficial responses of trientine treatment. Thus, copper-catalysed ROS production may provide a substantial contribution to defects in both the EDHF- and NO-mediated endothelial mechanisms in diabetes. Trientine had beneficial effects on the microvascular complications in an animal model of diabetes. Whether it has similar effects in diabetic patients remains to
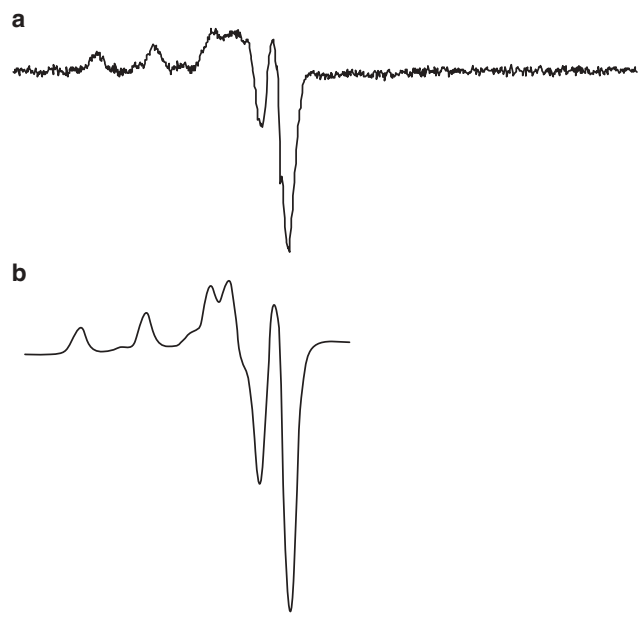

Fig. 6. Electron paramagnetic resonance-derived spectrum of (a) urine collected 15 minutes after intravenous injection of trientine $100 \mathrm{mg} / \mathrm{kg}$ into a diabetic rat, ${ }^{[42]}$ and (b) a chemically synthesized divalent copper (Cull)-triethylenetetramine complex (reproduced with permission from Siddiqui and Shepherd, ${ }^{[212]}$ (C) 1986, American Chemical Society). 

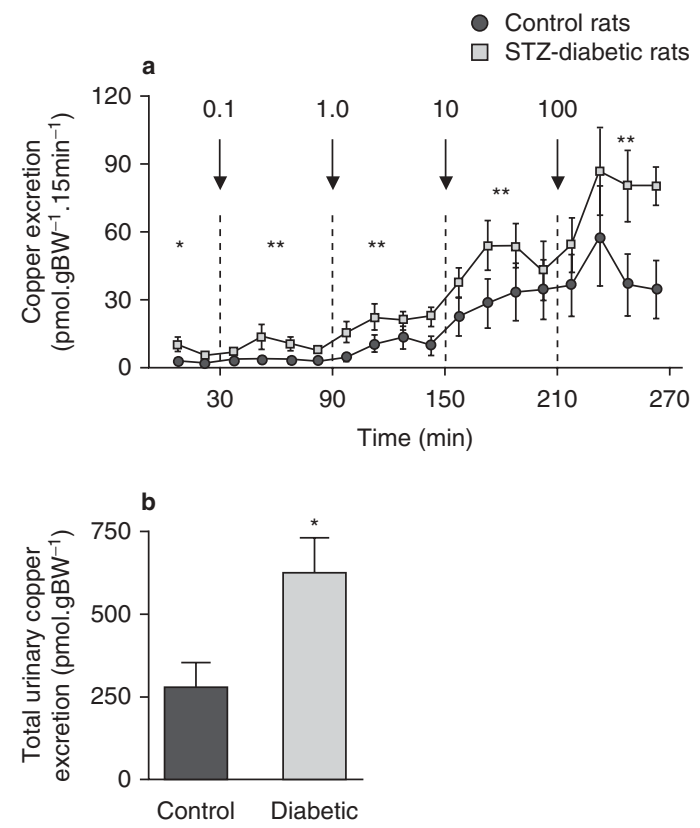

$\triangle[\mathrm{Cu}]$

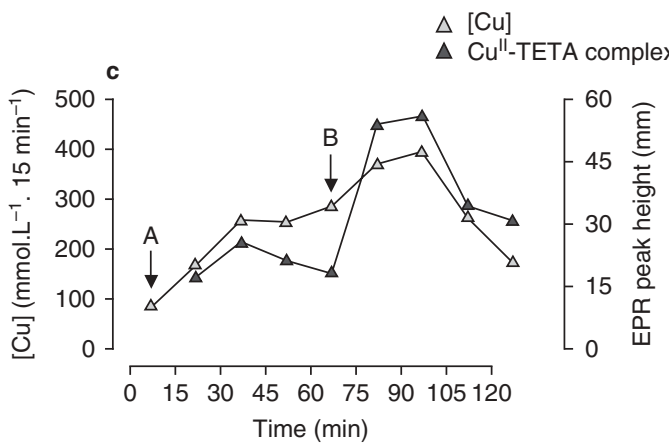

Fig. 7. Administration of intravenous trientine stimulates excessive urinary divalent copper (Cull) excretion from streptozotocin (STZ)diabetic rats compared with matched nondiabetic control animals. (a) Total urinary copper was determined by graphite furnace-atomic absorption spectroscopy after intravenous trientine $(0.1,1.0,10$ and $100 \mathrm{mg} / \mathrm{kg})$ in control $(n=7)$ and STZ-diabetic $(n=7)$ rats. (b) Sumtotal of urinary $\mathrm{Cu}$ excreted (mean $\pm \mathrm{SE}$ ). Copper concentration ([Cu]) and (c) the EPR signal from a Cu"-TETA complex in urine from a representative diabetic rat after $10 \mathrm{mg} / \mathrm{kg}(\mathrm{A})$ and $100 \mathrm{mg} / \mathrm{kg}(B) \mathrm{in}$ travenous trientine injections. Neither diabetes nor trientine injection had significant effects on iron urinary excretion. ${ }^{*} p<0.05,{ }^{* * *} p<0.01$ versus corresponding control values (reproduced from Cooper et al., ${ }^{[42]}$ with permission). EPR=electron paramagnetic resonance spectroscopy; gBW = grams of bodyweight; TETA = triethylenetetramine.

be tested in clinical trials, but observed cardiovascular improvements in trientine-treated diabetic patients ${ }^{[43]}$ could reflect such mechanisms, at least in part.

\subsection{Molecular Mechanism by Which Trientine Ameliorates Diabetic Cardiac and Arterial Diseases}

We have systematically evaluated the mechanism by which trientine can prevent or repair diabetic LV and arterial damage, and shown that it modifies the expression of molecular targets, including TGF- $\beta_{1}$, Smad4 and ECM proteins, (figures 4, 5), ${ }^{[20]}$ as well as extracellular SOD (EC-SOD or SOD3) ${ }^{[45]}$ and tissue heparan sulfate (HS) levels. ${ }^{[64]}$ Eight weeks of trientine treatment significantly improved cardiac diastolic function but not blood glucose in diabetic rats. LV and aortic messenger RNAs corresponding to TGF- $\beta_{1}$, Smad4, collagen types I, III, and IV, and fibronectin-1, and plasminogen activator inhibitor-1, were all elevated in untreated diabetic animals and apparently normalized by trientine treatment (figures 4, 5). Circulating EC-SOD was also elevated in T2DM patients and normalized by trientine treatment, ${ }^{[45]}$ whereas arterial HS levels were significantly decreased in diabetic rats and restored by drug treatment; ${ }^{[64]}$ these data are consistent with TETA-mediated repair of EC-SOD anchoring to vascular HS. Candidate molecular mechanisms by which trientine could ameliorate diabetic cardiac and arteriovascular disease include the

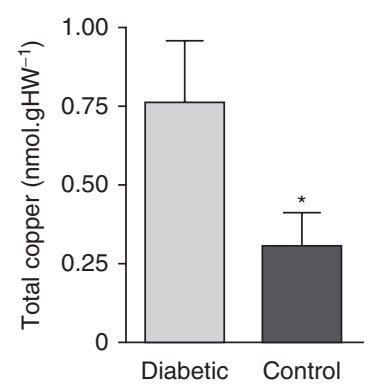

Fig. 8. Perfusion of the coronary circulation with trientine reveals excess chelatable copper in hearts from diabetic rats. Hearts were excised from anaesthetized streptozotocin (STZ)-treated rats after 7 weeks' diabetes and from matched controls ( $n=10$ per group), and perfused until stable ( $20 \mathrm{~min}$, nonworking mode). They then underwent retrograde perfusion ( $\mathrm{KHB}, 5 \mathrm{mmol} / \mathrm{L}$ trientine). 30 -sec fractions (for 2 min) were analysed (ICPMS, Elan 6100; Perkin Elmer), and total extracted copper calculated and normalized to heart weights from diabetic or control animals (reproduced from Cooper et al., ${ }^{[42]}$ with permission). $\mathbf{g H W}=$ grams of heart weight; ICPMS = inductively-coupled plasma mass spectroscopy; $\mathbf{K H B}=$ KrebsHenseleit buffer; ${ }^{*} p<0.04$. 

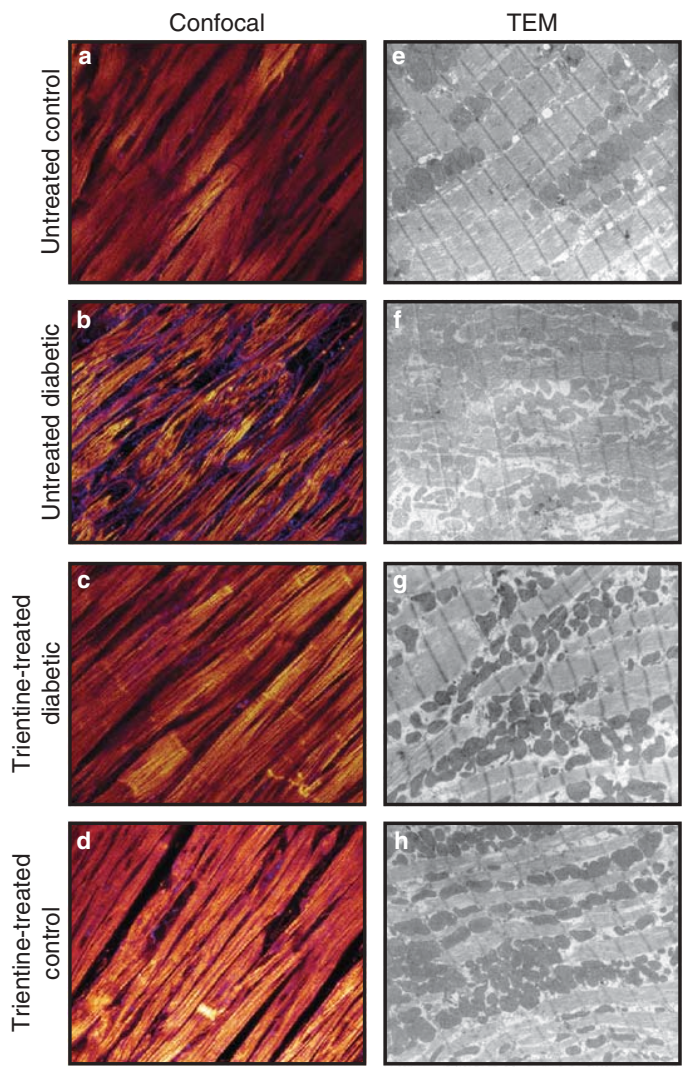

Fig. 9. Trientine improves cardiac left ventricle structure in streptozotocin-diabetic rats with heart failure. Images are representative of five optical sections per heart/three hearts per treatment for laserconfocal microscopy (LCM), and four sections per heart/five to six hearts per treatment for transmission electron microscopy (TEM). (a-d) LCM images of $120 \mu \mathrm{m}$ sections co-stained for f-actin (orange) and $\beta_{1}$-integrin (blue) [scale bar $=33 \mu \mathrm{m}$ ]. $(\mathbf{e}-\mathbf{h})$ TEM images of corresponding $70 \mathrm{~nm}$ sections stained with uranyl acetate/lead citrate (scale bar $=158 \mathrm{~nm}$ ) [reproduced from Cooper et al., ${ }^{[42]}$ with permission].

suppression of an activated TGF- $\beta_{1} /$ Smad signalling pathway that mediates increased ECM gene expression and restoration of normal ECSOD and HS regulation.

Proteomic analysis of the left ventricle in untreated and trientine-treated diabetic animals showed that trientine repairs the structure of myocardial mitochondria, ${ }^{[211]}$ consistent with its restoration of pathways that mediate oxidative phosphorylation, and the balance of fuel utilization between the citric acid cycle and fatty-acid $\beta$-oxidation pathways (figure 11). These findings are relevant to the mechanism by which TETA restorates cardiac and arterial structure/function in diabetes.

\section{Effects of Copper Chelation in an Animal Model of Diabetic Nephropathy}

\subsection{Trientine Treatment Ameliorates Diabetic Nephropathy in a Rat Model}

Diabetic nephropathy is the most common disorder leading to end-stage renal disease worldwide. Although adequate control of blood glucose may slow the rate of its progression, many diabetic patients find it difficult to achieve strict glycaemic control in the longer term, due at least in part to limitations of available therapeutic approaches. Despite the availability of treatments that lower elevated levels of blood glucose and/or blood pressure, many diabetic patients are still prone to developing kidney failure, which no currently available therapy can reverse. ${ }^{[214]}$ It is thus appropriate to search for new therapeutic approaches to the treatment of diabetic nephropathy, based on novel mechanisms of action. ${ }^{[68]}$

Based on our original observations that highly selective $\mathrm{Cu}^{\mathrm{II}}$ chelation restores cardiovascular structure and function damaged by diabetes, we measured responses to this therapy in a rat-based model of diabetic nephropathy, ${ }^{[68]}$ and subsequently performed a detailed proteomic analysis of the molecular mechanism. ${ }^{[201]}$ We found that renal tissue copper was substantively elevated by diabetes and normalized by trientine treatment (figure 12), which also suppressed whole-kidney and glomerular hypertrophy without lowering blood glucose levels (figure 13). In contrast, although renal tissue zinc and iron levels were also modestly elevated by diabetes, neither was restored by trientine. Therefore, the striking effects of trientine to improve renal structure and function in diabetes were probably mediated through its actions to normalize tissue copper rather than either of these other two transition metals.

The urinary albumin : creatinine ratio was significantly elevated in diabetic rats and lowered by trientine treatment (figure 14). Total collagen was 
also elevated in diabetic kidneys and significantly improved by treatment (figure 15). Furthermore, renal cortical levels of TGF- $\beta 1$, MAD homologue (Smad)-4, phosphorylated Smad2, fibronectin-1, collagen-III, collagen-IV, plasminogen activator inhibitor-1 and semicarbazide-sensitive amine oxidase (an extracellular $\mathrm{Cu}^{\mathrm{II}}$ enzyme) all tended to be elevated in diabetes and normalized following drug treatment (figure 15).
These molecular responses offer potential explanations, at least in part, for the pharmacodynamic response to trientine treatment. However, as can be seen, the response to drug encompasses beneficial changes in many different pathways with a common thread that seems to be disturbed copper homeostasis/defective organ copper regulation coupled with elevated oxidative stress.
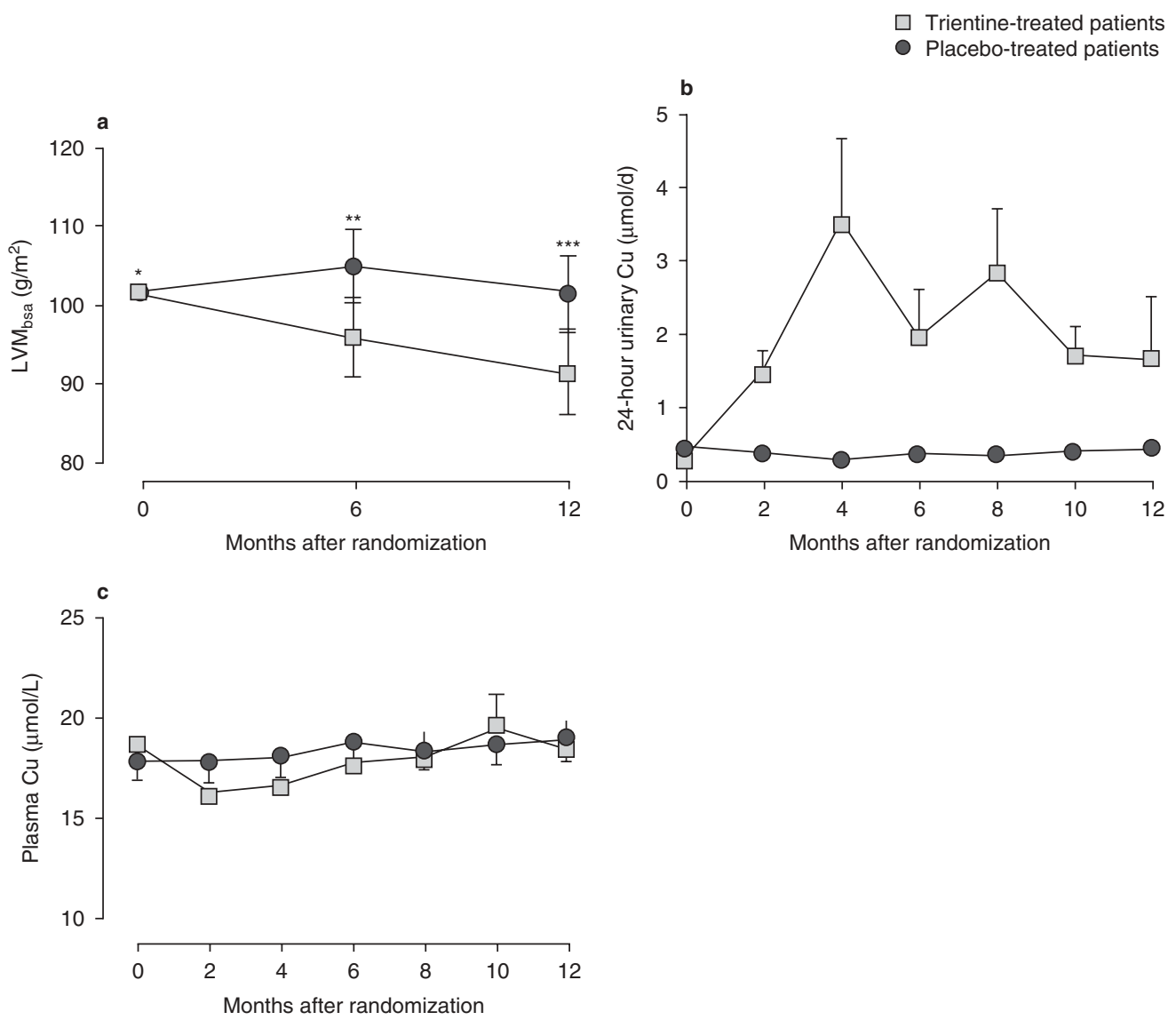

Fig. 10. Time-dependent responses of (a) left-ventricular mass indexed to body-surface area $\left(\mathrm{LVM}_{\mathrm{bsa}}\right)$, (b) urinary copper and (c) plasma copper in trientine-treated (600 mg twice daily; $n=15$ at baseline) or placebo-treated ( $n=15$ at baseline) type 2 diabetic patients over 12 months; numbers after 6 months' treatment were $n=14$ in both groups, and after 12 months' treatment were $n=9$ (drug) and $n=13$ (placebo). (a) p-Values denote contrasts in between-group differences in change in $\mathrm{LVM}_{\mathrm{bsa}}$ from baseline. (b) Exact p-values for differences in urinary copper at specified timepoints were as follows: baseline $0.34 ; 2$ months $0.0017 ; 4$ months $0.0044 ; 6$ months $0.014 ; 8$ months $0.0028 ; 10$ months 0.0020 ; and 12 months 0.13 . Plasma copper concentrations did not differ between groups at any timepoint, excluding the development of significant copper deficiency during trientine treatment. In a multiple-regression model that explained $\sim 75 \%$ of variation $\left(R^{2}=0.748, p=0.001\right)$, cumulative urinary copper excretion over 12 months was positively associated with trientine-evoked decreases in $\mathrm{LVM}_{\mathrm{bsa}}$. Values are means $\pm \mathrm{SE}$ (reproduced from Cooper et al.., ${ }^{[43]}$ with permission). ${ }^{*} p=$ not significant, ${ }^{* * *} p=0.0006$, $* * * 0.011$. 

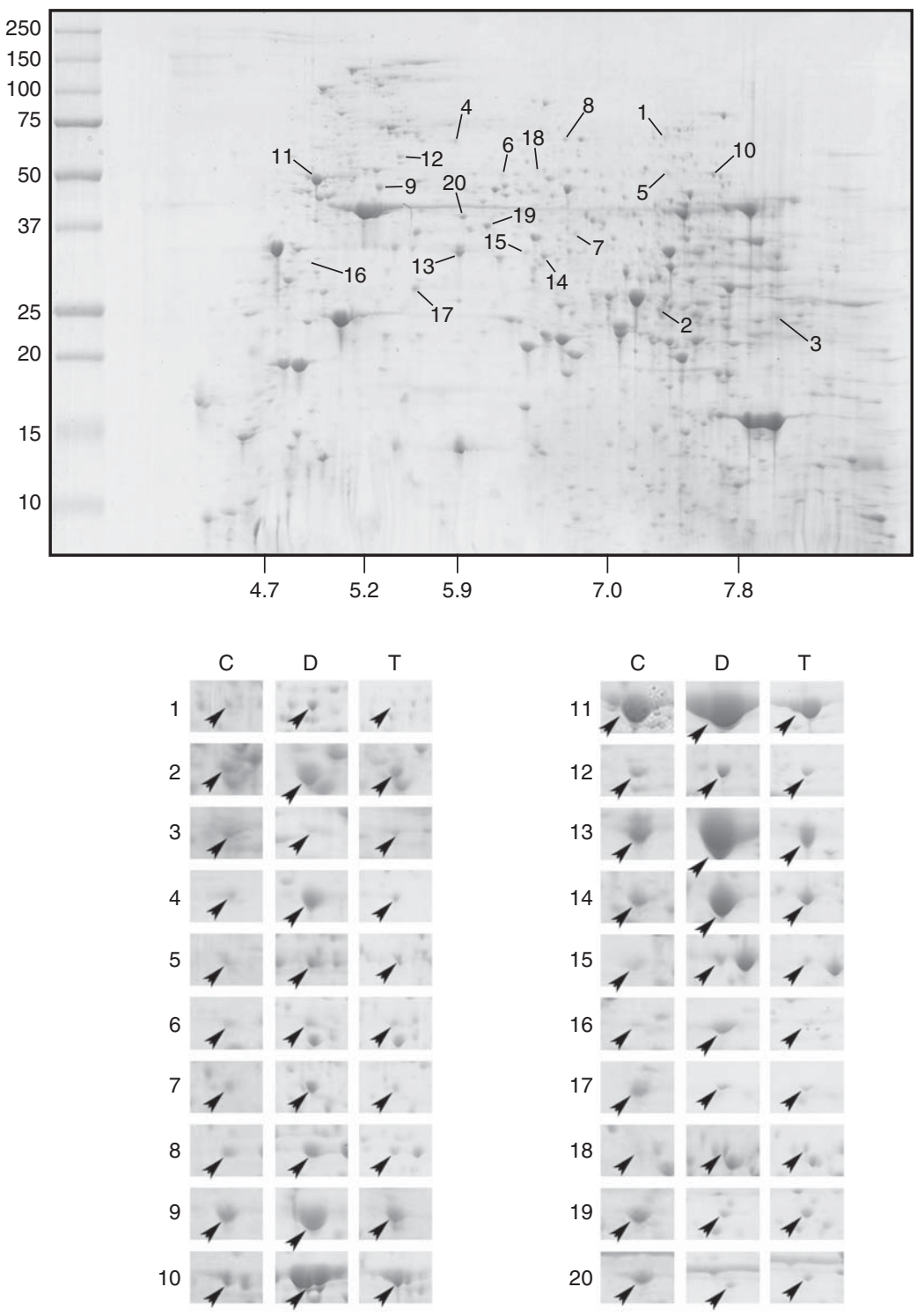

Fig. 11. Proteomic analysis of the cardiac left ventricle (LV) myocardium compared between control (C), streptozotocin-diabetic (D), and trientine-treated diabetic $(T)$ rats revealed that diabetes mellitus causes major perturbations in mitochondrial proteins implicated in fuel metabolism, and these defects are largely normalized by chelator treatment. Scanned images of LV homogenates that had been separated by two-dimensional gel electrophoresis. Numbers 1-20 correspond to specific proteins as listed below. Representative control gel with numbers to the left indicating molecular weights $(\mathrm{kDa})$ and those below, isoelectric point $(\mathrm{pl})$ values (upper panel). Gel spots from a control gel $(\mathrm{C})$ were compared with representative equivalent spots from untreated diabetic (D) and triethylenetetramine (TETA)-treated diabetic (T) groups (lower panels). The first 12 proteins listed below are of primary mitochondrial origin. Protein identities are as follows: 1 carnitine palmitoyltransferase-2; 2 enoyl-CoA hydratase; $\mathbf{3}$ short-chain I-3-hydroxyacyl-CoA dehydrogenase; $\mathbf{4}$ dihydrolipoamide $S$-acetyltransferase; 5 E2 subunit of pyruvate dehydrogenase $(\mathrm{PDH}) ; 6$ dihydroliposyllysine-residue succinyl-transferase, E2k residue of $\alpha$-ketoglutarate dehydrogenase; 7 nicotinamide adenine dinucleotide (NADH) dehydrogenase [ubiquitin] 1 alpha subcomplex subunit 10; 8 succinate dehydrogenase complex, subunit $A$; 9 ubiquinol cytochrome $\mathrm{c}$ reductase complex, core protein $1 ; 10$ adenosine triphosphate (ATP) synthase, $\alpha$-subunit; 11 ATP synthase, $\beta$-subunit; 12 heat-shock protein-60; 13 lactate dehydrogenase-2 (mitochondrial, cytosolic); 14 cytosolic malate dehydrogenase; 15 annexin A3; 16 annexin A5; 17 prohibitin; 18 aldehyde dehydrogenase-1; 19 actin, cardiac isoform; 20 actin, cardiac isoform (reproduced from Jüllig et al., ${ }^{[200]}$ with permission). 

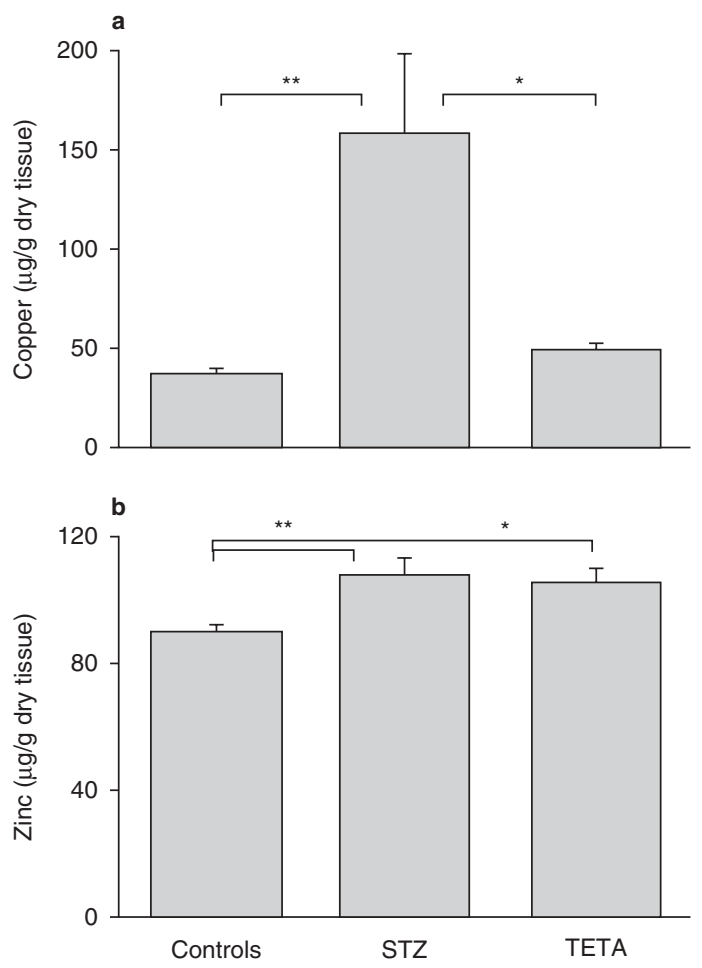

Fig. 12. Effect of trientine treatment on (a) total tissue copper and (b) zinc content in the kidneys of diabetic rats. Total tissue content of the following elements was measured by particle-induced x-ray emission spectroscopy (PIXE) with concomitant Rutherford backscatter spectroscopy in whole kidneys from nondiabetic control $(n=7)$, streptozotocin (STZ)-diabetic $(n=7)$ and triethylenetetramine (TETA)-treated diabetic $(n=7)$ rats: copper, zinc, iron, sodium, potassium, magnesium, calcium, phosphorus and chlorine; neither diabetes nor trientine altered levels of any elements other than copper and zinc as shown. Reciprocal transformation of data was performed prior to statistical analysis. Data are means $\pm S E .{ }^{*} p<0.01$, ${ }^{* *} \mathrm{p}<0.001$ by one-way ANOVA with post hoc Tukey's tests (reproduced from Gong et al.,, ${ }^{[68]}$ with kind permission from Springer Science + Business Media)

\subsection{Proteomic Analysis of the Molecular Mechanism by Which TETA Restores Renal Structure and Function in a Rodent Model of Diabetic Nephropathy}

We have performed quantitative studies of the molecular basis of diabetic nephropathy and its responsiveness to trientine treatment to identify proteins and pathways related to the pathogenesis of diabetic nephropathy and renal targets by which TETA reversed renal disease in diabetic rats. ${ }^{[201]}$ We synthesized and used a new vehicle for TETA delivery in these experiments, the experimental drug TETA disuccinate, which is more stable in aqueous solution than trientine itself. ${ }^{[198]}$

Key findings were as follows. In diabetic kidneys, tubulointerstitial nephritis antigen (TINag), voltagedependent anion-selective channel (VDAC)-1 and VDAC2 were up-regulated in parallel with alterations in expression of proteins with functions in oxidative stress and oxidative phosphorylation

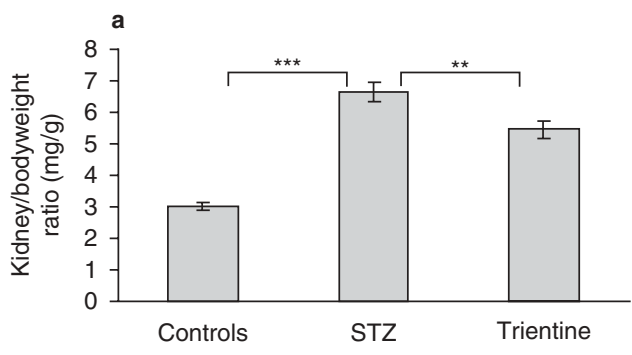

b
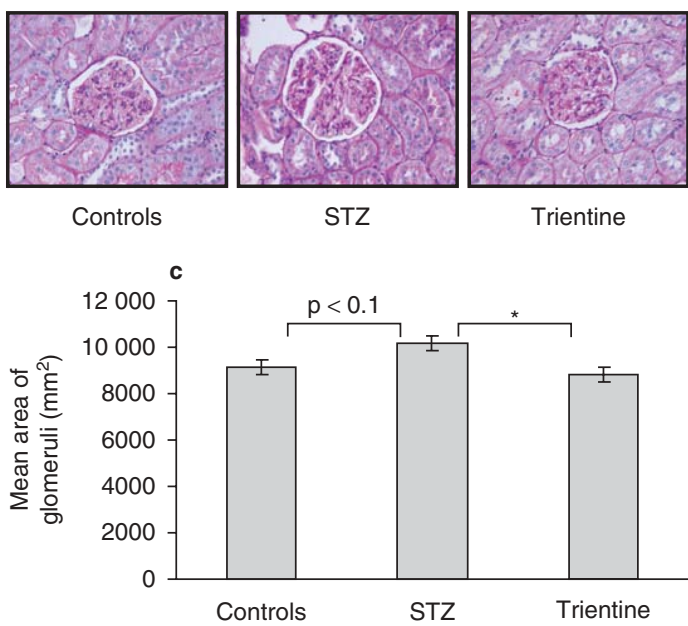

Fig. 13. Trientine treatment reversed nephromegaly and glomerular hypertrophy in rats with diabetic nephropathy. (a) Kidney weight: bodyweight ratios were measured in nondiabetic control $(n=6)$, streptozotocin (STZ)-diabetic $(n=9)$ and trientine-treated diabetic rats $(n=9)$. Data were log-transformed prior to analysis. (b) Representative photomicrographs of kidney sections stained with periodic acid Schiff stain (PAS) from nondiabetic control, diabetic and trientine-treated diabetic groups $(n=8)$ : scale bars, $50 \mu \mathrm{m}$. (c) Glomerular cross-sectional areas were measured from kidney sections stained with PAS. Bars represent means \pm SE from at least 50 individual glomeruli in sections from each of eight individual rats in each group (reproduced from Gong et al., ${ }^{[68]}$ with kind permission from Springer Science+Business Media). ${ }^{*} p<0.05$, ${ }^{* *} p<0.01$, ${ }^{* * * *} \mathrm{p}<0.001$, ${ }^{\#} \mathrm{p}<0.1$, by one-way ANOVA with post hoc Tukey's tests. 

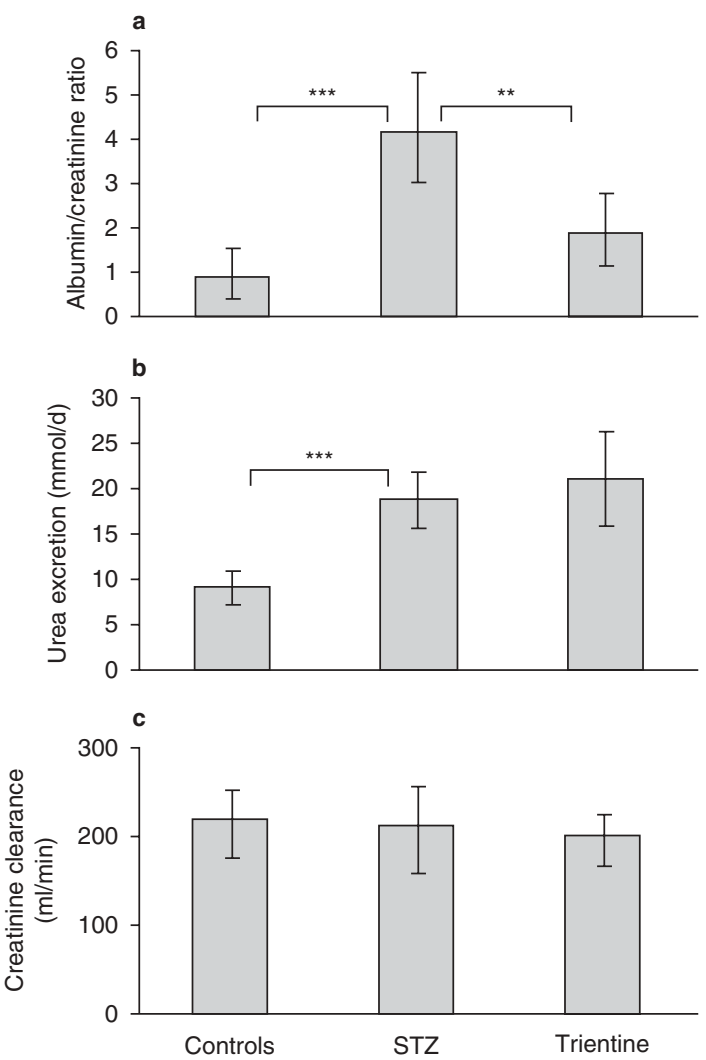

Fig. 14. Trientine treatment improved proteinuria in rats with diabetic nephropathy. (a) Urinary albumin: creatinine ratio (UACR), adjusted means $\pm S E$, (b) urine urea and (c) creatinine clearance in nondiabetic $(n=6)$, streptozotocin (STZ)-induced diabetic $(n=13)$ and trientinetreated diabetic $(n=13)$ rats. Trientine was administered from 8 weeks after diabetes induction for the next 7 weeks. A $24 \mathrm{~h}$ pooled urine sample was collected from each animal in a metabolic cage at week 15 (week 7 of diabetes) for each group. Square-root transformation was applied to UACR values (a) and a linear mixed-effects model, adjusting for inter-run variability, was then fitted. UACR means are presented. All data are means \pm SE and were analysed using a linear mixed-effects model (a) and one-way ANOVA with post hoc Tukey's tests $(\mathbf{b}, \mathbf{c}):{ }^{* *} p<0.01,{ }^{* * *} p<0.001$ (reproduced from Gong et al., ${ }^{668]}$ with kind permission from Springer Science + Business Media).

pathways. In contrast, mitochondrial heat shock protein (HSP) 60, SOD1, glutathione S-transferase a3 and aquaporin-1 were down-regulated in diabetic kidneys.

Following trientine treatment, levels of D-amino acid oxidase-1, epoxide hydrolase-1, aquaporin-1 and a number of mitochondrial proteins were normalized, with concomitant amelioration of albuminuria. Changes in levels of TINag, collagen-VIa1, actinin $4 \mathrm{a}$, apoptosis-inducing factor
1 , cytochrome $c$, histone $\mathrm{H} 3, \mathrm{VDAC} 1$ and aquaporin-1 were confirmed by western blotting or immunohistochemistry. Changes in expression of proteins related to tubulointerstitial function, podocyte structure and mitochondrial apoptosis are thus implicated in the mechanism of diabetic nephropathy and their reversal by TETA. These findings are consistent with the hypothesis that this new experimental therapy may be useful for treatment of diabetic nephropathy. ${ }^{[201]}$

\subsection{Effects of Diabetes and TETA Treatment on Renal Aquaporin-1 Regulation: An Illustration}

Many of the molecular findings in this study offer fascinating insights into the impact of copper toxicity in diabetic nephropathy and the response to its treatment. These are detailed in our recent paper ${ }^{[201]}$ and are far too numerous to discuss here in any detail. As an illustration, however, the effects of diabetes and of TETA treatment on aquaporin-1 are briefly presented.

Expression of aquaporin-1 in renal tubular cells is reportedly down-regulated in the kidneys of diabetic rats. ${ }^{[215]}$ Mice lacking aquaporin-1 were unable to concentrate their urine because of low water permeability in the proximal tubule, thin descending limb of the loop of Henle, and outer medullary descending vasa recta. ${ }^{[216]}$ In our study, renal aquaporin-1 levels were also decreased in diabetes, and TETA repaired this defect. It is known that renal tubular defects including impaired water excretion can occur in diabetic nephropathy. ${ }^{[217]}$ This finding is consistent with the possibility that TETA could improve water metabolism in diabetic kidneys - a topic to be explored in future work. Thus, diabetesmediated renal tubular dysfunction could well be caused by renal copper overload where $\mathrm{Cu}^{\mathrm{II}}$ may cause toxicity through mechanisms such as direct tubular toxicity, similar to that in copper poisoning ${ }^{[218,219]}$ or chronic copper overload, ${ }^{[172,173]}$ and removal of the offending renal copper (figure 12) can restore aspects of renal tubular function, such as water excretion via aquaporin-1.

\subsection{Next Steps}

These findings are consistent with the idea that diabetes-mediated copper overload and copper- 

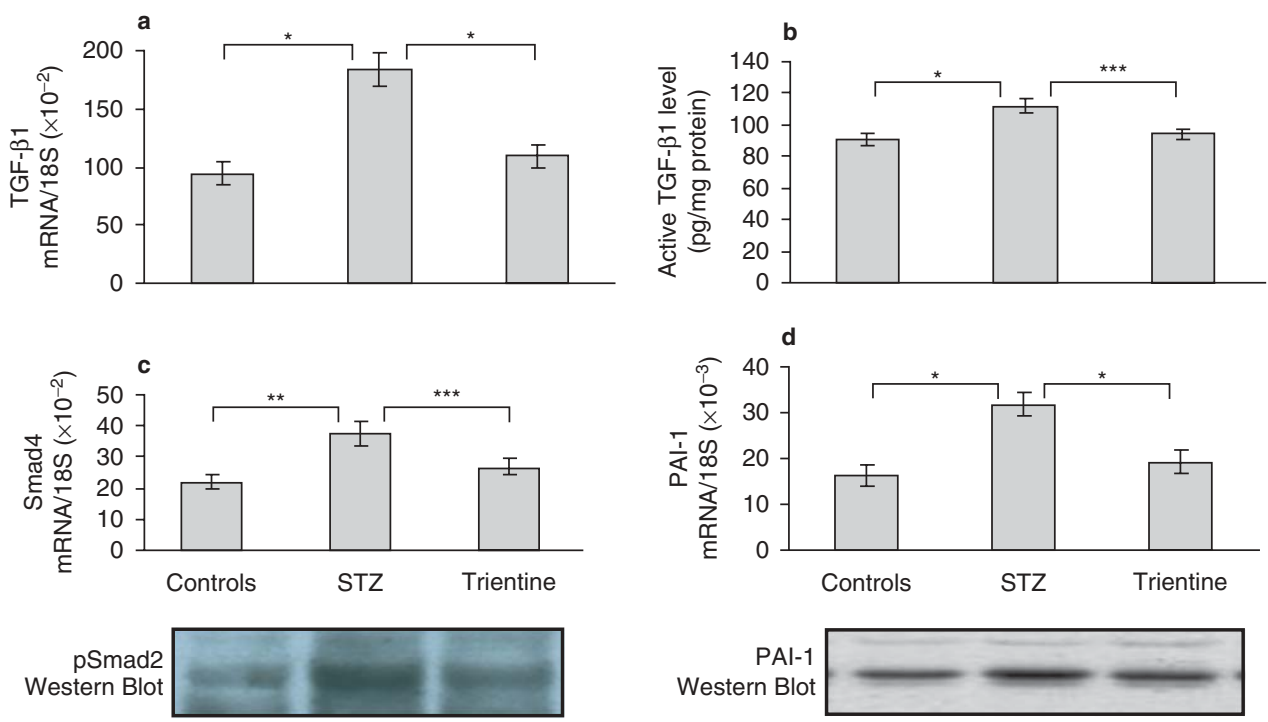

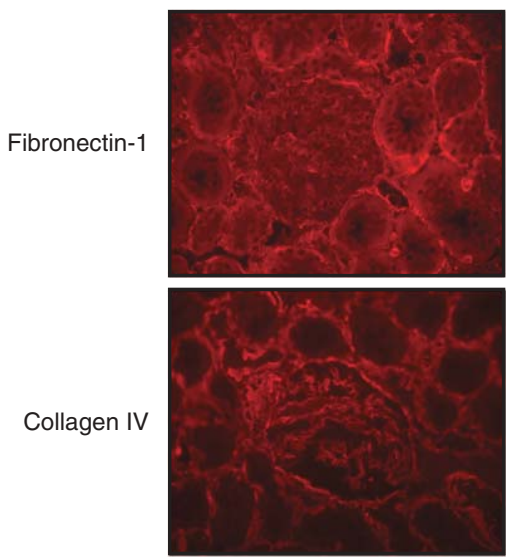

Controls
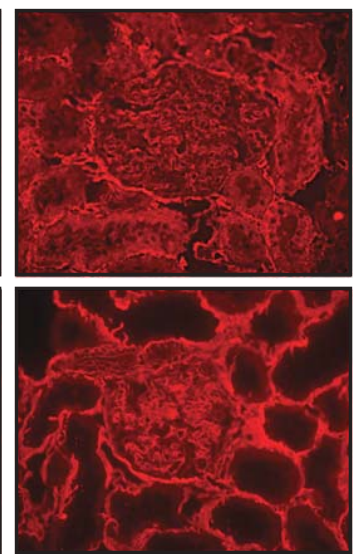

STZ
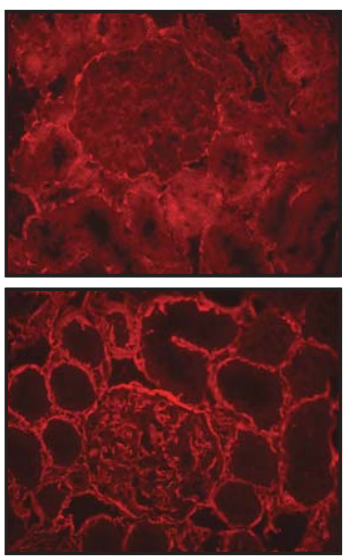

Trientine

Fig. 15. Effect of trientine treatment on (a) total collagen and (b) heparan sulfate content of diabetic kidneys. Trientine was administered for 8 weeks to rats that had already had untreated streptozotocin (STZ)-induced diabetes for 8 weeks. Total collagen content in both kidneys was determined by measuring hydroxyproline concentration in STZ-diabetic $(n=7)$, trientine-treated diabetic $(n=7)$ and nondiabetic control $(n=5)$ rats. A transformation of heparan sulfate data adequate to satisfy the requirements for ANOVA was not identified so the data were analysed using the Kruskal-Wallis and Wilcoxon rank sum tests with Bonferroni correction. Data are means \pm SE and were analysed by one-way ANOVA with post hoc Tukey's tests (a) and the Kruskal-Wallis test (b). ${ }^{*} p<0.05,{ }^{* *} p<0.01,{ }^{* * *} p<0.1$ (reproduced from Gong et al., ${ }^{[68]}$ with kind permission from Springer Science+Business Media). mRNA=messenger RNA; PAI-1=plasminogen activator inhibitor-1; pSmad2= phosphorylated mothers-against- decapentaplegic-protein-2 ; TGF =transforming growth factor.

evoked oxidative stress are pivotal to the molecular mechanisms that lead to or cause diabetic nephropathy, and to show that by removing excess $\mathrm{Cu}^{\mathrm{II}}$ through highly selective chelation, substantive regeneration of renal structure and function can be achieved in a widely employed animal model of diabetic nephropathy. Copper chelation evidently restores structure and function in multiple pathways, alleviating ionic stress (for example, via effects on VDAC1, mitochondrial stress, oxidative stress and metabolic stress, amongst others). Diabetesmediated dysregulation of renal structure/function 
is envisaged to occur through a combination of specific and general defects, namely specific defects engendered by altered regulation of particular copper-mediated processes coupled with more general abnormalities in ion transport, mitochondrial function, metabolic processes and glomerular structure and function, to name but a few.

The current plan is to proceed to a clinical trial of trientine treatment for the suppression/reversal of diabetic nephropathy. Clinical extension of these studies would appear to be well founded, given the evidence base now available.

\section{Evidence that Trientine Can Improve Pathogenetic Mechanisms in Diabetic Neuropathy}

There is evidence that trientine treatment can improve defects in motor nerve conduction velocity induced by STZ-diabetes in rats. ${ }^{[70,220]}$ In one report, ${ }^{[70]} 2$ weeks' treatment with either deferoxamine or trientine was equally effective in suppressing neuropathy. In the same study, sciatic endoneurial nutritive blood flow was $45 \%$ decreased by diabetes and completely corrected by treatment with either chelator, whereas, by contrast, chelation had no effect on these variables in nondiabetic rats. ${ }^{[70]}$ Increased concentrations of malondialdehyde in diabetic rats were partially but significantly ameliorated by trientine. ${ }^{[220]}$ The equivalent response to copper- or iron-selective chelation in the first study ${ }^{[70]}$ is apparently inconsistent with another study of other diabetic complications, including those of the heart, arteries and kidneys, ${ }^{[64]}$ where trientine was efficacious but the iron-selective chelator deferiprone was not. ${ }^{[64]}$ Further quantitative, side-by-side, dose-response studies may be required to resolve this possible disparity, which could also point to different mechanisms in neuropathy as opposed to the other forms of tissue damage. These findings are consistent with $\mathrm{Cu}^{\mathrm{II}}$-mediated hydroxyl radical formation as a pathogenetic mechanism of diabetic neuropathy. Such a role of hydroxyl radical is also consistent with amelioration of diabetic neuropathy by treatment with the hydroxyl radical scavenger, dimethylthiourea. ${ }^{[221]}$

\section{Diabetes Causes a Copper Overload State that is Reversible by Highly Selective Chelation}

Most cellular copper is tightly bound ${ }^{[85]}$ and regulated by binding proteins, and intracellular free copper is essentially undetectable. ${ }^{[88]} \mathrm{Cu}^{\mathrm{II}}$, which is present in urine from trientine-treated diabetic rats, ${ }^{[42]}$ is the most effective divalent ion for binding to organic molecules and the main extracellular copper ion, whereas $\mathrm{Cu}^{\mathrm{I}}$ predominates inside cells. ${ }^{[44]}$ Trientine binds $\mathrm{Cu}^{\mathrm{II}}$ less strongly than do most physiological copper-binding proteins. ${ }^{[4]}$ These observations, taken together with our recent findings showing the prompt increase in $\mathrm{Cu}^{\mathrm{II}}$ excretion after oral trientine administration in diabetic patients ${ }^{[42,45]}$ (figure 16), and after injection into the coronary arteries in ex vivo cardiac preparations from diabetic rats ${ }^{[42]}$ (figure 8), indicate that this increased $\mathrm{Cu}^{\mathrm{II}}$ is unlikely to be released from an intracellular pool. More likely, the $\mathrm{Cu}^{\mathrm{II}}$ is bound to ECM components, such as collagen; because it is readily extracted by trientine, the increased $\mathrm{Cu}^{\mathrm{II}}$ must be loosely bound and is therefore the probable cause of the observed

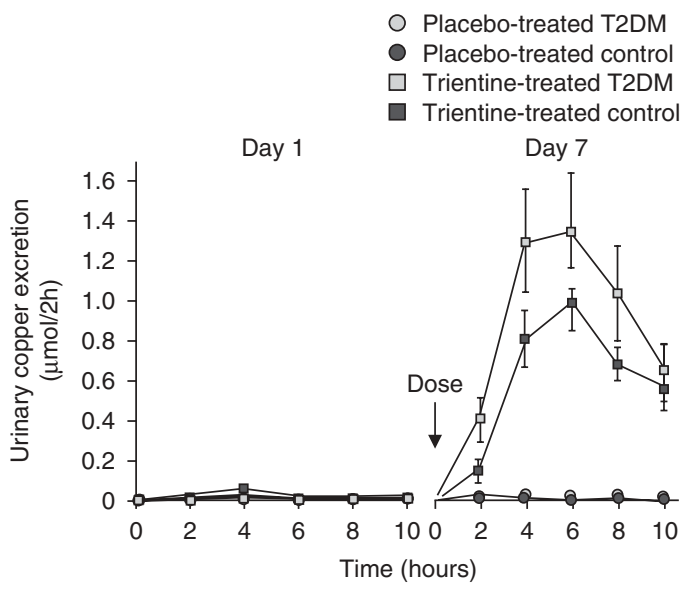

Fig. 16. Effects of trientine or placebo on urinary copper excretion in nondiabetic volunteers and patients with type 2 diabetes mellitus (T2DM). Effects of drug and placebo were compared between men with T2DM and age-matched nondiabetic volunteers. Urinary copper excretion $(\mu \mathrm{mol} / 2 \mathrm{~h})$ for $10 \mathrm{~h}$ on day 1 (baseline) and day 7 after single doses of trientine $2.4 \mathrm{~g}(\mathrm{n}=20)$ or matched placebo $(n=20)$ [administration time as arrowed]. Basal copper output was significantly greater in T2DM patients than controls $(p<0.001)$, and trientine extracted more copper from T2DM patients than controls $(p<0.05)$ [reproduced from Cooper et al., ${ }^{[42]}$ with permission]. 


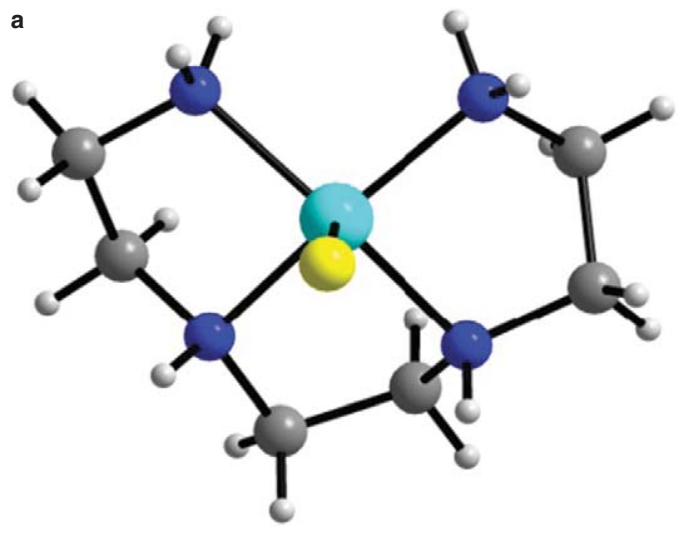

b

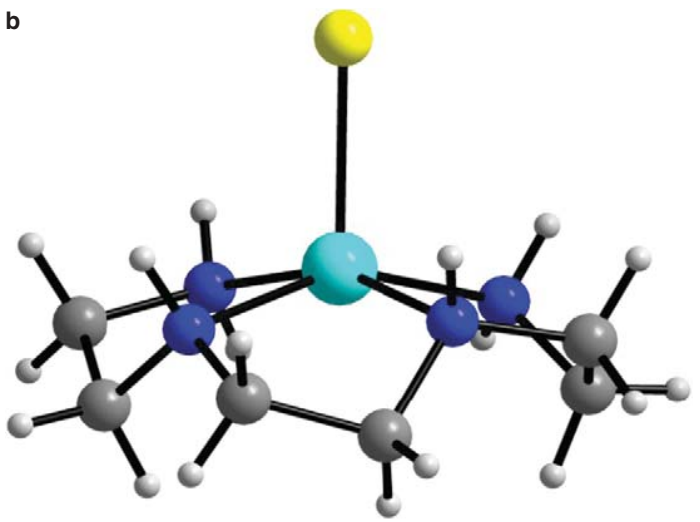

Fig. 17. X-ray crystallographic study of the structure of triethylenetetramine (TETA)-bound copper shown from the (a) vertical and (b) horizontal perspectives. Crystals were grown in a sodium chloride solution to mimic the effects of crystallization from the extracellular fluid. TETA is seen to complex a central divalent copper (Cull) atom (pale blue) in a distorted square pyramidal configuration with the four nitrogen atoms (dark blue) coordinated in the basa positions and a chloride ion (yellow) at the apex. This coordination is thought to suppress the catalytic activity of the centrally bound $\mathrm{Cu}^{\prime}$ atom, thereby providing a potential explanation for TETA's ability to protect tissues from $\mathrm{Cu}^{\prime \prime}$-catalysed reactive oxygen species-mediated damage.

increase in oxidative stress that is suppressed by trientine. ${ }^{[64]}$ Importantly, as confirmed by our recent x-ray crystallographic studies (figure 17), TETA's binding to $\mathrm{Cu}^{\mathrm{II}}$ is such that it suppresses its catalytic activity, thus protecting the renal tubules from $\mathrm{Cu}^{\mathrm{II}}$-mediated toxicity such as occurs in animals and humans undergoing acute copper poisoning.

Our recent measurements of concomitant urinary copper and TETA concentrations in diabetic animals and humans undergoing trientine treatment, confirm that the molar TETA : copper ratio is always $>1$, which information, taken together with the strong binding of TETA to $\mathrm{Cu}^{\mathrm{II}}$, implies that the renal tubules will be protected from any residual copper toxicity that might otherwise occur during its extraction into the urine.

\section{A Randomized, Placebo-Controlled Phase II Trial to Measure the Effects of Trientine on Transition Metal Regulation in Patients with Type 2 Diabetes (T2DM) and Matched Nondiabetic Volunteers}

None of the analyses discuss so far were sufficient to enable prediction of how trientine might modify transition metal homeostasis in diabetic patients in vivo. We therefore performed a phase II clinical trial in which we characterized the homeostasis of copper and eight other nutritionally essential elements under fully residential conditions in 20 men with established T2DM diagnosed at least 6 months before study enrolment, and 20 nondiabetic volunteers matched for age and sex. ${ }^{[45]}$ Diabetic patients were aged $50.7 \pm 10.4$ years (mean $\pm \mathrm{SD}$ ) at entry; had had diagnosed diabetes for 6.7 (1-34) [median (range)]; took their normal glucose-lowering medications throughout the study; had $\mathrm{HbA}_{1 \mathrm{c}}$ values of $9.2 \% \pm 2.2 \%$ at enrolment; and were not taking calcium channel blockers or diuretics. We then probed elemental balance with oral trientine in an immediately following, parallel-group, placebo-controlled study in the same participants. This study is seen as pivotal in interpreting the role of dysregulated copper homeostasis in the pathogenesis of the diabetic complications.

Before treatment, there were no detectable between-group differences in the balance of any element, although urinary output of several elements was greater in diabetic subjects. Mean EC-SOD activity was elevated in diabetic subjects, and this activity correlated strongly with the serum copper concentration- $\mathrm{HbA}_{1 \mathrm{c}}$ interaction (figure 18). Trientine caused the copper balance to become negative in diabetic subjects through elevated urinary copper losses and it also suppressed elevated serum EC-SOD levels. ${ }^{[45]}$ Basal 


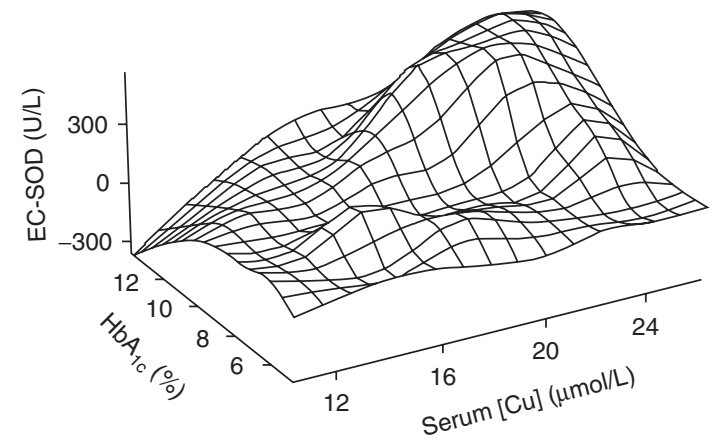

Fig. 18. An interaction between divalent copper $\left(\mathrm{Cu}^{\prime \prime}\right)$ and blood glucose may cause/contribute to elevated oxidative stress in type 2 diabetic patients. Spline fine-grid response surface fitted to a 3-dimensional plot of the relationship between $[\mathrm{Cu}]_{\text {serum }}\left(\mathrm{O}_{\mathrm{x}}\right)$, glycosylated haemoglobin $\left(\mathrm{HbA}_{1 \mathrm{c}}\right)\left[O_{y}\right]$ and serum extracellular $\mathrm{Cu} / \mathrm{zinc}(\mathrm{Zn})$ superoxide dismutase (SOD3) [EC-SOD] activity $\left(O_{z}\right)$ from a phase II clinical trial in a group of 20 type 2 diabetic patients $(p<0.0001)$. Maximum elevations in EC-SOD occurred mainly in subjects in whom both serum copper concentrations [Cu] and $\mathrm{HbA}_{1 \mathrm{c}}$ were high pointing to an interaction between copper and chronic hyperglycaemia associated with elevated EC-SOD as a marker of increased oxidative stress (reproduced from Cooper et al., ${ }^{[45]}$ with permission).

urinary copper predicted subsequent urinary copper losses during treatment, which caused extraction of systemic copper. We concluded from this study that cardiovascular complications in diabetes might be better controlled by therapeutic strategies that focus on concomitant lowering of both plasma glucose and loosely bound, catalytically active systemic $\mathrm{Cu}^{\mathrm{II}} \cdot{ }^{[45]}$

The demonstration of urinary $\mathrm{Cu}^{\mathrm{II}}$ that is extractable by TETA binding following trientine administration, and the excess of such copper present in diabetic animals and patients, are readily applicable tests for detection and quantification of this causative copper overload state. ${ }^{[42,43,45,64]}$

\subsection{Effects on Copper Regulation}

During this trial, we performed detailed measurements of a 6-day balance of nine elements (copper, iron, zinc, calcium, magnesium, manganese, molybdenum, selenium and chromium) to compare and contrast values between 20 diabetic and 20 age-matched nondiabetic control subjects, all males, in whom we subsequently probed systemic metal balance with oral trientine in a second, immediately following, 6-day balance study. Basal urinary outputs of copper and iron were significantly increased in the subjects with diabetes, and these values were strongly correlated. Trientine treatment increased urinary excretion of copper in a dose-dependent manner, as predicted by basal urinary copper, thereby causing a positive copper balance to become negative in diabetes. In contrast, it modified neither iron balance nor rates of urinary or faecal iron excretion in these subjects. Furthermore, trientine did not render negative the balance of any other element in either diabetic or control subjects, and was thus selective for copper over all other physiologically relevant transition metals. Regulation of copper metabolism was shown to be abnormal in diabetes and selectively modified by trientine, which did not concomitantly modify iron metabolism. This latter finding is highly significant, because it would seem to exclude an iron-mediated mechanism for trientine-evoked amelioration of the diabetic complications.

These findings are consistent with trientine's ability to reverse systemic accumulation of increased loosely bound, catalytically active $\mathrm{Cu}^{\mathrm{II}}$ in diabetes, which may help to explain its therapeutic effects in diabetic cardiovascular disease. Trientine treatment had no effect on serum levels of copper or caeruloplasmin in this study, consistent with our findings in the 12-month trial of trientine in diabetic patients with LVH. By these criteria, even prolonged trientine treatment did not cause systemic copper depletion. ${ }^{[43]}$

In these T2DM patients, circulating EC-SOD levels were markedly elevated and strongly associated with an interaction between $\mathrm{HbA}_{1 \mathrm{c}}$ and serum copper levels to increase oxidative stress (figure 18). ${ }^{[45]}$ The elevation in EC-SOD was completely eliminated after 7 days' trientine treatment, consistent with normalization of oxidative stress and restoration of normal levels of EC-SOD in the vascular epithelium. ${ }^{[68]}$

We found several aspects of copper metabolism to be defective in diabetic subjects. Basal urinary copper excretion was on average 1.4-fold higher in diabetic than control subjects, whereas serum copper levels did not differ significantly between the two groups. These findings are consistent with some previous reports, ${ }^{[222,223]}$ but others have reported elevated serum copper values in diabetes. ${ }^{[224]}$ 
There was a trend for the copper balance to be elevated in diabetic patients, as well as a significant effect of the interaction between trientine and diabetes on copper balance. ${ }^{[45]}$ Trientine markedly stimulated urinary copper in both subject groups, but lowered the copper balance only in diabetic patients. Urinary copper excretion during drug treatment was positively correlated with pretreatment urinary copper levels. Thus, elevated basal urinary copper predicted drug-induced cupriuresis, and individual responses may have been determined by prior systemic $\mathrm{Cu}^{\mathrm{II}}$ accumulation. In contrast, trientine decreased faecal copper in control subjects only, possibly through increased uptake, consistent with known actions of polyvalent chelators to increase metal absorption from the diet. ${ }^{[225]}$ An alternative mechanism that could have contributed to the observed effects of trientine on faecal metal excretion is that diabetes may modify hepatobiliary excretion of some or all of the elements concerned, although we are unaware of data to support this idea. Thus, regulation of copper homeostasis differed significantly between groups, and trientine elicited effects to reverse the elevated copper balance in diabetic subjects, mainly through stimulation of urinary copper excretion..$^{[42]}$

An important consideration that merits highlighting here is that several of the facets of dysregulated copper metabolism only become apparent upon probing with trientine. Until this series of studies was performed, the significance of the apparently subtle changes in copper values that have been observed in diabetes over the decades had remained uncertain.

\subsection{Effects on Iron Regulation}

A number of further important findings emerged from this study that merit comment. ${ }^{[45]}$ The findings concerning iron regulation are noteworthy. Trientine significantly modified the iron balance in the whole study population, but the corresponding trientine-metabolic status interaction term was not significant. It transpired that trientine increased the iron balance in control but not in diabetic subjects. Although basal urinary iron was elevated in diabetic subjects, it was unaffected by trientine, which had only borderline effects in diabetic subjects. Trientine modified faecal iron in the whole group, but the trientinemetabolic status interaction was again insignificant. Trientine lowered faecal iron excretion in control subjects. These data were consistent with lower fractional absorption of iron in diabetes and effects in nondiabetic volunteers to increase iron's bioavailability, whereas it had no effects on iron metabolism in diabetic patients. Thus trientine was strongly selective for copper over iron in diabetic patients in vivo.

The lack of trientine-mediated effects on iron regulation suggests that it is unlikely to cause serious unwanted effects on iron-mediated pathways. Furthermore, amelioration of the diabetic complications with trientine cannot be explained through effects on iron metabolism. This exclusion is of particular significance, because copper and iron are the two physiologically relevant transition metals that can generate oxidative stress via catalysing local production of hydroxyl radicals, ${ }^{[8,44]}$ and the exclusion of iron as a factor by this study provides important confirmatory evidence that it is copper, rather than iron, that is the transition metal implicated in oxidative stress generation in diabetes. This line of evidence excluding iron is one of several we have generated that are summarized in section 13.1.

That TETA evoked increases in iron uptake from the gut in nondiabetic humans indicates that this effect has distinct physical-chemical properties from that by which TETA removes systemic $\mathrm{Cu}^{\mathrm{II}}$ from the body. In particular, the equilibrium constant $\left(K_{\text {eq }}\right)$ of TETA for $\mathrm{Fe}^{\mathrm{II}}$ is many orders of magnitude less than that for $\mathrm{Cu}^{\mathrm{II}}$. The enhancement of $\mathrm{Fe}^{\mathrm{II}}$ absorption from digested food is mediated by relatively low-affinity binding, and is an effect that can also be expected with other divalent transition metal ions as well, such as $\mathrm{Zn}^{\mathrm{II}}$ (as discussed in section 12.3) and $\mathrm{Mn}^{\mathrm{II}}$, which TETA binds with much lower affinity than $\mathrm{Cu}^{\mathrm{II}}$.

\subsection{Effects on Zinc Regulation}

The effects on zinc metabolism are also noteworthy and of direct relevance to the potential utility of trientine for the long-term treatment of diabetes. ${ }^{[45]}$ Trientine elicited significant modification 
of the zinc balance in all subjects, and there were significant differences between its effects in the two study groups. Basal urinary zinc excretion was elevated in diabetic patients and trientine treatment elevated urinary zinc excretion in both treatment groups. However, it lowered faecal zinc excretion only in control subjects and had no effect on faecal zinc excretion in diabetic patients; in particular, trientine did not lower zinc absorption from the gut in diabetic patients and so is unlikely to cause depletion of body zinc stores or impairment of zincdependent processes, such as insulin secretion. These data are consistent with trientine-mediated enhancement of dietary zinc uptake as the main source of increased urinary zinc excretion, with greater effects in nondiabetic individuals, whereas in diabetic patients there is lower fractional zinc absorption in diabetes, probably caused by elevated gut metallothionein levels.

Further studies on the long-term regulation of copper, iron and zinc in diabetes will be required to confirm a number of the observations outlined in this section.

\section{Evidence That an Acquired Copper- Overload State is a Key Metabolic Defect that Causes Enhanced Oxidative Stress and Tissue Damage in Diabetes}

Of the essential trace metals, catalytically active iron and copper have the greatest potential to generate harmful ROS, particularly the hydroxyl radical. ${ }^{[8,44]}$ Here, evidence is summarized that indicates that defective regulation of copper, rather than any of the other trace metals, is the key cause of the elevated oxidative stress and tissue damage that occur in T1DM and T2DM. This matter is pivotal to understanding the molecular origins of the diabetic complications. Taken together, the evidence strongly supports a primary role for dysregulated copper.

\section{1 Evidence From a Metal Balance Study in Patients with T2DM}

I begin by extending the discussion of relevant comparative aspects of the balance study already described in some detail in section $12 .{ }^{[45]}$ This study is, to my knowledge, the only available clinical trial in which elemental balance has been systematically contrasted between essential trace elements in diabetic and matched control patients, both in the basal state and during probing with trientine. In it, we compared the regulation of nine essential elements between control and diabetic patients in both basal and trientine-treated states. Food intake did not differ between study groups or as a result of treatment, nor did the basal balance of any element differ between control and diabetic groups. Basal copper balance was variable but tended to be more positive in diabetic than in control subjects but this difference was not significant. Basal urinary excretion rates of copper, iron, zinc, calcium, manganese, selenium and chromium were all higher in diabetic patients, and basal urinary copper excretion was closely correlated with that of iron. Although urine volumes were higher in diabetic patients, statistical modelling indicated that neither urine volume nor glycosuria could explain any of the differences in elemental excretion between diabetic and control subjects. ${ }^{[45]}$

Trientine treatment increased the balances of each of zinc, iron and calcium compared with placebo in control participants, but this effect was absent from the diabetic patients. These effects were in each case driven by increased metal absorption from the chyme, consistent with trientine-mediated increases in the bioavailability of each metal in the control participants; such effects of chelators are known. ${ }^{[225]}$ In marked contrast, balances of zinc, iron and calcium in diabetic patients were resistant to these effects, pointing to lower fractional absorption of each metal in diabetic subjects and to the active suppression of chelator-mediated metal uptake. Thus, there are significant between-group differences in the gut-mediated handling of zinc, iron and calcium in diabetic patients compared with nondiabetic individuals, and active suppression of chelator-driven metal uptake was operative in the diabetic patients. This effect is probably mediated by elevated metallothionein expression in the case of zinc, but different metal-specific mechanisms must be at work for iron and calcium.

Contrasting findings between those for the other three metals and for copper are particularly informative. In control subjects, effects of trientine on 
copper were similar to those on the other metals: that is, trientine lowered faecal copper excretion consistent with chelator-mediated increases in copper bioavailability from the chyme. However, in marked contrast, trientine treatment caused the positive copper balance to become negative in diabetic patients. Trientine exerted strong stimulation on copper excretion in both control and diabetic groups, but, in the controls, this excretion was offset by the enhanced uptake from the diet, whereas in the diabetic patients, this did not occur. Thus, there is also a barrier, presumably in the gut wall, to chelator-mediated copper uptake in diabetic patients.

These findings are consistent with systemic copper overload accompanied by a barrier to gutmediated uptake of copper from the chyme in diabetes. They are indicative of the likely prior activation of defence mechanisms against metal overload, which are probably necessary to protect against the increased systemic uptake that might otherwise result from diabetic hyperphagia. To my knowledge, this is the first report of these chronic changes in metal regulation in diabetes. ${ }^{[45]}$

\section{What are the Necessary and Sufficient Properties of a Highly Selective Copper Chelator?}

Our group has employed trientine to probe relationships between copper, zinc, iron and other essential trace elements on the one hand and the biology of the diabetic complications on the other, and to measure the effects of copper chelation on tissue damage in diabetic rats and patients. In the following discussion, the term TETA refers to the active chelating moiety itself, whereas 'trientine' refers specifically to its dihydrochloride salt, which has been used as the vehicle for TETA administration in most of the reported nonclinical and clinical studies.

TETA binds $\mathrm{Cu}^{\mathrm{II}}$ strongly $\left(\log K_{\mathrm{f}} \sim 20 ; K_{\mathrm{f}}\right.$, formation constant) but also has significant affinity for $\mathrm{Zn}^{\mathrm{II}}\left(\log K_{\mathrm{f}} \sim 12\right)$, and lower affinity for $\mathrm{Fe}^{\mathrm{II}}\left(\log K_{\mathrm{f}}\right.$ $\sim 8)$ and $\mathrm{Mn}^{\mathrm{II}}\left(\log K_{\mathrm{f}} \sim 5\right) .{ }^{[226,227]}$ Such high-affinity binding to $\mathrm{Cu}^{\mathrm{II}}$ is considered necessary for chelators to display efficacy in the treatment of diabetes, probably because it is required to enable the re- moval of copper ions from the putative AGEderived binding sites. ${ }^{[42,43]}$ Indeed, measured values of affinity constants for $\mathrm{Cu}^{\mathrm{II}}$ binding to two significant AGE products, $\mathrm{N}$-e-carboxymethyllysine and $\mathrm{N}-\varepsilon$-carboxyethyllysine,${ }^{[36]}$ are consistent with the requirement for strong $\mathrm{Cu}^{\mathrm{II}}$ binding by chelators as necessary for removal of $\mathrm{Cu}^{\mathrm{II}}$ bound to such AGE-modified residues. These binding constants show that TETA has much higher affinity for $\mathrm{Cu}^{\mathrm{II}}$ than for any other essential divalent metal ion, but suggest that it could also perturb some aspects of the regulation of other metals, for example by enhancing the uptake of zinc, iron and manganese from the chyme; ${ }^{[4]}$ these constants do not by themselves show that TETA is highly selective for $\mathrm{Cu}^{\mathrm{II}}$ in the in vivo context. Based on these values alone, TETA can be classified as a transition metal chelator that is relatively selective for copper. However, that is far from the whole story.

A molecular basis for TETA's binding selectivity is generated by its tetradendate molecular geometry and in particular by the chemical properties of its four coordinating nitrogen atoms, which enable it to bind copper in preference to any other transition metal, ${ }^{[44]}$ and $\mathrm{Cu}^{\mathrm{II}}$ in absolute preference to $\mathrm{Cu}^{\mathrm{I}}$ (figure 16). ${ }^{[212]}$ Our EPR studies indicate that trientine treatment causes a TETA-Cu${ }^{\mathrm{II}}$ complex to appear in the urine of diabetic rats, where all the TETA-bound copper atoms are $\mathrm{Cu}^{\mathrm{II}[42,212]}$ (figures 6, 7c).

Our x-ray crystallographic studies of a TETA$\mathrm{Cu}^{\mathrm{II}}$ complex crystallized from a $\mathrm{NaCl}$-containing medium (to mimic the ionic milieu in the extracellular space) indicate that, under physiological conditions, TETA can bind to $\mathrm{Cu}^{\mathrm{II}}$ in a distorted square-pyramidal configuration wherein the four nitrogen atoms are coordinated around the base with a chloride ion at the apex (figure 16). Its ability to bind copper atoms in this configuration probably contributes to its inability to bind to $\mathrm{Cu}^{\mathrm{I}}$, which requires different ligand geometry. ${ }^{[228]}$ The outer-shell $d$-electrons of the bound $\mathrm{Cu}^{\mathrm{II}}$ atoms are thus incorporated into bonds, either with the four nitrogen atoms of the ligand itself or the chloride ion, and so the bound $\mathrm{Cu}^{\mathrm{II}}$ atoms become prevented from catalyzing hydroxyl radical formation. This pattern of bonding between $\mathrm{Cu}^{\mathrm{II}}$ and TETA will enable it to suppress effectively any 
residual catalytic/toxic activity of $\mathrm{Cu}^{\mathrm{II}}$, both in tissues and subsequently after extraction into the urine, thereby protecting the renal tubules from ROS-mediated damage that might otherwise ensue.

TETA's in vivo binding to $\mathrm{Cu}^{\mathrm{II}}$ is evidently sufficient to extract copper from its systemic binding sites into the urine (figure 16). It is thus possible to deduce that the $\mathrm{Cu}^{\mathrm{II}}$ extracted by TETA is bound to sites whose $K_{\mathrm{f}}$ values are $<20$ but greater than those for $\mathrm{Cu}^{\mathrm{II}}$ binding by penicillamine or deferiprone, which are less selective and were found to be ineffective at restoring diabetic cardiovascular, arterial or renal damage. ${ }^{[64]}$ The sites where 'TETA-chelatable' $\mathrm{Cu}^{\mathrm{II}}$ is bound in tissues are almost certainly not the physiological binding sites of copper proteins, where $\mathrm{Cu}^{\mathrm{II}}$ binds much more strongly than it binds to TETA. ${ }^{[88]}$

Interestingly, our studies in STZ-diabetic rats and diabetic patients indicate that the pool of chelatable/catalytically active $\mathrm{Cu}^{\mathrm{II}}$ is increased by about 2 - to 3 -fold in diabetic animals and patients (figures $7,8,12,16$ ) before the onset of trientine treatment: ${ }^{[42,43,45]}$ this proportionate increase is similar to the increase in $\mathrm{Cu}^{\mathrm{II}}$-binding capacity reported for glucose-modified collagen. ${ }^{[32]}$

Trientine treatment of diabetic patients with LVH was accompanied by a gradual decline in systemic copper-binding capacity between 4 and 12 months, consistent with a gradual decline in the content of $\mathrm{Cu}^{\mathrm{II}}$ binding sites over that time (figure 10b). ${ }^{[43]}$ This finding indicates that chronic trientine treatment may well cause a beneficial remodelling of ECM proteins and could also signal a fall in the AGE content of collagen. Consistent with this idea, $\mathrm{Cu}^{\mathrm{II}}$ catalysis is known to play a significant role in AGE formation, ${ }^{[229,230]}$ but it remains to be determined whether long-term TETA treatment can suppress or reverse AGE formation over this time scale.

The strong $\mathrm{Cu}^{\mathrm{II}}$ binding preference of TETA contrasts sharply with copper binding by penicillamine, the first-line therapy for Wilson's disease. There, the ligand-copper complex is a much larger structure containing eight sulfur (thiol)bound $\mathrm{Cu}^{\mathrm{I}}$ atoms as well as six $\mathrm{Cu}^{\mathrm{II}}$ atoms bound to both sulfur (thiol) and nitrogen (amine) atoms, yielding a composite $\left[\mathrm{Cu}_{8}^{\mathrm{I}} \mathrm{Cu}_{6}^{\mathrm{II}} \mathrm{L}_{12} \mathrm{Cl}\right]^{5-}$ cluster with the carboxylate groups clustered on the ex- ternal surface (where $\mathrm{L}$ indicates penicillamine acting as ligand). ${ }^{[231]}$ This marked difference in coordination chemistry could, at least in part, explain the inability of penicillamine to ameliorate diabetes-mediated damage in the heart, arteries and kidneys, where the main toxic effects are probably generated by extracellular $\mathrm{Cu}^{\mathrm{II}}$.64]

The marked structural differences between the copper complexes of penicillamine and TETA point to the probable existence of major differences between the molecular pharmacology of the processes by which each chelator eliminates copper from the body. However, fundamental information concerning the in vivo selectivity of penicillamine's effects is currently unavailable. It is also noteworthy that both penicillamine disulfide and penicillamine-cysteine disulfide occur in the urine of patients undergoing penicillamine therapy, so that at least some of the copper excreted may be in the form of complexes with these compounds, whose copper selectivity differs from that of the parent. ${ }^{[232]}$

\section{Close Linkages between Diabetes and Common Neurodegenerative Disorders Point to a Role of Divalent Copper (Cull) Toxicity in the Pathogenesis of Dementia}

\section{1 Epidemiological and Mechanistic Linkages between Dysglycaemia/Diabetes and the Common Neurodegenerative Diseases}

Dysglycaemia is the name given to hyperglycaemic states where blood glucose values are elevated but insufficient to meet the criteria for diabetes. There is now substantive evidence that dysglycaemic states and T2DM are closely linked to the pathogenesis of $\mathrm{AD}$, vascular dementia and dementia accompanying stroke. ${ }^{[12,46-50,233-237]}$ A recent carefully controlled community study found that more than $80 \%$ of an unselected group of patients with $\mathrm{AD}$ also had either T2DM or dysglycaemia. ${ }^{[12]}$ This finding points to mechanistic linkages between diabetes and $\mathrm{AD}$, perhaps vascular disease or a tendency to protein aggregation/amyloid formation. There is also substantive evidence linking amyloid angiopathy to dementia in several diseases. ${ }^{[238]}$ 
15.2 Mechanisms by Which Vascular Disease Plays a Major Role in the Pathogenesis of Alzheimer's Disease (AD)

There is substantive evidence that vascular disease plays a major role in the pathogenesis of dementia associated with $\mathrm{AD}$, vascular dementia and stroke, as well as in other situations including Lewy body disease and the hereditary Icelandic cerebrovascular amyloid angiopathy. ${ }^{[238]}$ Processes that have been identified that probably damage the ECM in blood vessels include protein misfolding leading to amyloid deposition, and dysglycaemia with associated AGE formation and vasculopathy, both of which lead to excessive $\mathrm{Cu}^{\mathrm{II}}$ binding. Together, these processes damage vascular structure and function, with probable secondary consequences of neuronal damage and progressive functional impairment. The long lead-time required for these processes to develop to the point that they irreversibly damage brain structure and function may well account for the decades required for the development of the neurodegenerative diseases and dementia.

\subsection{Evidence for Cerebrovascular AGE Formation and Defective Copper Regulation in $A D$}

Altered brain copper regulation has been implicated in the modulation of secondary structure in $A \beta$, and the causation of oxidative stress in the brain. $\mathrm{A} \beta$ also functions as a $\mathrm{Cu}^{\mathrm{II}}$-binding protein, so cerebrovascular amyloid deposits could serve to localize $\mathrm{Cu}^{\mathrm{II}}$-mediated oxidative stress into affected cerebral vessels, just as AGEs may do in diabetic vascular disease. ${ }^{\text {[239-243] }}$

There is also evidence for the significant accumulation of AGEs in the cerebral vasculature in AD. ${ }^{[6,29]}$ However, it remains to be determined whether the pathogenetic processes in these diseases are accompanied by a copper-overload state equivalent to that in T2DM, although the many AD and vascular dementia patients who also manifest T2DM will presumably also have copper overload.

Plasma levels of total copper, non-caeruloplasmin-bound copper and red-cell copper are elevated in patients with $\mathrm{AD}$, who also show evidence of defective ceruloplasmin processing. ${ }^{[24-246]}$ How- ever, to date the exact mechanism that causes these defects and the molecular basis by which they might lead to or cause neurodegeneration have not been determined. To my knowledge, there are no available data concerning the copper content of cerebral arterial tissue in AD.

\subsection{Copper Targeting by Vascular Amyloid and Advanced Glycation Endproducts: Common Themes in the Pathogenesis of Neurodegeneration/Dementia}

Cerebrovascular amyloid angiopathy has emerged as one of the key pathogenetic processes in $\mathrm{AD}$, and a similar process probably also makes a significant contribution in vascular dementia. ${ }^{[247-260]}$ In $\mathrm{AD}$, the principal amyloidogenic component of the cerebrovascular amyloid is thought to be formed mainly from the $A \beta$ peptides, probably mainly $A \beta_{1-40}$ and $A \beta_{1-42}$, which are processed from the amyloid-precursor protein. ${ }^{[253,261]}$ The amyloid monomer in conditions associated with vascular dementia is unlikely to be $A \beta$-related, but, to my knowledge, its exact molecular identity is unknown, whereas that in the hereditary Icelandic form of cerebrovascular amyloid angiopathy is generated by the neuropeptide cystatin C carrying the L68Q point-mutation. ${ }^{[238]}$

\subsection{What Might be the Appropriate Physicochemical Properties of a Copper Chelator Suitable for the Experimental Therapy of AD?}

Numerous lines of evidence point to alterations in copper metabolism ${ }^{[262]}$ or combined dysregulation of copper and zinc ${ }^{[263-265]}$ in the pathogenesis of $\mathrm{AD}$, and there have been numerous suggestions that copper-binding agents might be efficacious in its treatment. ${ }^{[266-268]}$ However, those clinical trials reported to date have employed the relatively non-specific copper-zinc chelator clioquinol. ${ }^{[264,265,269]}$ Trials with clioquinol itself have been discontinued because of concerns with toxicity, ${ }^{[264,267,269,270]}$ but this line of research is being continued with another 8hydroxyquinoline-derived compound, PBT2..271]

Although clioquinol is undoubtedly a transition-metal chelator, ${ }^{[272,273]}$ it remains unclear 
whether the therapeutic efficacy of drugs of this class rests on their chelating properties. ${ }^{[270,274]}$ The binding affinities of clioquinol and homologues may well be insufficient to dislodge $\mathrm{Cu}^{\mathrm{II}}$ from its ECM binding sites. Clioquinol itself binds both $\mathrm{Cu}^{\mathrm{II}}$ and $\mathrm{Zn}^{\mathrm{II}}$ with $2: 1$ stoichiometry. ${ }^{[272]}$ Its binding constants for these two cations are similar, and also similar to the affinity of TETA for $\mathrm{Zn}^{\mathrm{II}}$, ${ }^{273]}$ but $\sim 10^{10}$ less than the affinity of TETA for $\mathrm{Cu}^{\mathrm{II}}$ [44,227] $^{[4}$

\subsection{Diabetic Vasculopathy and Amyloid Formation as Pathogenetic Links between T2DM and Neurodegeneration}

Diabetes and AD have in common oxidative stress, vascular disease and the formation of localized protein aggregates, each of which may contribute to their respective pathogenetic mechanisms. ${ }^{[12,13,15]}$ There is also substantive epidemiological evidence to support the view that they probably share pathogenetic mechanisms. Although diabetes is defined by the elevated levels of glucose, the contribution played by hyperglycaemia to the pathogenesis of diabetic vasculopathy remains uncertain, and other metabolic disturbances such as impaired homeostasis of lipoproteins and lipids may play primary pathogenetic roles (unpublished observations). ${ }^{[275]}$ Increasing evidence indicates that blood vessel dysfunction, either overt or inducible, is detectable prior to any rise in blood glucose in patients who subsequently develop T2DM. ${ }^{[276,277]}$ Lesser degrees of dysglycaemia, such as impaired glucose tolerance and impaired fasting glucose, are also associated with increased rates of vascular disease and associated increases in cardiovascular risk, ${ }^{[278,279]}$ and with the formation of AGEs in tissues. Blood-vessel disease detectable before blood glucose becomes elevated is an early pathological finding before and at the onset of T2DM, so hyperglycaemia may be neither the only nor the earliest metabolic perturbation to occur in this disease, and bloodvessel responsiveness from biopsy studies is impaired in people likely to develop diabetes subsequently as well as in those who already have the disease, even when their blood glucose regulation is normal. ${ }^{[280]}$

\section{Recommendation for an Experimental Therapeutic Programme in $A D$ and Vascular Dementia}

\subsection{Overview}

Many workers have hypothesized that altered regulation of one or more of zinc, iron and/or copper plays a key role in the pathogenesis of neurodegenerative diseases, for example $\mathrm{AD}$, Parkinson's disease, Huntington's disease and amyotrophic lateral sclerosis. There is considerable evidence that regulation of each metal is probably disturbed in each of these neurodegenerative diseases, just as in diabetes. Furthermore, these diseases share numerous pathogenetic processes in common. Comprehensive reviews of arguments linking altered regulation of each metal to the pathogenesis of neurodegeneration are available. ${ }^{[263,266-269,281]}$

Many questions remain unanswered. First, is only one metal crucial in each disease state, or could it be two, or more? Which metal is actually implicated as the prime mover in the pathogenesis of each disease, and might some be bystanders, as may be the case in T2DM? ${ }^{[45,64]}$ Is it the same metal in each disease or are different metals key in different diseases?

There are some clues. Both copper and iron, if not properly liganded in vivo, can generate the hydroxyl radicals that are thought by many to be the most likely ultimate cause of tissue damage, perhaps abetted by one or more secondary reactive nitrogen species. ${ }^{[8,44,281]}$ Of the corresponding divalent cations, $\mathrm{Cu}^{\mathrm{II}}$ is the more effective in binding non-specifically to proteins in vivo. ${ }^{[44]}$ Could a mixture of iron and copper be responsible for pathogenesis in each case, or might it be copper in some and iron in others? How much of the overall pathogenetic processes might be accounted for by dysregulated transition-metal catalyzed oxidative stress, and how reversible might oxidative stress and tissue damage be in each disease? What molecular processes might be responsible for the dysregulation of each metal in each disease state? If defective liganding is the answer, what exactly does that mean in molecular terms, how can it be therapeutically targeted, and with what? In addition, 
how might it be possible to differentiate between these different possibilities, in order to select the best possible route forward?

Cerebral amyloid in AD binds/contains increased amounts of copper, iron and zinc compared with surrounding tissues, ${ }^{[282]}$ thereby providing a potential focusing mechanism for metal-catalysed pathogenetic mechanisms. There is also substantive evidence for increased vascular AGEs in AD and other neurodegenerative diseases, providing a second probable focusing mechanism. Moreover, atherosclerotic deposits, where present, may serve as a third mechanism that focuses copper-/ iron-catalysed oxidative stress in arteries and adjacent tissues. ${ }^{[283]}$

\subsection{Next Steps}

Ultimately, the decision as to which class of metal-binding molecules might have the best chance of exerting beneficial effects in each neurodegenerative disease will depend on the answers to the questions posed in section 16.1. One vital piece of information that is missing so far is a systematic comparative analysis of the balance/ regulation of essential elements in each neurodegenerative disease. A related requirement is that quantitative linkages between disturbances of metal metabolism and disease symptomatology need to be developed in informative nonclinical models, where these exist, as well as in patients. I expect that such quantitative studies could well point to the molecule best suited for experimental therapeutic application in each disease.

\subsection{Proposed Course of Action}

Taking all the available evidence together, I hypothesize that dysregulated $\mathrm{Cu}^{\mathrm{II}}$ leading to a copper-overload state similar to that which occurs in T2DM is a plausible culprit in the neurodegeneration of AD. I therefore recommend that a comprehensive quantitative analysis of essential elemental regulation, similar to that we performed in $\mathrm{T} 2 \mathrm{DM},{ }^{[45]}$ should now be performed in groups of patients with $\mathrm{AD}$ and matched controls. If clear evidence of copper overload is found, then a trial of TETA therapy should be undertaken, since this chelator is the best equip- ped of those available to strip $\mathrm{Cu}^{\mathrm{II}}$ from its pathological in vivo binding sites and to silence its untoward ability to generate oxidative stress. This programme could be based in part on information already available from the completed clinical trials I have reviewed in this article.

\section{Conclusions}

I have reviewed the evidence that diabetes causes a copper-overload state that generates focused $\mathrm{Cu}^{\mathrm{II}}$-mediated oxidative stress in the vascular beds of susceptible organs, which in turn leads to or causes the progressive organ damage known as the diabetic complications.

Accumulation of $\mathrm{Cu}^{\mathrm{II}}$-binding AGEs in the ECM of long-lived proteins, such as collagen, is thought to initiate the retention and targeting of catalytically active/chelatable $\mathrm{Cu}^{\mathrm{II}}$ in the vasculature of organs such as the kidney and the heart, and to mediate localized oxidative stress via catalysis of ROS such as hydroxyl radicals.

Treatment with highly selective copper chelation is a new experimental therapy for the treatment of diabetes that has so far been proven to be safe and efficacious in nonclinical models and in patients with T2DM, and merits further clinical investigation.

The metabolic defect that initiates diabetic vasculopathy is unlikely to be triggered by hyperglycaemia, but probably begins with alterations in the homeostasis of lipoproteins and lipids perhaps driven by adiponectin deficiency. Glucose-mediated processes may well contribute to the generation of AGEs and consequent disturbance of copper regulation downstream in the development of the pathogenetic process. Determining the time-course of metabolic deterioration with concomitant AGE formation and $\mathrm{Cu}^{\mathrm{II}}$ trapping will be important to enable planning for rational preventative strategies.

Diabetes is now known to be closely linked to the development of common neurodegenerative diseases such as AD and vascular dementia, with which it shares pathogenetic mechanisms including impaired copper regulation, elevated oxidative stress, vasculopathy with AGE accumulation in vessel walls and pathogenetic protein aggregation. 
Systematic metabolic profiling in patients and those at risk of AD and vascular dementia is expected to identify perturbations in groups of metabolites that presage disease onset, as has recently been shown in other complex metabolic diseases including diabetes. Clinical trials employing a suitable $\mathrm{Cu}^{\mathrm{II}}$-selective chelator will be required to ascertain the impact of such treatment in AD and vascular dementia.

In summary, the evidence reviewed here is consistent with the hypothesis that copperoverload states closely linked to those in diabetes may well occur in patients with AD and vascular dementia, based on their close epidemiological and mechanistic linkages, and that trials of highly selective copper chelation may be called for, once the degree of copper dysregulation in $\mathrm{AD}$ and vascular dementia is determined.

\section{Acknowledgements}

The author thanks C.A. Tse and V. Ward (School of Biological Sciences, University of Auckland, New Zealand) for administrative assistance/manuscript editing and art work, respectively. I also thank all of my colleagues who have contributed to this work over the past years. Work on this programme in my laboratories has been funded by grants from Endocore Research Associates; the Maurice and Phyllis Paykel Trust; Lottery Health (New Zealand); the Auckland Medical Research Foundation; the University of Auckland; the Department of Education (New Zealand) through a grant to the Maurice Wilkins Centre of Excellence for Molecular Biodiscovery; Protemix Corporation Ltd.; Fight for Sight (UK); and by programme grants from the Foundation for Research Science and Technology, New Zealand, and from the Health Research Council of New Zealand.

GJS Cooper acts as an honorary consultant to PhilERA, holder of patent rights to triethylenetetramine for the treatment of diabetes and related metabolic diseases.

\section{References}

1. Wolff SP, Jiang ZY, Hunt JV. Protein glycation and oxidative stress in diabetes mellitus and ageing. Free Radic Biol Med 1991; 10 (5): 339-52

2. Wolff SP. Diabetes mellitus and free radicals: free radicals, transition metals and oxidative stress in the aetiology of diabetes mellitus and complications. Br Med Bull 1993 Jul; 49 (3): 642-52

3. Monnier VM. Transition metals redox: reviving an old plot for diabetic vascular disease. J Clin Invest 2001 Apr; 107 (7): 799-801

4. Thomas MC, Baynes JW, Thorpe SR, et al. The role of AGEs and AGE inhibitors in diabetic cardiovascular disease. Curr Drug Targets 2005; 6: 453-74
5. Mattson MP, Magnus T. Ageing and neuronal vulnerability. Nat Neurosci 2006; 7: 278-94

6. Martinez A, Portero-Otin M, Pamplona R, et al. Protein targets of oxidative damage in human neurodegenerative diseases with abnormal protein aggregates. Brain Pathol 2010 Mar; 20 (2): 281-97

7. Forbes JM, Coughlan MT, Cooper ME. Oxidative stress as a major culprit in kidney disease in diabetes. Diabetes 2008 Jun; 57 (6): 1446-54

8. Halliwell B, Gutteridge JMC. Free radicals in biology and medicine. 4th ed. Oxford: Oxford University Press, 2007

9. Gil JM, Rego AC. Mechanisms of neurodegeneration in Huntington's disease. Eur J Neurosci 2008 Jun; 27 (11): 2803-20

10. Browne SE, Ferrante RJ, Beal MF. Oxidative stress in Huntington's disease. Brain Pathol 1999 Jan; 9 (1): 147-63

11. Barber SC, Shaw PJ. Oxidative stress in ALS: key role in motor neuron injury and therapeutic target. Free Rad Biol Med 2010; 48: 629-41

12. Janson J, Laedtke T, Parisi JE, et al. Increased risk of type 2 diabetes in Alzheimer disease. Diabetes 2004 Feb; 53 (2): 474-81

13. Cooper GJS, Aitken JF, Zhang S. Is type 2 diabetes an amyloidosis and does it really matter (to patients)? Diabetologia 2010; 53: 1011-6

14. Zhang S, Liu H, Yu H, et al. Fas-associated death receptor signaling evoked by human amylin in islet beta-cells. Diabetes 2008 Feb; 57 (2): 348-56

15. Aitken JF, Loomes KM, Scott DW, et al. Tetracycline treatment retards the onset and slows the progression of diabetes in human amylin/islet amyloid polypeptide transgenic mice. Diabetes 2010 Jan; 59 (1): 161-71

16. Panel on Dietary Antioxidants and Related Compounds, Subcommittees on Upper Reference Levels of Nutrients and of Interpretation and Use of Dietary Reference Intakes on Upper Reference Levels of Nutrients and Interpretation and Uses of DRIs, Standing Committee on the Scientific Evaluation of Dietary Reference Intakes, Food and Nutrition Board. Dietary reference intakes for vitamin $C$, vitamin $\mathrm{E}$, selenium, and carotenoids. Washington, DC: National Academy of Sciences, 2000

17. Yusuf S, Dagenais G, Pogue J, et al., The Heart Outcomes Prevention Evaluation Study Investigators. Vitamin E supplementation and cardiovascular events in high-risk patients. N Engl J Med 2000 Jan 20; 342 (3): 154-60

18. Heart Protection Study Collaborative Group. MRC/BHF Heart Protection Study of antioxidant vitamin supplementation in 20536 high-risk individuals: a randomised placebo-controlled trial. Lancet 2002; 360: 23-33

19. Roberts AB, McCune BK, Dunn SR. TGF- $\beta$ : regulation of extracellular matrix. Kidney Int 1992; 41: 557-9

20. Gong D, Lu J, Chen X, et al. Molecular changes evoked by triethylenetetramine treatment in the extracellular matrix of the heart and aorta in diabetic rats. Mol Pharmacol 2006 Dec; 70 (6): 2045-51

21. Pohlers D, Brenmoehl J, Loffler I, et al. TGF-beta and fibrosis in different organs-molecular pathway imprints. Biochim Biophys Acta 2009 Aug; 1792 (8): 746-56

22. Roth M. "Glycated hemoglobin," not "glycosylated" or "glucosylated" [letter]. Clin Chem 1983 Nov; 29 (11): 1991 
23. Ahmed MU, Thorpe SR, Baynes JW. Identification of $\mathrm{N}$ epsilon-carboxymethyllysine as a degradation product of fructoselysine in glycated protein. J Biol Chem 1986 Apr 15; 261 (11): 4889-94

24. Brownlee M, Vlassara H, Cerami A. Nonenzymatic glycosylation and pathogenesis of diabetes complications. Ann Intern Med 1984; 101: 527-37

25. Brownlee M, Cerami A, Vlassara H. Advanced glycosylation end products in tissue and the biochemical basis of diabetic complications. N Engl J Med 1988 May 19; 318 (20): 1315-21

26. Baynes JW, Thorpe SR. Role of oxidative stress in diabetic complications: a new perspective on an old paradigm. Diabetes 1999 Jan; 48 (1): 1-9

27. Monnier VM, Sell DR. Prevention and repair of protein damage by the Maillard reaction in vivo. Rejuvenation Res 2006; 9 (2): 264-73

28. Smith MA, Taneda S, Richey PL, et al. Advanced Maillard reaction end products are associated with Alzheimer disease pathology. Proc Natl Acad Sci U S A 1994; 91: 5710-4

29. Sasaki N, Fukatsu R, Tsuzuki K, et al. Advanced glycation end products in Alzheimer's disease and other neurodegenerative diseases. Am J Pathol 1998 Oct; 153 (4): 1149-55

30. Schleicher ED, Wagner E, Nerlich AG. Increased accumulation of the glycoxidation product N-epsilon-(carboxymethyl)lysine in human tissues in diabetes and aging. J Clin Invest 1997; 99 (3): 457-68

31. Qian M, Liu M, Eaton JW. Transition metals bind to glycated proteins forming redox active "glycochelates": implications for the pathogenesis of certain diabetic complications. Biochem Biophys Res Commun 1998 Sep 18; 250 (2): $385-9$

32. Saxena AK, Saxena $\mathrm{P}, \mathrm{Wu} \mathrm{X}$, et al. Protein aging by carboxymethylation of lysines generates sites for divalent metal and redox active copper binding: relevance to diseases of glycoxidative stress. Biochem Biophys Res Commun 1999 Jul 5; 260 (2): 332-8

33. Qian M, Eaton JW. Glycochelates and the etiology of diabetic peripheral neuropathy. Free Radic Biol Med 2000; 28: 652-6

34. Eaton JW, Qian M. Interactions of copper with glycated proteins: possible involvement in the etiology of diabetic neuropathy. Mol Cell Biochem 2002 May-Jun; 234-5 (12): $135-42$

35. Hamada Y, Nakashima E, Naruse K, et al. A copper chelating agent suppresses carbonyl stress in diabetic rat lenses. J Diabetes Complications 2005 Nov-Dec; 19 (6): 328-34

36. Seifert ST, Krause R, Gloe K, et al. Metal complexation by the peptide-bound Maillard reaction products N-e-fructoselysine and N-e-carboxymethyllysine. $\mathrm{J}$ Ag Food Chem 2004; 52: 2347-50

37. Nishikawa T, Edelstein D, Du XL, et al. Normalizing mitochondrial superoxide production blocks three pathways of hyperglycaemic damage. Nature 2000 Apr 13; 404 (6779): 787-90

38. Brownlee M. Biochemistry and molecular cell biology of diabetic complications. Nature 2001 Dec 13; 414 (6865): 813-20
39. Brownlee M. The pathobiology of diabetic complications: a unifying mechanism. Diabetes 2005 Jun; 54 (6): 1615-25

40. Semba RD, Beck J, Sun K, et al. Relationship of a dominant advanced glycation end product, serum carboxymethyl-lysine, and abnormal glucose metabolism in adults: the Baltimore Longitudinal Study of Aging. J Nutr Health Aging 2010; 14 (7): 507-13

41. Kadiiska MB, Hanna PM, Hernandez L, et al. In vivo evidence of hydroxyl radical formation after acute copper and ascorbic acid intake: electron spin resonance spintrapping investigation. Mol Pharmacol 1992; 42: 723-9

42. Cooper GJS, Phillips ARJ, Choong SY, et al. Regeneration of the heart in diabetes by selective copper chelation. Diabetes 2004 Sep; 53 (9): 2501-8

43. Cooper GJ, Young AA, Gamble GD, et al. A copper(II)selective chelator ameliorates left-ventricular hypertrophy in type 2 diabetic patients: a randomised placebocontrolled study. Diabetologia 2009 Apr; 52 (4): 715-22

44. Fraústo da Silva JJ, Williams RJ. The biological chemistry of the elements: the inorganic chemistry of life. 2nd ed. Oxford: Clarendon Press, 2001: 418-35

45. Cooper GJS, Chan YK, Dissanayake AM, et al. Demonstration of a hyperglycemia-driven pathogenic abnormality of copper homeostasis in diabetes and its reversibility by selective chelation: quantitative comparisons between the biology of copper and eight other nutritionally essential elements in normal and diabetic individuals. Diabetes 2005 May; 54 (5): 1468-76

46. Ferri CP, Prince M, Brayne C, et al. Global prevalence of dementia: a Delphi consensus study. Lancet 2005; 366: $2112-7$

47. Launer LJ. Demonstrating the case that AD is a vascular disease: epidemiologic evidence. Ageing Res Rev 2002; 1: 61-77

48. Luchsinger JA, Tang MX, Stern Y, et al. Diabetes mellitus and risk of Alzheimer's disease and dementia with stroke in a multiethnic cohort. Am J Epidemiol 2001 Oct 1; 154 (7): 635-41

49. Skoog I. Status of risk factors for vascular dementia Neuroepidemiology 1998; 17 (1): 2-9

50. Skoog I, Kalaria RN, Breteler MMB. Vascular factors and Alzheimer disease. Alzheimer Dis Assoc Disord 1999; 13: S106-S14

51. Diabetes Control and Complications Trial/Epidemiology of Diabetes Interventions and Complications Research Group. Retinopathy and nephropathy in patients with type 1 diabetes four years after a trial of intensive therapy. N Engl J Med 2000 Feb 10; 342 (6): 381-9

52. DCCT/EDIC Research Group. Effect of intensive therapy on the microvascular complications of type 1 diabetes mellitus. J Am Med Assoc 2002; 287: 2563-9

53. The Diabetes Control and Complications Trial/ Epidemiology of Diabetes Interventions and Complications (DCCT/EDIC) Study Research Group. Intensive diabetes treatment and cardiovascular disease in patients with type 1 diabetes. N Engl J Med 2005; 353 (25): 2643-53

54. UK Prospective Diabetes Study (UKPDS) Group. Intensive blood-glucose control with sulphonylureas or insulin compared with conventional treatment and risk of complications in patients with type 2 diabetes (UKPDS 33). Lancet 1998 Sep 12; 352 (9131): 837-53 
55. Oresic M, Simell S, Sysi-Aho M, et al. Dysregulation of lipid and amino acid metabolism precedes islet autoimmunity in children who later progress to type 1 diabetes. J Exp Med 2008; 205 (13): 2975-84

56. Duckworth W, Abraira C, Moritz T. Glucose control and vascular complications in veterans with type 2 diabetes. N Engl J Med 2009; 360 (2): 129-39

57. Gerstein HC, Miller ME, Byington RP, et al. Effects of intensive glucose lowering in type 2 diabetes. $\mathrm{N}$ Engl J Med 2008 Jun 12; 358 (24): 2545-59

58. Holman RR, Paul SK, Bethel MA, et al. Ten-year followup of intensive glucose control in type 2 diabetes. $\mathrm{N} \mathrm{Engl}$ J Med 2008; 358: 1577-89

59. Patel A, MacMahon S, Chalmers J, et al. Intensive blood glucose control and vascular outcomes in patients with type 2 diabetes. N Engl J Med 2008 Jun 12; 358 (24): 2560-72

60. Gaede P, Lund-Andersen H, Parving HH, et al. Effect of a multifactorial intervention on mortality in type 2 diabetes. N Engl J Med 2008; 358: 580-91

61. Mohamed Q, Gillies MC, Wong TY. Management of diabetic retinopathy: a systematic review. J Am Med Assoc 2007; 298: 902-16

62. The ACCORD Study Group, Ginsberg HN, Elam MB, Lovato LC, et al. Effects of combination lipid therapy in type 2 diabetes mellitus. N Engl J Med 2010; 362 (17): 1563-74

63. Rosca MG, Mustata TG, Kinter MT, et al. Glycation of mitochondrial proteins from diabetic rat kidney is associated with excess superoxide formation. Am J Physiol Renal Physiol 2005 Aug; 289 (2): F420-30

64. Lu J, Gong D, Choong SY, et al. Copper(II)-selective chelation improves function and antioxidant defences in cardiovascular tissues of rats as a model of diabetes: comparisons between triethylenetetramine and three less copper-selective transition-metal-targeted treatments. Diabetologia 2010 Jun; 53 (6): 1217-26

65. Feder JN, Gnirke A, Thomas W, et al. A novel MHC class I-like gene is mutated in patients with hereditary haemochromatosis. Nat Genet 1996; 13: 399-408

66. Buja LM, Roberts WC. Iron in the heart: etiology and clinical significance. Am J Med Genet 1971; 51: 209-21

67. Telfer PT, Prestcott E, Holden S, et al. Hepatic iron concentration combined with long-term monitoring of serum ferritin to predict complications of iron overload in thalassaemia major. Br J Haematol 2002; 110: 971-7

68. Gong D, Lu J, Chen X, et al. A copper(II)-selective chelator ameliorates diabetes-evoked renal fibrosis and albuminuria, and suppresses pathogenic TGF-beta activation in the kidneys of rats used as a model of diabetes. Diabetologia 2008 Sep; 51 (9): 1741-51

69. Cameron NE, Cotter MA. Effects of an extracellular metal chelator on neurovascular function in diabetic rats. Diabetologia 2001 May; 44 (5): 621-8

70. Cameron NE, Cotter MA. Neurovascular dysfunction in diabetic rats: potential contribution of autoxidation and free radicals examined using transition metal chelating agents. J Clin Invest 1995 Aug; 96 (2): 1159-63

71. Inkster ME, Cotter MA, Cameron NE. Effects of trientine, a metal chelator, on defective endothelium-dependent re- laxation in the mesenteric vasculature of diabetic rats. Free Radic Res 2002 Oct; 36 (10): 1091-9

72. Keegan A, Cotter MA, Cameron NE. Effects of chelator treatment on aorta and corpus cavernosum from diabetic rats. Free Radic Biol Med 1999 Sep; 27 (5-6): 536-43

73. Olivieri NF, Brittenham GM, McLaren CE, et al. Longterm safety and effectiveness of iron-chelation therapy with deferiprone for thalassemia major. N Engl J Med 1998; 339: 417-23

74. Dahlman T, Hartvig P, Lofholm M, et al. Long-term treatment of Wilson's disease with triethylene tetramine dihydrochloride (trientine). Q J Med 1995; 88: 609-16

75. Kopp SJ, Klevay LM, Feliksik JM. Physiological and metabolic characterization of a cardiomyopathy induced by chronic copper deficiency. Am J Physiol Heart Circ Physiol 1983; 245: H855-66

76. Saari JT. Copper deficiency and cardiovascular disease: role of peroxidation, glycation, and nitration. Can J Physiol Pharmacol 2000 Oct; 78 (10): 848-55

77. Saari JT, Schuschke DA. Cardiovascular effects of dietary copper deficiency. Biofactors 1999; 10: 359-75

78. Jaksch M, Horvath R, Horn N, et al. Homozygosity $(\mathrm{E} 140 \mathrm{~K})$ in $\mathrm{SCO} 2$ causes delayed infantile onset of cardiomyopathy and neuropathy. Neurol 2001; 57: 1440-6

79. Jaksch M, Ogilvie I, Yao J, et al. Mutations in SCO2 are associated with a distinct form of hypertrophic cardiomyopathy and cytochrome $\mathrm{C}$ oxidase deficiency. Hum Mol Genet 2000; 9: 795-801

80. Jaksch M, Paret C, Stucka R, et al. Cytochrome c oxidase deficiency due to mutations in SCO2, encoding a mitochondrial copper-binding protein, is rescued by copper in human myoblasts. Hum Mol Genet 2001; 10: 3025-35

81. Ferns GA, Lamb DJ, Taylor A. The possible role of copper ions in atherogenesis: the Blue Janus. Atheroscler 1997; 133: $139-52$

82. Culotta VC, Gitlin JD. Disorders of copper transport. In: Scriver CR, Beaudet AL, Sly WS, et al., editors. The metabolic and molecular bases of inherited disease. 8th ed. New York: McGraw-Hill, 2001: 3105-26

83. Harris ED. Basic and clinical aspects of copper. Crit Rev Clin Lab Sci 2003 Oct; 40 (5): 547-86

84. Finney LA, O'Halloran TV. Transition metal speciation in the cell: insights from the chemistry of metal ion receptors. Science 2003; 300: 931-6

85. Huffman DL, O'Halloran TV. Function, structure, and mechanism of intracellular copper trafficking proteins. Annu Rev Biochem 2001; 70: 677-701

86. Linder MC, Hazegh-Azam M. Copper biochemistry and molecular biology. Am J Clin Nutr 1996; 63 Suppl.: $797-$ $811 \mathrm{~S}$

87. Peña MM, Lee J, Thiele DJ. A delicate balance: homeostatic control of copper uptake and distribution. J Nutr 1999; 129: 1251-60

88. Rae TD, Schmidt PJ, Pufahl RA, et al. Undetectable intracellular free copper: the requirement of a copper chaperone for superoxide dismutase. Science 1999; 284: 805-8

89. Iskandar M, Swist E, Trick KD, et al. Copper chaperone for $\mathrm{Cu} / \mathrm{Zn}$ superoxide dismutase is a sensitive biomarker of mild copper deficiency induced by moderately high intakes of zinc. Nutr J 2005; 4: 35 
90. Wang J, Song Y, Elsherif L, et al. Cardiac metallothionein induction plays the major role in the prevention of diabetic cardiomyopathy by zinc supplementation. Circulation 2006 Jan 31; 113 (4): 544-54

91. Lutsenko S, Barnes NL, Bartree ME, et al. Function and regulation of human copper-transporting ATPases. Physiol Rev 2007; 87: 1011-46

92. Tanzi RE, Petrukhin K, Chernov I, et al. The Wilson disease gene is a copper transporting ATPase with homology to the Menke's disease gene. Nat Genet 1993; 5: 344-50

93. Dameron CT, Harrison MD. Mechanisms for protection against copper toxicity. Am J Clin Nutr 1998; 67 Suppl.: 1091S-7S

94. Turnlund JR, Keyes WR, Anderson HL, et al. Copper absorption and retention in young men at three levels of dietary copper by use of the stable isotope ${ }^{65} \mathrm{Cu}$. Am J Clin Nutr 1989; 1989: 870-8

95. Turnlund JR, Jacob RA, Keen CL, et al. Long-term high copper intake: effects on indexes of copper status, antioxidant status, and immune function in young men. Am $\mathbf{J}$ Clin Nutr 2004; 79 (6): 1037-44

96. Panel on Micronutrients, Subcommittees on Upper Reference Levels of Nutrients and of Interpretation and Use of Dietary Reference Intakes, and the Standing Committee on the Scientific Evaluation of Dietary Reference Intakes, Institute of Medicine. Dietary reference intakes for vitamin $\mathrm{A}$, vitamin $\mathrm{K}$, arsenic, boron, chromium, copper, iodine, iron, manganese, molybdenum, nickel, silicon, vanadium, and zinc. Washington, DC: National Academy of Sciences, 2001

97. Turnlund JR, Keyes WR, Peiffer GL, et al. Copper absorption, excretion and retention by young men consuming low dietary copper, determined by using the stable isotope ${ }^{65} \mathrm{Cu}$. Am J Clin Nutr 1998; 67: 1219-25

98. Moriya M, Ho YH, Grana A, et al. Copper is taken up efficiently from albumin and alpha2-macroglobulin by cultured human cells by more than one mechanism. Am J Physiol Cell Physiol 2008 Sep; 295 (3): C708-21

99. Liu N, Lo LS, Askary SH, et al. Transcuprein is a macroglobulin regulated by copper and iron availability. J Nutr Biochem 2007 Sep; 18 (9): 597-608

100. Linder MC. Biochemistry of copper. New York: Plenum, 1991

101. Linder MC, Wooten L, Cerveza P, et al. Copper transport. Am J Clin Nutr 1998 May; 67 (5 Suppl.): 965-71S

102. Zaitseva I, Zaitsev V, Cara G, et al. The x-ray structure of human ceruloplasmin at $3.1 \mathrm{D}$ resolution: nature of the copper centers. J Biol Inorgan Chem 1996; 1: 15-23

103. Gitlin JD. Aceruloplasminemia. Pediatr Res 1998; 44 (3): 271-6

104. Hellman NE, Schaefer M, Gehrke S, et al. Hepatic iron overload in aceruloplasminaemia. Gut 2000; 47 (6): 858-60

105. Hellman NE, Gitlin JD. Ceruloplasmin metabolism and function. Annu Rev Nutr 2002; 22: 439-58

106. Nittis T, Gitlin JD. The copper-iron connection: hereditary aceruloplasminemia. Semin Hematol 2002; 39: 282-9

107. Turnlund JR. Copper. In: Shils ME, Olson JA, Shike M, et al., editors. Modern nutrition in health and disease. 9th ed. Baltimore (MD): Williams and Wilkins, 1998: 241-52
108. Cordano A. Clinical manifestations of nutritional copper deficiency in infants and children. Am J Clin Nutr 1998; 67 (5 Suppl.): 1012-6S

109. Panel on Micronutrients, Subcommittees on Upper Reference Levels of Nutrients and of Interpretation and Use of Dietary Reference Intakes, and the Standing Committee on the Scientific Evaluation of Dietary Reference Intakes, Institute of Medicine. Dietary reference intakes for vitamin $\mathrm{A}$, vitamin $\mathrm{K}$, arsenic, boron, chromium, copper, iodine, iron, manganese, molybdenum, nickel, silicon, vanadium, and zinc. Washington, DC: National Academy of Sciences, 2002: 224-57

110. Bennetts HW, Beck AB. Enzootic ataxia and copper deficiency of sheep in Western Australia. Aust Commonwealth Sci Ind Res Bull 1942; 147: 1-52

111. Innes JRM. Swayback: a demyelinating disease of lambs with affinities to Schilder's encephalitis and its prevention by copper. J Neurol Psychiatr 1939; 147: 323-34

112. Elsherif L, Wang L, Saari JT, et al. Regression of dietary copper restriction-induced cardiomyopathy by copper repletion in mice. J Nutr 2004; 134: 855-60

113. Zidar BL, Saddrich RK, Zeigher Z, et al. Observations on the anemia and neutropenia of human copper deficiency. Am J Hematol 1977; 3: 177-85

114. Dawson R, Milne G, Williams A. Changes in the collagen of rat heart in copper-deficiency-induced cardiac hypertrophy. Cardiovasc Res 1982; 16: 559-65

115. Hill KE, Davidson JM. Induction of increased collagen and elastin biosynthesis in copper-deficient pig aorta. Atheroscler 1986; 6: 98-104

116. Hawk SN, Uriu-Hare JY, Daston GP, et al. Rat embryos cultured under copper-deficient conditions develop abnormally and are characterized by an impaired oxidant defense system. Teratology 1998; 57: 310-20

117. Yang SL, Keen CL, Lanoue L, et al. Low nitric oxide: a key factor underlying copper deficiency teratogenicity. Free Radic Biol Med 2007; 43: 1639-48

118. Yamamoto M, Aklyama C, Alkawa H. D-Penicillamineinduced copper deficiency in suckling mice: neurological abnormalities and brain mitochondrial enzyme activities. Dev Brain Res 1990; 55: 51-5

119. Bennetts HW, Chapman FE. Copper deficiency in sheep in Western Australia: a preliminary account of the etiology of enzootic ataxia of lambs and an anaemia of ewes. Aust Vet J 1937; 13: 138-49

120. Roberts HE, Williams BM, Harvard A. Cerebral oedema in lambs associated with hypocuprosis, and its relationship to swayback: I. Field, clinical, gross anatomical and biochemical observations. J Comp Pathol 1966; 76: 279-83

121. Chalmers GA. Swayback (enzootic ataxia) in Alberta lambs. Can J Comp Pathol 1974; 38: 111-7

122. Percival SS. Neutropenia caused by copper deficiency. Nutr Rev 1995; 53: 59-66

123. Lewis G, Terlecki S, Allcroft R. The occurrence of swayback in the lambs of ewes fed a semipurified diet of low copper content. Vet Rec 1967; 81: 415-6

124. Mills CF, Fell BF. Demyelination in lambs born of ewes maintained on high intakes of sulphate and molybdate. Nature 1960; 185: 20-2 
125. Frank A, Danielsson R, Jones B. Experimental copper and chromium deficiency and additional molybdenum supplementation in goats: II. Concentrations of trace and minor elements in liver, kidneys and ribs: haematology and clinically chemistry. Sci Total Environ 2000; 249: 143-70

126. Flynn AA, Franzman AW, Arneson PD, et al. Indications of copper deficiency in a subpopulation of Alaska moose. J Nutr 1977; 107: 1182-9

127. Frank A, Sell DR, Danielsson R, et al. A syndrome of molybdenosis, copper deficiency, and type 2 diabetes in the moose population of south-west Sweden. Sci Total Environ 2000 Apr 17; 249 (1-3): 123-31

128. Gogan PJP, Jessup DA, Akeson M. Copper deficiency in tule elk at Point Reyes, California. J Range Management 1989; 42: 233-8

129. Wildman RE, Medeiros DM, Hamlin RL, et al. Aspects of cardiomyopathy in copper-deficient pigs: electrocardiography, echocardiography, and ultrastructural findings. Biol Trace Elem Res 1996; 55: 55-70

130. Coulson WF, Carnes WWH. Cardiovascular studies on copper-deficient swine: XIII. The effect of chronic copper deficiency on the cardiovascular system of miniature pigs. Lab Invest 1962; 11: 1316-21

131. Weissman N, Shields G, Carnes W. Cardiovascular studies on copper-deficient swine: IV. Content and solubility of the aortic elastin, collagen and hexosamine. J Biol Chem 1963; 238: $3115-8$

132. Linker A, Coulson W, Carnes W. Cardiovascular studies on copper-deficient swine: VI. The mucopolysaccharide composition of aorta and cartilage. J Biol Chem 1964; 239: $1690-3$

133. Viestenz KE, Klevay LM. A randomized trial of copper therapy in rats with electrocardiographic abnormalities due to copper deficiency. Am J Clin Nutr 1982; 35: 258-66

134. Owen CAJ, Hazelrig JR. Copper deficiency and copper toxicity in the rat. Am J Physiol 1968; 215: 334-8

135. Mao S, Medeiros DM, Wildman RE. Cardiac hypertrophy in copper-deficient rats is owing to increased mitochondria. Biol Trace Elem Res 1998; 64 (1-3): 175-84

136. Kang YJ, Zhou ZX, Wu H, et al. Metallothionein inhibits myocardial apoptosis in copper-deficient mice: role of atrial natriuretic peptide. Lab Invest 2000 May; 80 (5): 745-57

137. Klevay LM. Atrial thrombosis, abnormal electrocardiograms and sudden death in mice due to copper deficiency. Atherosclerosis 1985; 54: 213-24

138. Song Y, Wang J, Li Y, et al. Cardiac metallothionein synthesis in streptozotocin-induced diabetic mice, and its protection against diabetes-induced cardiac injury. Am J Pathol 2005 Jul; 167 (1): 17-26

139. Kang YJ, Wu H, Saari JT. Alterations in hypertrophic gene expression by dietary copper restriction in mouse heart. Proc Soc Exp Biol Med 2000; 223: 282-7

140. Tapia L, González-Aqüero M, Cisternas MF, et al. Metallothionein is crucial for safe intracellular copper storage and cell survival at normal and supra-physiological exposure levels. Biochem J 2004; 378 (Pt 2): 617-24

141. Saari JT, Dahlen GM. Nitric oxide and cyclic GMP are elevated in the hearts of copper-deficient rats. Med Sci Res 1998; 26: 495-7
142. Cartwright GE, Wintrobe MM. The question of copper deficiency in man. Am J Clin Nutr 1964; 94-110

143. Danks DM. Copper deficiency in humans. Annu Rev Nutr 1988; 8: 235-57

144. Danks DM. Disorders of copper transport. In: Scriver CR, Beaudet AL, Sly WS, et al., editors. The metabolic basis of inherited disease. 6th ed. New York: McGraw-Hill, 1989: 1411-31

145. Heller RM, Kirchner SG, O'Neill JA, et al. Skeletal changes of copper deficiency in infants receiving prolonged total parenteral nutrition. J Pediatr 1978; 92 (6): 947-9

146. Karpel JT, Peden VH. Copper deficiency in long-term parenteral nutrition. J Pediatr 1972; 80 (1): 32-6

147. Sutton AM, Harvie A, Cockburn F, et al. Copper deficiency in the preterm infant of very low birthweight: four cases and a reference range for plasma copper. Arch Dis Child 1985; 60: 644-51

148. Graham GC, Cordano A. Copper depletion and deficiency in the malnourished infant. Johns Hopkins Med J 1969; 124: $39-50$

149. Cordano A, Graham GG. Copper deficiency complicating severe chronic malabsorption. Pediatr 1966; 38: 596-604

150. Graham GG, Cordano A. Copper depletion and deficiency in the malnourished infant. Johns Hopkins Med J 1969; 124: $139-50$

151. Josephs HW. Treatment of anemia in infants with iron and copper. Bull Johns Hopkins Hosp 1931; 49: 246-54

152. Peltonen L, Kuivaniem H, Palotie A, et al. Alterations of copper and collagen metabolism in the Menkes syndrome and a new subtype of Ehlers-Danlos Syndrome. Biochemistry 1983; 22: 6156-63

153. Turnlund JR. Copper status and metabolism studied with isotopic tracers. In: Lowe N, Jackson M, editors. Advances in isotope methods for the analysis of trace elements in man. Boca Raton (FL): CRC Press, 2001: 117-27

154. Mason KE. A conspectus of research on copper metabolism and requirements of man. J Nutr 1979; 109: 1979-2066

155. Mertz W. The use and misuse of balance studies. J Nutr 1987; 117: 1811-3

156. Turnlund JR, Scott KC, Peiffer GL, et al. Copper status of young men consuming a low copper diet. Am J Clin Nutr 1997; 65: 72-8

157. Bremner I. Manifestations of copper excess. Am J Clin Nutr 1998; 67 Suppl.: 1069-73S

158. Sriramachari S, Nayak NC. Indian childhood cirrhosis: several dilemmas resolved. Indian J Med Res 2008; 128 : 93-6

159. Muller T, Muller W, Feichtinger H. Idiopathic copper toxicosis. Am J Clin Nutr 1998; 67 Suppl.: 1082-6S

160. Uriu-Adams JY, Keen CL. Copper, oxidative stress, and human health. Mol Aspects Med 2005 Aug-Oct; 26 (4-5): 268-98

161. Turnlund JR, Keyes WR, Kim SK, et al. Long-term high copper intake: effects on copper absorption, retention, and homeostasis in men. Am J Clin Nutr 2005; 81: 822-8

162. Turnlund JR, Domek JM, Nair PP, et al. Copper retention in intestinal musosal cells of young men at normal and high copper intakes. J Trace Elem Exp Med 2003; 16: 105-8 
163. Tanner MS. The role of copper in Indian childhood cirrhosis. Am J Clin Nutr 1998; 67 Suppl.: 1074-81S

164. Wijmenga C, Müller T, Murli IS, et al. Endemic Tyrolean infantile cirrhosis is not an allelic variant of Wilson's disease. Eur J Hum Genet 1998; 6: 624-8

165. Muller T, Feichtinger H, Berger H, et al. Endemic Tyrolean infantile cirrhosis: an ecogenetic disorder. Lancet 1996; 347: $877-80$

166. Yuzbasiyan-Gurkan V, Grider A, Nostrant T, et al. Treatment of Wilson's disease with zinc: X. Intestinal metallothionein induction. J Lab Clin Med 1992 Sep; 120 (3): $380-6$

167. Brewer GJ. Zinc acetate for the treatment of Wilson's disease. Exp Opin Pharmacotherap 2001; 2: 1473-7

168. Allen MM, Harding JDJ. Experimental copper poisoning in pigs. Vet Rec 1962; 74: 173-9

169. Fuentealba IC, Aburto EM. Animal models of copperassociated liver disease. Comp Hepatol 2003; 2: 5

170. Fuentealba I, Haywood S, Foster J. Cellular mechanisms of toxicity and tolerance in the copper-loaded rat: II. Pathogenesis of copper toxicity in the liver. Exp Mol Pathol 1989; 50: 26-37

171. Fuentealba IC, Davis RW, Elmes ME, et al. Mechanisms of tolerance in the copper-loaded rat liver. Exp Mol Pathol 1993; 59: 71-84

172. Ishmael J, Gopinath C, Howell JM. Experimental chronic copper toxicity in sheep: biochemical and haematological studies during the development of changes in the liver. Res Vet Sci 1972; 13: 22-9

173. Ishmael J, Gopinath C, Howell J. Experimental chronic copper toxicity in sheep: histological and histochemical changes during development of the changes in the liver. Res Vet Sci 1971; 12: 358-66

174. Peña MM, Koch KA, Thiele DJ. Dynamic regulation of copper uptake and detoxification genes in Saccharomyces cerevisiae. Mol Cell Biol 1998; 18: 2514-23

175. Furst P, Hu S, Hackett R, et al. Copper activates metallothionein gene transcription by altering the conformation of a specific DNA binding protein. Cell 1988 Nov 18; 55 (4): 705-17

176. Gralla EB, Thiele DJ, Silar P, et al. ACE1, a copperdependent transcription factor, activates expression of the yeast copper, zinc superoxide dismutase gene of the yeast copper, zinc superoxide dismutase gene. Proc Natl Acad Sci U S A 1991; 88: 8558-62

177. Shinyashiki M, Chiang KT, Switzer $\mathrm{CH}$, et al. The interaction of nitric oxide (NO) with the yeast transcription factor Ace1: a model system for NO-protein thiol interactions with implications to metal metabolism. Proc Natl Acad Sci U S A 2000; 97 (6): 2491-6

178. Georgatsou E, Mavrogiannis LA, Fragiadakis GS, et al. The yeast Fre1p/Fre2p cupric reductases facilitate copper uptake and are regulated by the copper-modulated Maclp activator. J Biol Chem 1997; 272: 13786-92

179. Gross C, Kelleher M, Iyer VR, et al. Identification of the copper regulon in Saccharomyces cerevisiae by DNA microarrays. J Biol Chem 2000; 275 (41): 32310-6

180. Dameron CT, Harris ED. Regulation of aortic CuZnsuperoxide dismutase with copper: caeruloplasmin and albumin re-activate and transfer copper to the enzyme in culture. Biochem J 1987; 248: 669-75

181. Dameron CT, Harris ED. Regulation of aortic CuZnsuperoxide dismutase with copper: effects in vivo. Biochem J 1987; 248: 663-8

182. Thomas GR, Forbes JR, Roberts EA, et al. The Wilson disease gene: the spectrum of mutations and their consequences. Nat Genet 1995; 210-7

183. Krajacic P, Qian Y, Hahn P, et al. Retinal localization and copper-dependent relocalization of the Wilson and Menkes disease proteins. Invest Ophthalmol Vis Sci 2006 Jul; 47 (7): 3129-34

184. Kuan P. Cardiac Wilson's disease. Chest 1987; 91: 579-83

185. Walshe JM. Copper chelation in patients with Wilson's disease: a comparison of penicillamine and triethylene tetramine dihydrochloride. Q J Med 1973; 42: 441-52

186. Brewer GJ. Raulin Award Lecture: Wilson's disease therapy with zinc and tetrathiomolybdate. J Trace Elem Exp Med 2000; 13: 51-61

187. Walshe JM. Treatment of Wilson's disease with trientine (triethylene tetramine) dihydrochloride. Lancet $1982 \mathrm{Mar}$ 20; 1 (8273): 643-7

188. Siegemund R, Lößner J, Günther K, et al. Mode of action of triethylenetetramine dihydrochloride on copper metabolism in Wilson's disease. Acta Neurol Scand 1991; 83: 364-6

189. Morita J, Yoshino M, Watari H, et al. Wilson's disease treatment by triethylene tetramine dihydrochloride (trientine, $2 \mathrm{HCl}$ ): long-term observation. Dev Pharmacol Therap 1992; 19: 6-9

190. Kodama H, Murata Y, Iitsuka T, et al. Metabolism of administered triethylene tetramine dihydrochloride in humans. Life Sci 1997; 61: 899-907

191. Condamine L, Hermine O, Alvin P, et al. Acquired sideroblastic anaemia during treatment of Wilson's disease with triethylene tetramine dihydrochloride. Br J Haematol 1993; 83: 166-8

192. Joyce DA. D-penicillamine. Baillières Clin Rheumato 1990; 4: 553-74

193. Keen CL, Mark-Savage P, Lonnerdal B, et al. Teratogenesis and low copper status resulting from D-penicillamine in rats. Teratology 1982; 26: 163-5

194. Frank A. 'Mysterious' moose disease in Sweden: similarities to copper deficiency and/or molybdenosis in cattle and sheep. Biochemical background of clinical signs and organ lesions. Sci Tot Environ 1998; 209 (1): 17-26

195. Frank A, Danielsson R, Jones B. The 'mysterious' disease in Swedish moose: concentrations of trace elements in liver and kidneys and clinical chemistry. Comparisons with experimental molybdenosis and copper deficiency in the goat. Sci Total Environ 2000; 249: 107-22

196. Gibbs KR, Walshe LM. Orphan diseases and orphan drugs. In: Scheinberg IH, Walshe JM, editors. Orphan diseases and orphan drugs. Manchester: Manchester University Press, 1986: 33-42

197. Cho HY, Blum RA, Sunderland T, et al. Pharmacokinetic and pharmacodynamic modeling of a copper-selective chelator (TETA) in healthy adults. J Clin Pharmacol 2009 Aug; 49 (8): 916-28

198. Wichmann KA, Boyd PDW, Söhnel T, et al. Characterization of dicarboxylic salts of protonated triethylenete- 
tramine useful for the treatment of copper-related pathologies. Crystal Growth Design 2007; 7: 1844-50

199. Cockcroft DW, Gault MH. Prediction of creatinine clearance from serum creatinine. Nephron 1976; 16: 31-41

200. Jüllig M, Hickey AJ, Crossman DJ, et al. Reversal of diabetes-evoked changes in mitochondrial protein expression of cardiac left ventricle by treatment with a copper(II)selective chelator. Proteomics Clin Appl 2007; 1 (4): 387-99

201. Gong D, Chen X, Middleditch M, et al. Quantitative proteomic profiling identifies new renal targets of copper(II)selective chelation in the reversal of diabetic nephropathy in rats. Proteomics 2009 Sep; 9 (18): 4309-20

202. Lu J, Poppitt SD, Othman AA, et al. Pharmacokinetics, pharmacodynamics, and metabolism of triethylenetetramine in healthy human participants: an open-label trial. J Clin Pharmacol 2010 Feb 9; 50 (6): 647-58

203. Othman A, Lu J, Sunderland T, et al. Development and validation of a rapid HPLC method for the simultaneous determination of triethylenetetramine and its two main metabolites in human serum. J Chromatogr B Analyt Technol Biomed Life Sci 2007 Dec 1; 860 (1): 42-8

204. Lu J, Chan YK, Gamble GD, et al. Triethylenetetramine and metabolites: levels in relation to copper and zinc excretion in urine of healthy volunteers and type 2 diabetic patients. Drug Metab Dispos 2007 Feb; 35 (2): 221-7

205. Lu J, Chan YK, Poppitt SD, et al. Determination of triethylenetetramine (TETA) and its metabolites in human plasma and urine by liquid chromatography-mass spectrometry (LC-MS). J Chromatogr B Analyt Technol Biomed Life Sci 2007 Nov 1; 859 (1): 62-8

206. Persson L. Polyamine homoeostasis. Essays Biochem 2009; 46: $11-24$

207. Pegg AE. Spermidine/spermine-N1-acetyltransferase: a key metabolic regulator. Am J Physiol Endocrinol Metab 2008; 294: E995-1010

208. Laurent S, Cockcroft J, Van Bortel L, et al. Expert consensus document on arterial stiffness: methodological issues and clinical applications. Eur Heart J 2006 Nov; 27 (21): 2588-605

209. Cruickshank K, Riste L, Anderson SG, et al. Aortic pulsewave velocity and its relationship to mortality in diabetes and glucose intolerance: an integrated index of vascular function? Circulation 2002; 106: 2085-90

210. Jüllig $\mathrm{M}$, Chen $\mathrm{X}$, Vazhoor $\mathrm{G}$, et al. Illuminating the molecular basis of diabetic arteriopathy: a proteomic comparison of aortic tissue from diabetic and healthy rats. Proteomics 2010; 10: 1-10

211. Jüllig M, Hickey AJ, Middleditch MJ, et al. Characterization of proteomic changes in cardiac mitochondria in streptozotocin diabetic rats using $\mathrm{iTRAQ}^{\mathrm{TM}}$ isobaric tags. Proteomics Clin Appl 2007; 1: 565-76

212. Siddiqui S, Shepherd RE. Electron spin resonance studies of copper(II) polyamine and imidazole complexes. Inorg Chem 1986; 25 (22): 3869-76

213. Baynes JW, Murray DB. The metal chelators, trientine and citrate, inhibit the development of cardiac pathology in the Zucker diabetic rat. Exp Diabetes Res. Epub 2009 Apr 15

214. Susztak K, Raff AC, Schiffer M, et al. Glucose induced reactive oxygen species cause apoptosis of podocytes and podocyte depletion at the onset of diabetic nephropathy. Diabetes 2006; 55: 225-33

215. Vidotti DB, Arnoni CP, Maquigussa E, et al. Effect of long-term type 1 diabetes on renal sodium and water transporters in rats. Am J Nephrol 2008; 28: 107-14

216. Verman AS. Roles of aquaporins in kidney revealed by transgenic mice. Semin Nephrol 2006; 26: 200-8

217. Hryciw DH, Lee EM, Pollock CA, et al. Molecular changes in proximal tubule function in diabetes mellitus. Clin Exp Pharmacol Physiol 2004; 31 (5-6): 372-9

218. Chuttani HK, Gupta PS, Gulati S, et al. Acute copper sulfate poisoning. Am J Med 1965; 39: 849-54

219. Franchitto N, Gandia-Mailly P, Georges B, et al. Acute copper sulphate poisoning: a case report and literature review. Resuscitation 2008; 78: 92-6

220. Nakamura J, Hamada Y, Chaya S, et al. Transition metals and polyol pathway in the development of diabetic neuropathy in rats. Diabetes Metab Res Rev 2002 Sep-Oct; 18 (5): $395-402$

221. Cameron NE, Tuck Z, McCabe I, et al. Effects of the hydroxyl radical scavenger, dimethylthiourea, on peripheral nerve tissue perfusion, conduction velocity and nociception in experimental diabetes. Diabetologia 2001; 44: 1161-9

222. Smith RG, Heise CC, King JC, et al. Serum and urinary magnesium, calcium and copper levels in insulindependent diabetic women. J Trace Elem Electrolytes Health Dis 1988; 2: 239-43

223. Ito S, Fujita H, Narita T, et al. Urinary copper excretion in type 2 diabetic patients with nephropathy. Nephron 2001; 88: $307-12$

224. Walter RMJ, Uriu-Hare JY, Olin KL, et al. Copper, zinc, manganese, and magnesium status and complications of diabetes mellitus. Diabetes Care 1991; 14: 1050-6

225. Hurrell RF, Ribas S, Davidsson L. $\mathrm{NaFe}_{3}$ EDTA as a food fortificant: influence on zinc, calcium and copper metabolism in the rat. Br J Nutr 1994; 71: 85-93

226. National Institute of Standards and Technology. National Institute of Standards and Technology Critically Selected Stability Constants for Metal Complexes Database, Version 6.0 (20899-3460). Gaithersburg (MD): Department of Commerce, 2001

227. Jonassen HB, Hurst GG, LeBlanc RB, et al. Inorganic complex compounds containing polydentate groups: VI. Formation constants of complex ions of diethylenetetramine and triethylenetetramine with divalent ions. $\mathrm{J}$ Phys Chem 1952; 56: 16-9

228. Tisato F, Marzano C, Porchia M, et al. Copper in diseases and treatments, and copper-based anticancer strategies. Medicinal Res Rev 2010; 30 (4): 708-49

229. Sajithlal GB, Chithra P, Chandrakasan G. An in vitro study on the role of metal catalyzed oxidation in glycation and crosslinking of collagen. Mol Cell Biochem 1999 Apr; 194 (1-2): 257-63

230. Sajithlal GB, Chithra P, Chandrakasan G. The role of metal-catalyzed oxidation in the formation of advanced glycation end products: an in vitro study on collagen. Free Radic Biol Med 1998 Aug; 25 (3): 265-9

231. Birker PJM, Freeman HC. Structure, properties, and function of a copper(I)-copper(II) complex of D- 
penicillamine: pentathallium(I) mu 8-Chloro-dodeca(Dpenicillaminato)octacuprate(I)hexacuprate(II) $n$-Hydrate. J Am Chem Soc 1977; 99 (21): 6890-9

232. Thich JA, Mastropaolo D, Potenza J, et al. Crystal and molecular structure of bis[copper(II) D-penicillamine disulfide] nonahydrate, a derivative of copper(II) cystinate. J Am Chem Soc 1974; 96 (3): 726-31

233. Tatemichi TK, Desmond DW, Paik M, et al. Clinical determinants of dementia related to stroke. Ann Neurol 1993 Jun; 33 (6): 568-75

234. Skoog I, Nilsson L, Palmertz B, et al. A population-based study of dementia in 85-year-olds. N Engl J Med 1993 Jan 21; 328 (3): 153-8

235. Schönberger SJ, Edgar PF, Kydd R, et al. Proteomic analysis of the brain in Alzheimer's disease: molecular phenotype of a complex disease process. Proteomics 2001 Dec; 1 (12): 1519-28

236. Peila R, Rodriguez BL, Launer LJ. Type 2 diabetes, APOE gene, and the risk for dementia and related pathologies: the Honolulu-Asia Aging Study. Diabetes 2002 Apr; 51 (4): 1256-62

237. Ritchie K, Lovestone S. The dementias. Lancet 2002; 360: 1759-66

238. Palsdottir A, Helgason A, Palsson S, et al. A drastic reduction in the life span of cystatin C L68Q carriers due to life-style changes during the last two centuries. PLoS Genet 2008; 4 (6): e1000099

239. Loske C, Gerdemann A, Schepl W, et al. Transition metalmediated glycoxidation accelerates cross-linking of betaamyloid peptide. Eur J Biochem 2000 Jul; 267 (13): 4171-8

240. Kowalik-Jankowska T, Ruta-Dolejsz M, Wisniewska K, et al. Coordination of copper(II) ions by the 11-20 and 1128 fragments of human and mouse beta-amyloid peptide. J Inorg Biochem 2002 Sep 30; 92 (1): 1-10

241. Dong J, Atwood CS, Anderson VE, et al. Metal binding and oxidation of amyloid-beta within isolated senile plaque cores: Raman microscopic evidence. Biochemistry 2003 Mar 18; 42 (10): 2768-73

242. Drew SC, Noble CJ, Masters CL, et al. Pleomorphic copper coordination by Alzheimer's disease amyloid-beta peptide. J Am Chem Soc 2009; 131: 1195-207

243. Lin CJ, Huang HC, Jiang ZF. Cu(II) interaction with amyloid-beta peptide: a review of neuroactive mechanisms in AD brains. Brain Res Bull 2010 Jul 30; 82 (5-6): 235-42

244. Squitti R, Lupoi D, Pasqualetti P, et al. Elevation of serum copper levels in Alzheimer's disease. Neurology 2002 Oct 22; 59 (8): 1153-61

245. Rossi L, Squitti R, Pasqualetti P, et al. Red blood cell copper, zinc superoxide dismutase activity is higher in Alzheimer's disease and is decreased by D-penicillamine. Neurosci Lett 2002 Aug 30; 329 (2): 137-40

246. Squitti R, Quattrocchi CC, Dal Forno G, et al. Ceruloplasmin (2-D PAGE) pattern and copper content in serum and brain of Alzheimer disease patients. Biomarker Insights 2006; 1: 205-13

247. Jeynes B, Provias J. The possible role of capillary cerebral amyloid angiopathy in Alzheimer lesion development: a regional comparison. Acta Neuropathol 2006 Oct; 112 (4): $417-27$
248. Jellinger KA, Attems J. Cerebral amyloid angiopathy in Lewy body disease. J Neural Transm 2008; 115 (3): 473-82

249. Jellinger KA. Prevalence and impact of cerebrovascular lesions in Alzheimer and Lewy body diseases. Neurodegener Dis 2010; 7 (1-3): 112-5

250. Jellinger KA, Attems J. Prevalence and impact of vascular and Alzheimer pathologies in Lewy body disease. Acta Neuropathol 2008 Apr; 115 (4): 427-36

251. Chalmers K, Wilcock GK, Love S. APOE epsilon 4 influences the pathological phenotype of Alzheimer's disease by favouring cerebrovascular over parenchymal accumulation of A beta protein. Neuropathol Appl Neurobiol 2003 Jun; 29 (3): 231-8

252. Attems J, Jellinger KA, Lintner F. Alzheimer's disease pathology influences severity and topographical distribution of cerebral amyloid angiopathy. Acta Neuropathol 2005 Sep; 110 (3): 222-31

253. Attems J, Lintner F, Jellinger KA. Amyloid beta peptide 142 highly correlates with capillary cerebral amyloid angiopathy and Alzheimer disease pathology. Acta Neuropathol 2004 Apr; 107 (4): 283-91

254. Attems J, Jellinger KA. Only cerebral capillary amyloid angiopathy correlates with Alzheimer pathology: a pilot study. Acta Neuropathol 2004 Feb; 107 (2): 83-90

255. Alafuzoff I, Thal DR, Arzberger T, et al. Assessment of beta-amyloid deposits in human brain: a study of the BrainNet Europe Consortium. Acta Neuropathol 2009 Mar; 117 (3): 309-20

256. Maeda A, Yamada M, Itoh Y, et al. Computer-assisted three-dimensional image analysis of cerebral amyloid angiopathy. Stroke 1993 Dec; 24 (12): 1857-64

257. Nicoll JA, Yamada M, Frackowiak J, et al. Cerebral amyloid angiopathy plays a direct role in the pathogenesis of Alzheimer's disease: pro-CAA position statement. Neurobiol Aging 2004 May-Jun; 25 (5): 589-97; discussion 603-4

258. Preston SD, Steart PV, Wilkinson A, et al. Capillary and arterial cerebral amyloid angiopathy in Alzheimer's disease: defining the perivascular route for the elimination of amyloid beta from the human brain. Neuropathol Appl Neurobiol 2003 Apr; 29 (2): 106-17

259. Sveinbjornsdottir S, Sigurdsson S, Aspelund T, et al. Cerebral microbleeds in the population based AGESReykjavik study: prevalence and location. J Neurol Neurosurg Psychiatry 2008; 79: 1002-6

260. Weller RO, Preston SD, Subash M, et al. Cerebral amyloid angiopathy in the aetiology and immunotherapy of Alzheimer disease. Alzheimers Res Ther 2009; 1 (2): 6

261. Glenner GG, Wong CW. Alzheimer's disease: initial report of the purification and characterization of a novel cerebrovascular amyloid protein. Biochem Biophys Res Commun 1984 May 16; 120 (3): 885-90

262. Sparks DL, Schreurs BG. Trace amounts of copper in water induce beta-amyloid plaques and learning deficits in a rabbit model of Alzheimer's disease. Proc Natl Acad Sci U S A 2003 Sep 16; 100 (19): 11065-9

263. Bush AI, Tanzi RE. The galvanization of beta-amyloid in Alzheimer's disease. Proc Natl Acad Sci U S A 2002 May 28; 99 (11): 7317-9 
264. Bush AI. The metallobiology of Alzheimer's disease. Trends Neurosci 2003 Apr; 26 (4): 207-14

265. Cherny RA, Atwood CS, Xilinas ME, et al. Treatment with a copper-zinc chelator markedly and rapidly inhibits betaamyloid accumulation in Alzheimer's disease transgenic mice. Neuron 2001 Jun; 30 (3): 665-76

266. Squitti R, Salustri C. Agents complexing copper as a therapeutic strategy for the treatment of Alzheimer's disease. Curr Alzheimer Res 2009 Dec; 6 (6): 476-87

267. Bush AI. Metal complexing agents as therapies for Alzheimer's disease. Neurobiol Aging 2002 Nov-Dec; 23 (6): 1031-8

268. Brewer GJ. The risks of free copper in the body and the development of useful anticopper drugs. Curr Opin Clin Nutr Metab Care 2008 Nov; 11 (6): 727-32

269. Ritchie CW, Bush AI, Mackinnon A, et al. Metal-protein attenuation with iodochlorhydroxyquin (clioquinol) targeting Abeta amyloid deposition and toxicity in Alzheimer disease: a pilot phase 2 clinical trial. Arch Neurol 2003 Dec; 60 (12): 1685-91

270. Cahoon L. The curious case of clioquinol. Nat Med 2009 Apr; 15 (4): 356-9

271. Lannfelt L, Blennow K, Zetterberg H, et al. Safety, efficacy, and biomarker findings of PBT2 in targeting Abeta as a modifying therapy for Alzheimer's disease: a phase IIa, double-blind, randomised, placebo-controlled trial. Lancet Neurol 2008; 7 (9): 779-86

272. Di Vaira M, Bazzicalupi C, Orioli P, et al. Clioquinol, a drug for Alzheimer's disease specifically interfering with brain metal metabolism: structural characterization of its zinc(II) and copper(II) complexes. Inorg Chem 2004; 43 (13): $3795-7$

273. Ferrada E, Arancibia V, Loeb B, et al. Stoichiometry and conditional stability constants of $\mathrm{Cu}(\mathrm{II})$ or $\mathrm{Zn}$ (II) clioquinol complexes; implications for Alzheimer's and Huntington's disease therapy. Neurotoxicol 2007; 28 (3): 445-9

274. Bush AI. Drug development based on the metals hypothesis of Alzheimer's disease. J Alzheimers Dis 2008; 15 (2): $223-40$

275. McGarry JD. Dysregulation of fatty acid metabolism in the etiology of type 2 diabetes. Diabetes 2001; 51: 7-18
276. Anastasiou E, Lekakis JP, Alevizaki M, et al. Impaired endothelium-dependent vasodilatation in women with previous gestational diabetes. Diabetes Care 1998; 21: 2111-5

277. Meigs JB, O’Donnell CJ, Tofler GH, et al. Hemostatic markers of endothelial dysfunction and risk of incident type 2 diabetes. The Framingham Offspring study. Diabetes 2006; 55 : 530-7

278. Alberti KG, Zimmet PZ. Definition, diagnosis and classification of diabetes mellitus and its complications: part 1. Diagnosis and classification of diabetes mellitus provisional report of a WHO consultation. Diabet Med 1998 Jul; 15 (7): 539-53

279. NAVIGATOR Study Group. Effect of valsartan on the incidence of diabetes and cardiovascular risk. N Engl J Med 2010; 362 (16): 1477-90

280. Greenstein AS, Paranthaman R, Burns A, et al. Cerebrovascular damage in late-life depression is associated with structural and functional abnormalities of subcutaneous small arteries. Hypertension 2010 Oct; 56 (4): 734-40

281. Kell DB. Towards a unifying, systems biology understanding of large-scale cellular death and destruction caused by poorly liganded iron: Parkinson's, Huntington's, Alzheimer's, prions, bactericides, chemical toxicology and others as examples. Arch Toxicol 2010; 84: 825-89

282. Lovell MA, Robertson JD, Teesdale WJ, et al. Copper, iron and zinc in Alzheimer's disease senile plaques. J Neurol Sci 1998; 158: 47-52

283. Stadler N, Lindner RA, Davies MJ. Direct detection and quantification of transition metal ions in human atherosclerotic plaques: evidence for the presence of elevated levels of iron and copper. Arterioscler Thromb Vasc Biol 2004; 24 (5): 949-54

Correspondence: Professor Garth J.S. Cooper, Level 4, Thomas Building, School of Biological Sciences, University of Auckland, Private Bag 92019, Auckland 1142, New Zealand.

E-mail: garth.cooper@manchester.ac.uk 